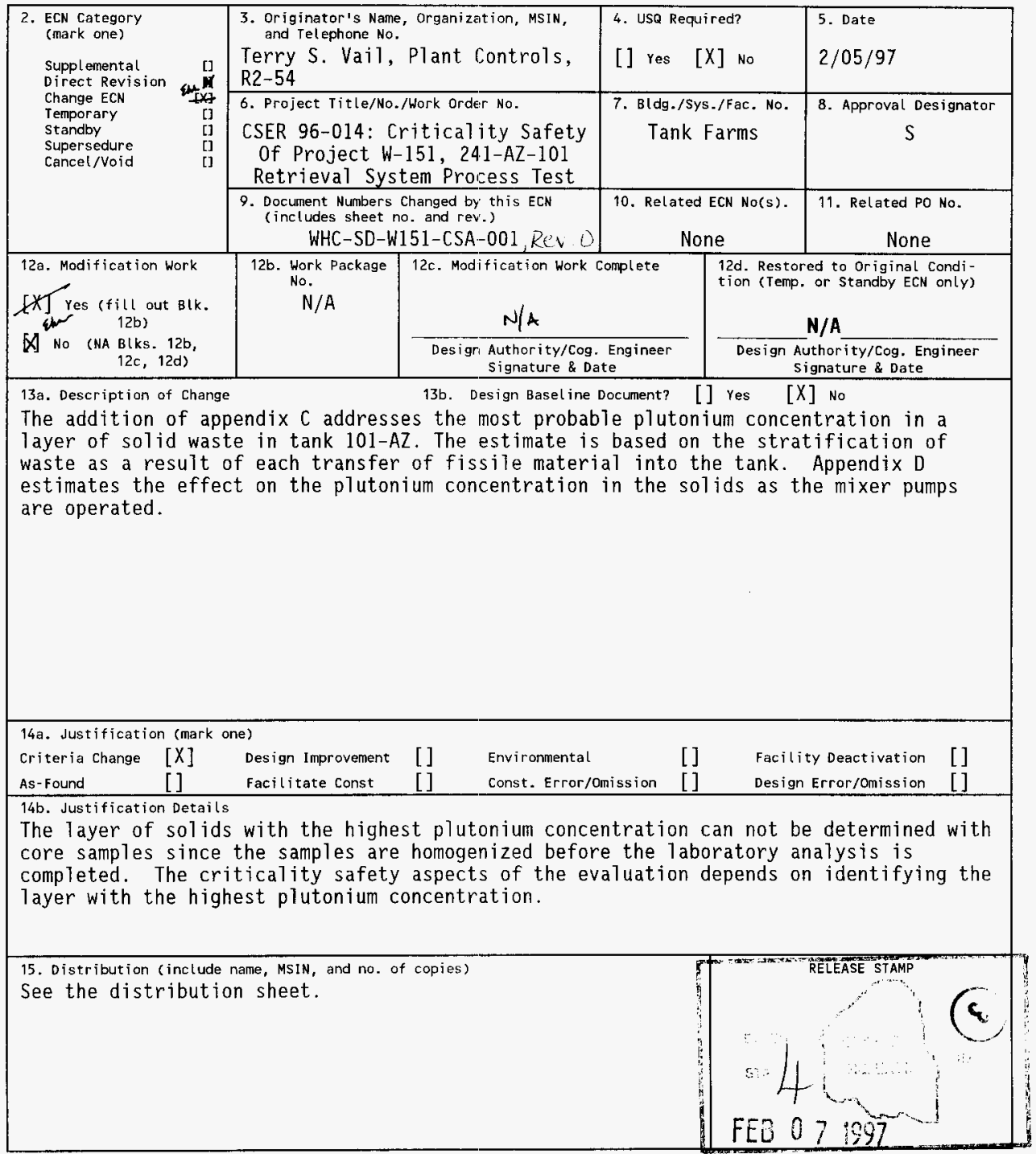




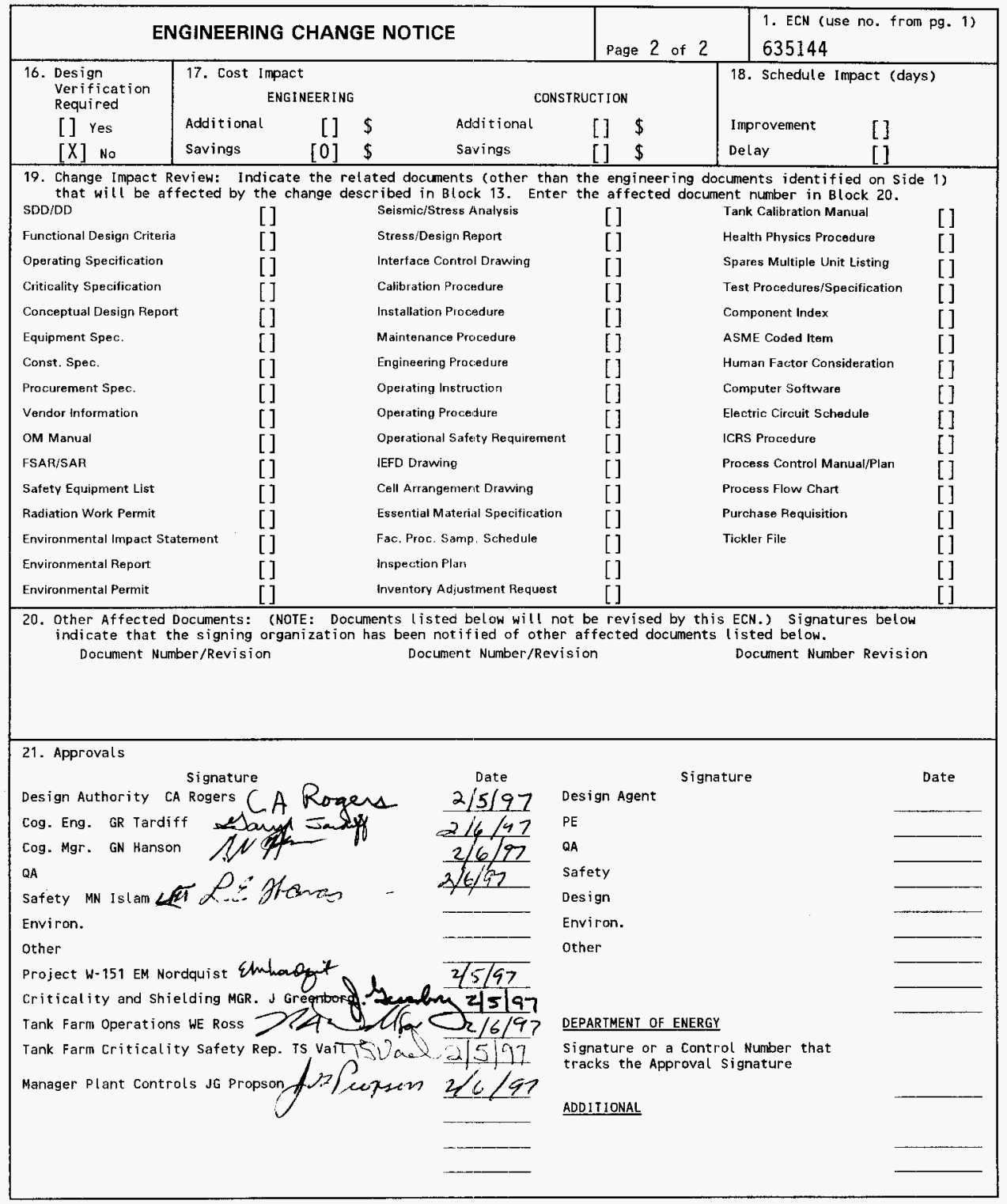




\title{
CSER 96-014: Criticality Safety Of Project W-151, 241-AZ-101 Retrieval System Process Test
}

Terry S. Vail

Duke Engineering \& Services Hanford, Richland, WA 99352

U.S. Department of Energy Contract DE-AC06-96RL13200

\author{
EDT/ECN: $635144 \quad$ UC: 2030 \\ Org Code: 2N120 Charge Code: D23J4 \\ B\&R Code: 39EW31301 Total Pages: /.3/
}

Key Words: criticality safety, 101-AZ, Project $W-151$, mixer pumps, process test

Abstract: This Criticality Safety Evaluation Report (CSER) documents a review of the criticality safety implications of a process test to be performed in tank 241-AZ-101 (101-AZ). The process test will determine the effectiveness of the retrieval system for mobilization of solids and the practicality of the system for future use in the underground storage tanks at Hanford. The scope of the CSER extends only to the testing and operation of the mixer pumps and does not include the transfer of waste from the tank. Justification is provided that a nuclear criticality is extremely unlikely, if not impossible, in this tank.

TRADEMARK DISCLAIMER, Reference herein to any specific commercial product, process, or service by trade name, trademark, manufacturer, or otherwise, does not necessarily constitute or imply its endorsement, recommendation, or favoring by the United States Government or any agency thereof or its contractors or subcontractors.

Printed in the United States of America. To obtain copies of this document, contact: Document Control Services, P.O. Box 950, Mailstop H6-0B, Richland WA 99352. Phone (509) 372-2420; Fax (509) $376-4989$.
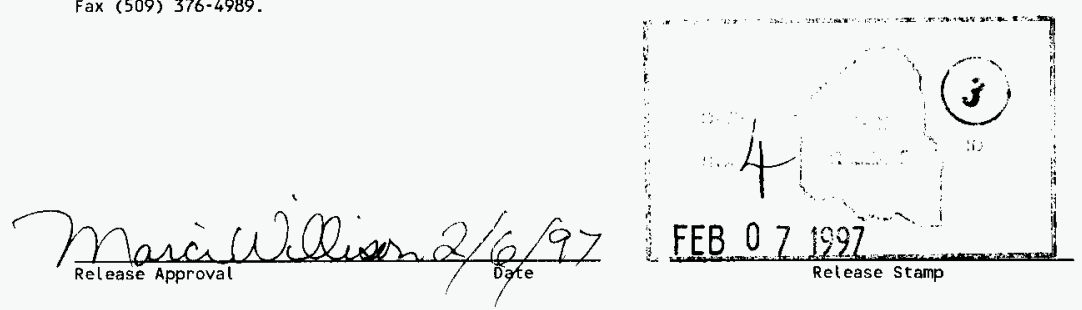

\section{Approved for Public Release}


RECORD OF REVISION

(1) Document Number

HNF-SD-W151-CSA001

Page :

(2) Title

CSER 96-014: Criticality Safety of Project W-151, 241-AZ-101 Retrieval System Process Test

CHANGE CONTROL RECORD

\begin{tabular}{l|l} 
(3) Revision & (4) Description of Change - Replace, Add, and Delete Pages \\
\hline 1 RS & (7) Add Appendix C and D \\
\hline
\end{tabular}

Authorized for Release

(5) Cog. Engr, (6) Cog. Mgr. Date

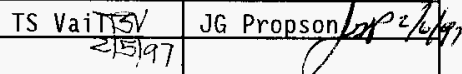

\begin{tabular}{|l|l|l|l|l|}
\hline & & & \\
\hline & & & \\
\hline
\end{tabular}


HNF-SD-W151-CSA-001, Rev. I

CSER 96-014

Title: Criticality Safety of Project W-151

241-AZ-101 Retrieva1 System Process Test

Prepared by:
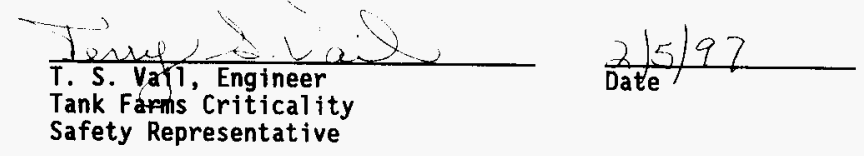

Reviewed by:
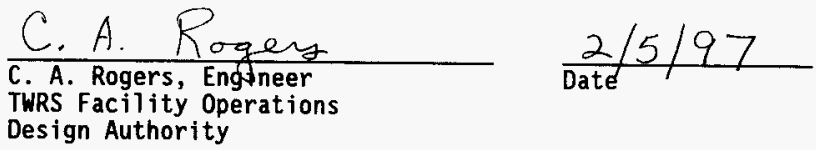

Approved by:
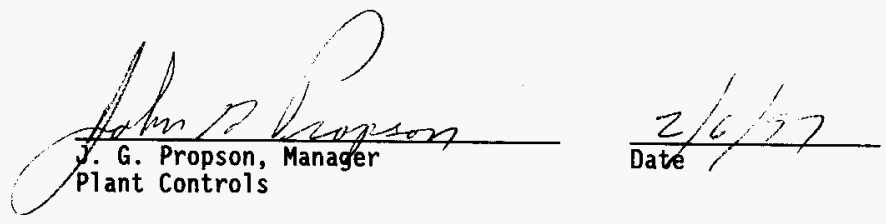

Approved by: $\frac{\text { (on }}{\text { M.N. Islam, Manager }}$

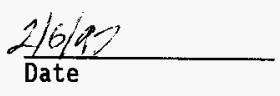

Approved by:
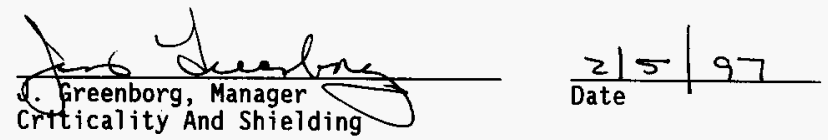


\section{CONTENTS}

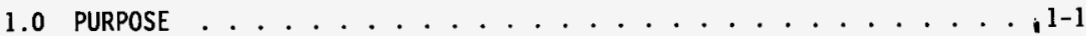

2.0 SUMMARY AND CONCLUSIONS ............... . . .

3.0 INTRODUCTION . . . . . . . . . . . . . . . . . . . .

4.0 DESCRIPTION . . . . . . . . . . . . . . . . . . . 4-1

4.1 WASTE DESCRIPTION . . . . . . . . . . . . . . 4-1

4.2 WASTE CHARACTERIZATION .............. 4-1

4.3 COMPARISON BETWEEN THE TANK SUPERNATE AND SLUDGE ...... 4-5

4.4 THE SLUDGE ................. 4-6

5.0 DISCUSSION . . . . . . . . . . . . . . . . . 5-1

5.1 PRIMARY CRITICALITY SAFETY PARAMETERS . . . .

5.1 .1 MACROSCOPIC ABSORPTION CROSS SECTION . . . . . . . 5-1

5.1 .2 SUBCRITICAL MASS RATIOS . . . . . . . . . 5-4

5.2 CHEMICAL CONSIDERATIONS ............. 5-5

5.3 PUMP TEST AND SOLIDS DISTRIBUTION . . . . . . . . 5-6

6.0 BASIC PaRAMETERS . . . . . . . . . . . . . 6-1

6.1 SOLUBILITY OF PLUTONIUM IN WASTE ........... 6-1

6.2 DENSITY OF SOLIDS . . . . . . . . . . . 6-3

6.3 PLUTONIUM CRITICAL PARAMETERS . . . . . . . . . . . 6-4

6.4 MiXING MECHANISMS . . . . . . . . . . . . . 6-5

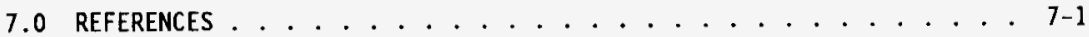
APPENDICES

A ORIGINAL DATA AND CALCULATIONS .............. . . A-1

B REVIEMER'S COMMENTS ................... . . . . 1

C AN EVALUATION OF LAYERS OF WASTE IN 241-AZ-101 WITH THE HIGHEST
CONCENTRATION OF PLUTONIUM ....... C-1

D PLUTONIUM MIXING SIMULATION IN PUMP INTAKE AND HOUSING . . . . . D-1 
HNF-SD-W151-CSA-001, Rev. 1

\section{LIST OF TABLES}

4-1 Selected Analyte Analysis of Centrifuged Supernate . . . . . . . 4-3

4-2 Selected Analyte Analysis of Core 1 Sludge . . . . . . . . . 4-3

4-3 Selected Analyte Analysis of Core 2 Sludge . . . . . . . . . 4-4

5-1 Total Absorption of the Solids in Core 1........... 5-2

5-2 Total Absorption of the Solids in Core 2........... . 5-2

5-3 Mass Ratio Subcritical Limit . . . . . . . . . . . . . . . 5-4

5-4 Mass Ratios of Absorber-to-Plutonium . . . . . . . . . . . 5-4 
HNF-SD-W151-CSA-001, Rev. I

\section{LIST OF TERMS}

$\begin{array}{ll}\text { ALC } & \text { air lift circulators } \\ \text { AWF } & \text { Aging Waste Facility } \\ \text { CPS } & \text { Criticality Prevention Specification } \\ \text { CSER } & \text { Criticality Safety Evaluation Report } \\ \text { DST } & \text { double-shell tank } \\ \text { ECR } & \text { effective cleaning radius } \\ \text { NCAW } & \text { neutralized current acid waste } \\ \text { PUREX } & \text { Plutonium Uranium Extraction } \\ \text { SST } & \text { single-shell tank }\end{array}$


HNF-SD-W151-CSA-001, Rev. 1

This page intentionally left blank. 


\subsection{PURPOSE}

This Criticality Safety Evaluation Report (CSER) documents a review of the criticality safety implications of a process test to be performed in tank 241-AZ-101 (101-AZ). The process test will determine the effectiveness of the retrieval system for mobilization of solids and the practicality of the system for future use in the underground storage tanks at the Hanford Site. The scope of the CSER extends only to the testing and operation of the mixer pumps and does not include the transfer of waste from the tank. Justification is provided that a nuclear criticality is extremely unlikely, if not impossible, in this tank.

This CSER is necessary because of the potential that mixing, suspension, and settling of fissile material bearing solids may result in a localized configuration that is a criticality safety concern. A primary objective of the process test for the two mixer pumps installed in tank 101-AZ is the suspension, mixing, and settling of plutonium bearing solids currently being stored in the tank. 
HNF-SD-W151-CSA-001, Rev. 1

This page intentionally left blank. 
HNF-SD-W151-CSA-001, Rev. I

\subsection{SUMMARY AND CONCLUSIONS}

"CSER 94-004: Criticality Safety of Double-Shel1 Tanks, WHC-SD-SQA-CSA-20368," (Rogers 1994) spells out criteria against which waste can be evaluated to ensure an adequate margin of subcriticality. It provides the technical basis for limits and controls to be used in Criticality Prevention Specifications (CPS) (Vail 1995) to ensure that the waste remains in a highly subcritical state.

Unless the plutonium concentration in tank 101-AZ waste is increased by a large factor, criticality is not possible. Mixing within the waste tends to disperse the plutonium, and none of the mechanisms capable of increasing plutonium concentration appear capable of overcoming the dispersal and blending mechanisms. No identified scenario associated with the mixing test could credibly lead to criticality. It is concluded that the margin of safety is sufficient to permit testing of the mixer pumps. Also, the plutonium was not washed out of the solid phase by the water as evidenced by the low plutonium values of the water-washed supernate fraction of the samples. The rigorous laboratory procedure that centrifuged and tumbled the sample for several hours failed to dislodge the plutonium from the solid phase. The centrifuge and tumbling of the sludge is considered similar to the mixing action of the mixer pump.

The analysis of waste characterization samples taken in FY 1989 of the waste in tank 101-AZ indicates that the tank contains approximately 23,203 $\mathrm{g}$ of plutonium ( $63 \mathrm{~g}$ in the supernate and $23,140 \mathrm{~g}$ in the sludge layer). The majority of the waste is neutralized current acid waste (NCAW) which is the result of denitrating high-level waste with sugar, then neutralizing with sodium hydroxide. The tank $\mathrm{pH}$ is around 13.8. Because plutonium is a precipitate in alkaline salt solutions, it primarily resides in the solids layer of the waste tanks. The concentration of plutonium in all waste transfers is low; therefore, the sludge in tank 101-AZ contains a low concentration of plutonium at $0.175 \mathrm{~g} \mathrm{Pu} / \mathrm{L}$ (Gray et al 1993) and the supernate contains plutonium at a concentration of $0.000019 \mathrm{~g} \mathrm{Pu} / \mathrm{L}$ (Gray et al 1993). Because the plutonium concentration in the sludge is several orders of magnitude greater than the concentration in the supernate, even though there is 26 times more supernate, the data indicating that the sludge layer contains almost all the plutonium in the tank is reasonable. The highest concentration of plutonium in the supernate and sludge for the two core samples is used in this CSER, to provide some conservatism in the conclusions. The double-shell tank (DST) Fissile Material Tracking System currently estimates $19,249 \mathrm{~g}$ of plutonium in tank 101-AZ.

The upper limit on plutonium solubility in alkaline salt solutions is reported as $0.0017 \mathrm{~g} \mathrm{Pu} / \mathrm{L}$ (Hobbs et al. 1993). The concentration of plutonium in the supernate and interstitial liquids in tank 101-AZ, reported from analyzed samples, is less than the upper limit on solubility, as expected. The plutonium inventory and distribution as determined from the analysis of the samples is considered reasonable and representative of the tank waste. The plutonium concentration in the supernate is more than 378,000 times less than the minimum critical plutonium concentration in water of $7.2 \mathrm{~g} \mathrm{Pu} / \mathrm{L}$ (Rogers 1994). 
Waste tank criticality safety is primarily focused on the plutonium in the solids phase because the plutonium concentration is higher in the solids than in the supernate $(0.175 \mathrm{~g} \mathrm{Pu} / \mathrm{L}$ versus $0.000019 \mathrm{~g} \mathrm{Pu} / \mathrm{L})$. The potential for an increase in the plutonium concentration in tank 101-AZ sludge up to the minimum critical concentration of an infinite system of waste tank solids under optimum conditions of $2.6 \mathrm{~g} \mathrm{Pu} / \mathrm{L}$ (Rogers 1993) of waste solids is extremely remote. An increase of plutonium concentration in the solid phase can be accomplished only by removing either the absorbers leaving the plutonium behind or precipitating additional plutonium without absorbers. The analytical data and laboratory procedures indicate that subjecting the sludge to many hours of centrifuging, water wash, and tumbling will not by itself separate the plutonium from the solid phase. Also, the rigorous laboratory procedure did not successfully remove neutron absorbers from the solid phase. One fraction of the solid phase of the samples was analyzed after the extreme chemical treatment of fusion with potassium hydroxide and another fraction was treated by sodium hydroxide. It can be concluded that the mechanical mixing of the solid material will not provide the dramatic chemical change required to separate the plutonium from the solid matrix.

The minimum critical areal density in tank waste is $2,582 \mathrm{~g} \mathrm{Pu} / \mathrm{m}^{2}$ $\left(240 \mathrm{~g} \mathrm{Pu} / \mathrm{ft}^{2}\right.$ ) (Carter et al. 1969). The settling of all the plutonium would need to occur within an area of $8.4 \mathrm{~m}^{2}\left(90.6 \mathrm{ft}^{2}\right)$ to achieve an areal density of $2,582 \mathrm{~g} \mathrm{Pu} / \mathrm{m}^{2}\left(240 \mathrm{~g} \mathrm{Pu} / \mathrm{ft}^{2}\right)$. This assumes that all the plutonium in the supernate also settles out into the solids layer. The tank floor has an area of $409 \mathrm{~m}^{2}\left(4,400 \mathrm{ft}^{2}\right)$ and there is no mechanisms available that would force the solids to settle within an area covering only $2.06 \%$ of the total floor area.

The macroscopic absorption cross section of the waste in tank 101-AZ was compared to the macroscopic absorption cross section of the model (Rogers 1993). The comparison provides some knowledge of the margin of safety of the tank waste versus the model which was used to establish the minimum critical plutonium concentration of $2.6 \mathrm{~g} \mathrm{Pu} / \mathrm{L}$. When the absorption cross section is calculated for one gram of waste material, it is found to be $0.01516 \mathrm{~cm}^{-1} / \mathrm{g}$ for the model composition. This can then be compared to $0.0334 \mathrm{~cm}^{-1} / \mathrm{g}$ for core 1 and to $0.0344 \mathrm{~cm}^{-1} / \mathrm{g}$ for core 2 . The absorption cross section for the waste in tank 101-AZ is more than double the cross section of the model, when they are compared on the basis of the same mass per liter. Because the analyzed components of the waste samples comprise only about one-third of the total material in the waste, the total neutron absorption per liter of waste is expected to be more than twice that obtained for the analyzed components. The neutron absorbing qualities of the actual waste is therefore found to be greater than that of the waste composition used to calculate the minimum critical parameters.

It is reasonable to expect that before mixing, some radial and vertical heterogeneity with respect to the concentration of plutonium exists. The two $300 \mathrm{hp}$ mixing pumps will sufficiently suspend and mix the majority of solids, providing a dispersing mechanism for the plutonium in the tank. The suspended solids will settle out of the supernate into a flat slab with a potential for the plutonium solids to form a thin slab at the bottom of the solids layer. If the plutonium is concentrated in a layer of waste at the bottom of the tank to $8 \mathrm{~g} \mathrm{Pu} / \mathrm{L}$, the waste would be subcritical for waste thicknesses up to $38 \mathrm{~cm}$ 
(15 in.) (Braun et a1. 1994). The suspension and dispersing action of the pump is expected to preclude the settling of the plutonium solids over an area small enough to achieve the minimum critical areal density or create an increase in the plutonium concentration.

A postulated scenario considered in this CSER is the increase of plutonium concentration as a result of the plutonium solids settling at a faster rate than other solid material. Initially, the rigorous laboratory procedure of centrifuging, agitation, water washes, fusion with potassium hydroxide and acid dissolution supports the assertion that the plutonium and other solid-phase material will not separate. The thin slab of plutonium bearing solids will also include the other solid-phase material at the mass ratios calculated in Section 5.1.2, which is highly subcritical. Secondly, if all the plutonium in the tank settles out in a thin layer at the bottom of the tank the areal density will be $56.8 \mathrm{~g} \mathrm{Pu} / \mathrm{m}^{2}\left(5.3 \mathrm{~g} \mathrm{Pu} / \mathrm{ft}^{2}\right)$, which is still highly subcritical and will not increase with additional mixing. Thirdly, if the plutonium solids settle into a thin slab at the bottom of the tank, the average concentration will depend on the thickness of the slab and the area over which the slab is distributed. Unless some mechanism for restricting the surface area over which the solids can settle is installed, the plutonium concentration will unlikely increase above the average. For waste thicknesses up to $38.1 \mathrm{~cm}$ (15 in.) the slab is subcritical for piutonium concentrations up to $8 \mathrm{~g} \mathrm{Pu} / \mathrm{L}$, which requires an increase in the plutonium concentration of 46 times. Also, $38.1 \mathrm{~cm}$ (15 in.) of waste at $8 \mathrm{~g} \mathrm{Pu} / \mathrm{L}$ over the entire area of the tank requires over $1,000 \mathrm{kgs}$ of plutonium, which far exceeds the quantity in the tank.

The estimated effective cleaning radius (ECR) of the pumps is $9.8 \mathrm{~m}(32 \mathrm{ft}$ ). The pumps are not in the center of the tank, so at least two areas of unsuspended solids called "dead zones" may exist; one on the east side of the tank and one on the west side. These areas are estimated to be $13.9 \mathrm{~m}^{2}$ (147 $\mathrm{ft}^{2}$ ) each, which is a little larger than $6.6 \%$ of the floor area. These "dead zones" are of little concern because the plutonium concentration in the undisturbed solids cannot change. Also, any plutonium rich material that may settle on top of these solids, after the pumps are turned off, will form a thin slab similar to the slab on the bottom of the tank and commingle with the unsuspended solid material. The discussion which supposes that all the plutonium in the tank separates and settles is conservative because the plutonium contained in the "dead zones" will not be available for concentrating in other areas of the tank.

Additional mixing and settling of all the plutonium in the tank cannot continually increase the concentration of plutonium above the average concentration allowed by the total mass of plutonium in the tank. An increase in plutonium concentration caused by separation of plutonium from the other solid-phase material in the waste would require an extremely efficient separation process to even begin to approach the concentration at which criticality is possible. If the plutonium inventory in tank 101-AZ did separate and concentrate to $8 \mathrm{~g} \mathrm{Pu} / \mathrm{L}$ at the bottom of the tank, the slab would only be $0.7 \mathrm{~cm}(0.26 \mathrm{in}$.) thick, which is highly subcritical. 
The solubility of plutonium in alkaline salt solutions is sufficiently low so that tank 10l-AZ supernate solution cannot hold enough dissolved plutonium to achieve a criticality. The solubility, concentration and distribution of plutonium in the supernate and solids are affected by many different elements and compounds (e.g., organic complexing agents, hydroxide, carbonate and metal oxides). This CSER considers the effect of these materiais, only insofar as they impact criticality safety. Variations in the distribution of plutonium between the solids and the supernate will not impact critical safety, because all the plutonium could be either in the solids or supernate and the tank will remain subcritical.

The conservative plutonium concentration of the solids material as determined from core sample $2(0.175 \mathrm{~g} \mathrm{Pu} / \mathrm{L})$, is at least 14.9 times less than the minimum critical concentration in waste solids of $2.6 \mathrm{~g} \mathrm{Pu} / \mathrm{L}$ (Rogers 1993). The plutonium concentration in the supernate, as determined from core sample 2 $(0.000019 \mathrm{~g} \mathrm{Pu} / \mathrm{L})$, is at least 382,978 times less than the minimum critical concentration in water of $7.2 \mathrm{~g} \mathrm{Pu} / \mathrm{L}$. 
HNF-SD-W151-CSA-001, Rev. 1

\subsection{INTROOUCTION}

High-level radioactive waste from nuclear fuels processing is stored in the underground double-she1l storage tank 241-AZ-101 located in the 241-AZ Aging Waste Facility (AWF) tank farm on the Hanford Site. This newer DST is an active tank and may be used to receive waste.

Waste in tank 101-A7 storage contains low concentrations of fissile isotopes, primarily ${ }^{235} \mathrm{U}$ and ${ }^{239} \mathrm{Pu}$. An important safety concern is the preclusion of a self-sustaining neutron chain reaction, also known as a nuclear criticality. This CSER reviews the process test (Symons 1996) and the first phase sludge mobilization test of the tank 10l-AZ submersible mixer pumps and provides justification that a nuclear criticality cannot occur. This evaluation does not extend to the actual transfer of solids from the tank or sludge washing.

The initial activity in the disposal of Hanford Defense Waste is retrieving liquid and sludge from DSTs and converting the waste to solid forms. Project $W-151$ has been assigned the task to develop and demonstrate a method of retrieving the waste. Tank $241-A Z-101$ has been selected as the first location for testing the retrieval system. The information and experience gained during the process test is expected to confirm the mobilization characteristics of the waste sludge, provide the bases to optimize the number, location, and the time cycles of the mixer pumps, and establish the effects of the mixer pump operation on the tank and other operating parameters.

Tank 101-AZ currently has 22 air lift circulators (ALCs) which have been used to mix the waste and suspend the solids. Because of the mixing action of the ALCs, the plutonium is expected to be relatively dispersed in the solids layer at the beginning of the process test. During the mixer pump tests, the ALCs will be turned off to allow for accurate evaluation of the effectiveness of the mixer pumps. Structural analysis was completed which showed the ALCs will withstand the mixer pump jet forces during the tests.

One $300 \mathrm{HP}$ mixer pump is installed in each of the 01A and 01C risers. Each pump will take in fluid from the tank bottom and discharge the fluid horizontally through two opposing nozzles located 38 to $46 \mathrm{~cm}$ (12 to 18 in.) above the tank bottom. The nozzle assembly will rotate (180 degrees) for 360 degree mixing at 0.05 to $0.2 \mathrm{rpm}$ to sweep the entire projected area of the tank bottom. The mixer pump is designed to operate within the temperature range of 10 to $130^{\circ} \mathrm{C}$ and are capable of operation in $30 \mathrm{ft}$ deep liquid waste at temperatures of $130^{\circ} \mathrm{C}$. The mixer pump nozzles are $15 \mathrm{~cm}$ ( 6 in.) in diameter with a designed flow rate of $19,680 \mathrm{~L} / \mathrm{min}(5,200 \mathrm{gal} / \mathrm{min})$. Based on the sludge shear strength of $10,000 \mathrm{dyn} / \mathrm{cm}^{2}$ the expected ECR will be approximately $9.8 \mathrm{~m}(32 \mathrm{ft})$.

The composition and the distribution of waste components inside tank 10I-AZ waste is uncertain because of the complexity of discharged waste and the mixing with previously stored tank waste. Because of this uncertainty, criticality safety depends on demonstrating inherent characteristics of waste that ensure subcriticality. Primary among waste characteristics that support criticality safety are the large proportion of waste solids to fissile 
material and the relative uniform mixing of components within each waste layer. The continued dilution of fissile material in the solids during the mixing operations is key to the safety of the tank 101-AZ process test.

For criticality safety purposes, the Tank Farm Facility is classified as a limited control facility. The facility's status as a limited control facility requires a documented criticality safety evaluation which demonstrates that a criticality is prevented by the form or distribution of fissionable material, after allowing for credible accidents. The criticality safety evaluation for DSTs is provided in CSER 94-004 (Rogers 1994).

Critical parameters for tank waste are based on a hypothetical waste composition referred to as the conservative waste model. This waste composition is defined by Rogers (1993) and is based on 28 waste compositions analyzed for 16 single-shell tanks (SSTs). Although only samples from SSTs were used to derive the conservative waste model, critical parameters derived from the model may be applied to all tank waste because: the physics upon wich the analyses are based is identical; DST waste is similar to SST waste; and considerable conservatism is included in the waste model. The conservative waste model defines a waste composition that has a smaller absorption cross section than any actual waste.

Additional information on the criticality safety of tank waste can be found in High-Level Waste Subcriticality Safety Assessment (Braun et al. 1994), which describes process history, waste streams, waste sample data, and waste tank chemistry. The basis for criticality safety is also discussed. 


\subsection{DESCRIPTION}

Tank 101-AZ is a double-shell underground storage tank with components suspended into the tank and supported from the tank dome. The tank went into service in 1976 as one of four double-she1] tanks designated to receive aging waste. It is $22.9 \mathrm{~m}(75 \mathrm{ft})$ in diameter and is designed to nominally store $3,785 \mathrm{kiloliter}(\mathrm{kL})(1,000 \mathrm{kgal})$. The primary tank maximum waste level safety limit in tank $101-\mathrm{AZ}$ is $3,849 \mathrm{~kL}(1,017 \mathrm{kgal})$ or $9.39 \mathrm{~m}$ (370 in.).

The tank presently contains approximately 3,497 kL (924 kgal) of waste in the form of supernate and solids. The total waste is the combined supernate and solids, it contains $3,365 \mathrm{~kL}$ ( $889 \mathrm{kgal}$ ) of supernate and $132 \mathrm{~kL}$ (35 kgal) of sludge (Hanlon, February 1996). The maximum temperature for the tank ranged from 74.4 to $84.4{ }^{\circ} \mathrm{C}$ (166 to $184^{\circ} \mathrm{F}$ ) for December 1993 through December 1994 (Hodgson and Tran 1995). The heat generation from radioactivity is estimated at 241,600 BTU/hr (70,700 watts) (Hodgson and Tran 1995).

Tank 101-AZ is an active receiver of waste so the waste volume is expected to change. Waste transfers since 1986 are mainly from a series of small waste additions from 241-AY-102 and 241-AZ-102 and transfers of dilute noncomplexed waste. Waste volume fluctuations are mainly from evaporation and dilute solutions added to makeup losses. These small waste volume changes include only small quantities of solids and will not change the conciusions of this evaluation.

\subsection{WASTE DESCRIPTION}

The majority of waste in tank 101-AZ is aging waste or NCAW which is high-level first cycle solvent extraction waste from the Plutonium and Uranium Extraction (PUREX) plant. Between 1976 and the third quarter 1983, tank 101-AZ received and transferred out a mixture of evaporator feed, double-shell slurry feed, complexed, noncomplexed, and dilute noncomplexed waste. During the third quarter 1983, the tank was emptied in preparation for receiving aging waste exclusively from the PUREX plant. In March 1986, the tank reached its maximum aging waste fill. The NCAW waste is the result of denitrating high-level waste with sugar, then neutralizing with sodium hydroxide.

The sludge heel was initially measured in 1980 (Brevick et al. 1995). The latest solids volume update of September 30,1990, indicate a sludge volume of $130 \mathrm{~kL}$ (35 kgal). The volume values of supernate and sludge used for this evaluation are $3,365 \mathrm{~kL}(889 \mathrm{kgal})$ of supernate and $132 \mathrm{~kL}$ (35 kgal) of sludge (Hanton, February 1996).

\subsection{MASTE CHARACTERIZATION}

Since 1983, when tank 101-AZ was designated as a receiver for NCAW, approximately 20 samples have been taken. For this evaluation, only the most recent sludge and supernate analys is will be used. In March 1995, supernate samples were retrieved from tank 101-AZ using the bottle-on-a-string. The 
sample analysis for these samples documented by internal memo, 75970-95-037, dated September 11, 1995, from Michelle D. Rollison to J. M. Jones, reports three $239 / 240 \mathrm{Pu}$ values which are all "less than" values. Because the "less than" values are considered inaccurate they were not used in this evaluation. Eight solid sample analysis are reported in WHC-SD-WM-ER-400, Tank Waste Source Term Inventory Validation (Brevick et al. 1995) for tank 101-AZ. The laboratory analysis from core 2 has the highest plutonium concentration of the eight reported samples.

In FY 1989 WHC successfully obtained three core samples from tank 101-AZ. Two cores consisted of two segments each and the third core sample consisted of only one segment. The analysis of the third core is not used in this evaluation because the only planned analysis for the segment was the Miller number measurement. The first core sample obtained from riser \#15F consisted of two 19-inch long segments of waste. Problems encountered during the sampling activity prevented the lower segment from maintaining the stratification of waste. The stratification of waste sample is not important to this evaluation because the intent of the process test is to mix at least $90 \%$ of the solid waste.

The first segment of the first core contained $280 \mathrm{~g}$ of only supernate. The second segment consisted of $200 \mathrm{~g}$ of dark brown solids and $118 \mathrm{~g}$ drainable liquid. The solids were soft, creamy, and sticky and did not maintain the cylindrical shape of the sampler. The supernate and solids had densities of 1.2 and $1.7 \mathrm{~g} / \mathrm{ml}$, respectively. The supernate had a $\mathrm{pH}$ of 13.7 and contained 26.9\% dissolved solids (Peterson et al. 1989). Both segments were combined to form a composite core for which several physical properties were measured. The centrifuged solids and supernate from the composite core were analyzed for chemical and radiochemical properties (Peterson et a1. 1989). Table 4-1 lists the supernate analysis and Table 4-2 lists the solids analysis.

The first segment of the second core contained $305 \mathrm{~g}$ of only solids with no drainable 1iquid. The second segment consisted of $208 \mathrm{~g}$ of dark brown solids and $109 \mathrm{~g}$ drainable liquid. The density and $\mathrm{pH}$ of the drainable liquid drained from the second segment were $1.22 \mathrm{~g} / \mathrm{L}$ and 13.8 , respectively (Gray et a1. 1993). The solids from both segments were combined and homogenized and were titled "composite solids" (Gray et al. 1993). Table 4-1 lists the supernate analysis and Table 4-3 lists the solids analysis.

The estimated quantity of plutonium in the supernate, currently stored in tank 101-AZ is determined by multiplying the plutonium concentration by the quantity of supernate. The tank contains $3,364,865 \mathrm{~L}(889,000 \mathrm{gal})$ of supernate and the conservative approach is to use the highest concentration of plutonium found in the two supernate samples (core 2).

$$
3,364,865 \mathrm{~L} \times 9.55 \mathrm{E}-4 \frac{\mathrm{uCi}}{\mathrm{g}} \times 1220 \frac{\mathrm{g}}{\mathrm{L}} \times \frac{\mathrm{Ci}}{1 \mathrm{E}+6 \mathrm{uCi}} \times \frac{\mathrm{g}}{0.062 \mathrm{Ci}}=63.2 \mathrm{~g} \mathrm{Pu} .
$$


HNF-SD-W151-CSA-001, Rev. 1

Table 4-1. Selected Analyte Analys is of Centrifuged Supernate. (a) 1 values in mol/g supernate, except as noted)

\begin{tabular}{|l|c|c|}
\hline & & U. \\
\hline $\mathrm{pH}$ & 13.7 & 13.8 \\
\hline $\mathrm{Al}$ & 0.332 & 0.0816 \\
\hline $\mathrm{Ni}$ & $<0.0002$ & 0.000043 \\
\hline $\mathrm{Fe}$ & 0.0002 & 0.000351 \\
\hline $\mathrm{Cr}$ & 0.013 & 0.00829 \\
\hline $\mathrm{K}$ & 0.088 & 0.0521 \\
\hline $\mathrm{Mn}$ & 0.00002 & 0.000008 \\
\hline $\mathrm{Na}$ & 3.76 & 2.02 \\
\hline Density $\mathrm{g} / \mathrm{mL}$ & 1.2 & 1.22 \\
\hline $239 / 240 \mathrm{Pu}, \mathrm{uCi} / \mathrm{g}$ & 0.00043 & 0.000955 \\
\hline
\end{tabular}

Notes:

'Peterson et al. (1989)

"Gray et al. (1993)

Table 4-2. Selected Analyte Analys is of Core 1 Sludge. Results reported by Peterson et al. (1991)

(all values in $\mathrm{mmol} / \mathrm{g}$, except as noted).

\begin{tabular}{|c|c|c|c|}
\hline 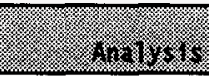 & 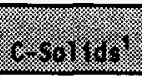 & 40 & \%orking \\
\hline $\mathrm{Na}$ & 3.42 & 1.53 & 0.769 \\
\hline A1 & 1.46 & 0.0739 & 0.277 \\
\hline $\mathrm{Fe}$ & 1.5 & $4.98 E-6$ & 0.365 \\
\hline $\mathrm{Cr}$ & 0.055 & $5.53 \mathrm{E}-3$ & 0.00803 \\
\hline$M n$ & 0.086 & $<2 . E-6$ & 0.0166 \\
\hline $\mathrm{Ni}$ & 0.06 & $<2 . E-5$ & $<0.002$ \\
\hline Density $\mathrm{g} / \mathrm{L}$ & 1800 & 1080 & 1400 \\
\hline${ }^{239 / 240} \mathrm{Pu}, \mathrm{mCi} / \mathrm{g}$ & 0.0044 & $6.4 E-8$ & 0.00079 \\
\hline
\end{tabular}

Notes:

'Centrifuged solids from the core composite

${ }^{2} 30$ volx supernate +35 volx wash $1+35$ volx wash 2

Water-washed solids 
Table 4-3. Selected Analyte Analysis of Core 2 Sludge. Results reported by Gray et al. (1993) (all values in $\mathrm{mmol} / \mathrm{g}$, except as noted).

\begin{tabular}{|c|c|c|c|}
\hline$\frac{1}{4}$ & 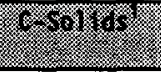 & 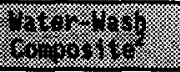 & 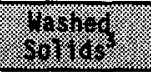 \\
\hline $\mathrm{Na}$ & 3.89 & 0.769 & 0.299 \\
\hline$\overline{A 1}$ & 0.733 & 0.0344 & 0.312 \\
\hline $\mathrm{Fe}$ & 2.500 & 0.000004 & 1.010 \\
\hline $\mathrm{Cr}$ & 0.0163 & 0.00277 & 0.00354 \\
\hline Mn & 0.0375 & 0.000001 & 0.0155 \\
\hline $\mathrm{Ni}$ & 0.112 & $<0.000002$ & 0.0688 \\
\hline Density $g / L$ & 1730 & $1220^{4}$ & 1140 \\
\hline${ }^{239 / 240} \mathrm{Pu}, \mathrm{mC} \mathrm{i} / \mathrm{g}$ & 0.00626 & $3.03 \mathrm{E}-7$ & 0.00239 \\
\hline
\end{tabular}

Notes:

'Centrifuged solids from the core composite

${ }^{2}$ Combined supernate from washed solids

"Water-uashed sol ids

'Density of the water wash was not reported, the density of the supernate will be used.

The column headings in Tables 4-2 and 4-3 are explained as follows:

- C-Solids--Solids portion of the composite core after centrifuged supernate was decanted.

- Water-Wash Composite--deionized water was added to the centrifuged solids. Then agitated, allowed to settle and the supernate was decanted. This procedure was completed twice and the supernate from both washes was combined to form the composite.

- Washed Solids--the solid material remaining after the water washes is labeled washed solids.

The estimated quantity of plutonium in the sludge, currently stored in tank 101-AZ is determined by multiplying the plutonium concentration by the quantity of sludge. The tank contains $132,475 \mathrm{~L}(35,000 \mathrm{gal})$ of sludge and the conservative approach is to use the highest concentration of plutonium found in the two sludge samples (core 2).

$$
132,475 \mathrm{~L} \times 0.00626 \frac{\mathrm{mCi}}{\mathrm{g}} \times 1730 \frac{\mathrm{g}}{\mathrm{L}} \times \frac{\mathrm{Ci}}{1000 \mathrm{mCi}} \times \frac{\mathrm{g}}{0.062 \mathrm{Ci}}=23,140 \mathrm{~g} \mathrm{Pu} .
$$

The total quantity of plutonium in tank 101-AZ is the addition of the quantity of plutonium in the sludge and the supernate. The plutonium inventory is then estimated to be about $23,203 \mathrm{~g}$. 


$$
\text { HNF-SD-W151-CSA-001, Rev. } 1
$$

The calculations indicate that almost all of the plutonium resides in the solid phase of the waste in the tank. If all of the plutonium is assumed to reside entirely in the sludge layer the concentration would be:

$$
23,203 \mathrm{~g} \mathrm{Pu} \times \frac{1}{132,475 \mathrm{~L}}=0.175 \frac{\mathrm{g} \mathrm{Pu}}{\mathrm{L}}
$$

The composition of waste (sludge and supernate) in tank 101-AZ is expected to be represented by the analysis of the core samples taken in 1989. The minor fluctuations in waste volume is not significant because it is due mostly to evaporation and makeup additions. The DST Fissile Material Tracking System currently estimates $19,249 \mathrm{~g}$ of plutonium in tank 101-AZ. The plutonium inventory as determined from the core samples and the inventory tracking system are in good agreement; however, a quantified accuracy was not determined. The highest plutonium concentration of the eight laboratory analysis of solid samples from tank 101-AZ documented by Brevick (1995) is from core 2. Because the other seven samples are all lower in plutonium concentration than core 2, it can be concluded that an upper bounds of plutonium inventory was used in this evaluation.

\subsection{CONPARISON BETWEEN THE TANK SUPERNATE AND SLUDGE}

The total amount of actual solid-phase material in the sludge samples was reviewed. The two sample segments from each core were combined to form a core composite from which the volume percent (vol\%) of settled solids and centrifuged solids were measured. Settled solids for the composite of core 1 measured 48 vol\% and the centrifuged solids measured 16 vol\%. The vol\% settled solids for the composite of core 2 measured at 100 vol\%, while the centrifuged solids measured 71 vol\%. The difference between the amount of settled solids in the two core samples is the amount of drainable liquid obtained in the sample.

A comparison of the quantity of solid-phase material in terms of weight percent (wt\%) solids in each sample is more relevant. The samples were allowed to air dry overnight, then transferred to a drying oven or furnace at $105 \pm 5^{\circ} \mathrm{C}$. The wt\% total solids in the two samples were in good agreement with core 1 at 58.9 wt\% and core 2 at 57 wt\%. The reported values for tank 101-AZ are considerably higher than typical Hanford waste which is about 8 wt\% (Herting 1994).

The significance of the amount of solids lies with the determination of which analytes are actually solid-phase material and which are dissolved in the liquid portion of the solids. Therefore, every $100 \mathrm{~g}$ of sludge contains approximately $40 \mathrm{~g}$ of liquid phase material with a composition of the supernate.

The sample analysis of sludge material actually contains $40 \%$ liquid phase so any analyte that exists only in the liquid phase will have a concentration in the sludge of about $40 \%$ as high as in the supernate. Conversely, any analyte that is significantly higher in the sludge samples than in the supernate 
samples can be presumed to be present in the solid phase. For the solids phase this is true for $\mathrm{Fe}, \mathrm{Mn},{ }^{239 / 240} \mathrm{Pu}$ and to a lesser extent $\mathrm{Al}$. This data supports the assertion that the plutonium resides primarily in the solids phase of the tank waste, along with the metal constituents necessary to ensure significant neutron absorption.

\subsection{THE SLUDGE}

The sludge volume in tank 101-AZ is approximately $132,475 \mathrm{~L}(35,000 \mathrm{gal})$. The distribution of plutonium and absorbers between the centrifuged solid material, the supernate and the washed solids are shown in Tables 4-1, 4-2, and 4-3. The various sample analysis strongly supports the conclusion that almost all the plutonium is in the solid-phase material. The solid phase of each sample was centrifuged, followed by a water wash to remove residual interstitial liquor. To measure the elements and nonvolatile radioisotopes in the solid samples, part of the solids were fused with 1) sodium hydroxide in a nickel crucible and 2) potassium hydroxide in a zirconium crucible. The fused material was dissolved in either nitric acid or hydrochloric acid, depending upon the analytical method used.

The relative distribution of plutonium between the solid phase and the liquid phase in the sludge layer was determined and is outlined below:

Core 1

Centrifuged solids of the composite sample $\mathrm{Pu}$ in the water-wash faction

Pu in the water-wash solids Core?

Centrifuged solids of the composite sample $\mathrm{Pu}$ in the water-wash faction $\mathrm{Pu}$ in the water-wash solids $\begin{array}{lll}\text { 4. } 40 \mathrm{E}-3 \mathrm{mCi} & \mathrm{Pu} / \mathrm{g} \\ 6.40 \mathrm{E}-8 \mathrm{mC} & \mathrm{Pu} / \mathrm{g} \\ \text { 7.79E-4 } \mathrm{mC} i \mathrm{Pu} / \mathrm{g}\end{array}$

$(99.992 \%)$

6. 26E-3 mCi $\mathrm{Pu} / \mathrm{g}$

3.03E-7 mCi Pu/g

2.39E-3 mCi Pu/g

The relative distribution of plutonium in the sludge layer was calculated to provide an understanding of the distribution of plutonium between the different phases in the sludge. The calculations using values of the centrifuged solids provides supporting evidence that virtually all of the plutonium in the centrifuged portion of the sample is in the solid phase. Also, the plutonium was not washed out of the solid phase by the water as evidenced by the low plutonium values of the water-washed supernate fraction of the samples. The rigorous laboratory procedure that centrifuged and tumbled the sample for several hours failed to dislodge the plutonium from the solid phase. The centrifuge and tumbling of the sludge is considered similar to the mixing action of the mixer pump.

Note that subcriticality is assured when the plutonium concentration is less than $2.6 \mathrm{~g} \mathrm{Pu} / \mathrm{L}$ in dry waste solids (sludge). This is the minimum plutonium concentration that can be made critical in tank solid waste. Tank 101-AZ contains a plutonium concentration significantly less than the minimum critical concentration. 


\subsection{DISCUSSION}

Waste contained in the Hanford Site underground storage tanks is a complex mixture of fission products and chemicals left over from plutonium separation processes. Some knowledge of the form and distribution of fissionable material and absorbers has been obtained from operations documents and waste characterization activities, but quantified accuracies of waste compositions are largely unknown. The demonstration of criticality safety depends on knowing the minimum critical parameters for the waste material combined with a qualitative discussion of the likelihood the parameters will be satisfied given the mixer pump operations. Section 6.0 contains more information which supports the context and conclusions in Section 5.0.

\subsection{PRIMARY CRITICALITY SAFETY PARAMETERS}

An important parameter for criticality safety is the solubility of plutonium. The dilution of plutonium with specific absorber elements depends on the physical state of the plutonium species under consideration. Plutonium which is dissolved or suspended in the supernate is more homogeneously distributed than plutonium in the solid-phase material. The variation in plutonium concentration in supernate is considered a minor concern because the upper boundary on solubility of plutonium in alkaline salt solutions is about 4,200 times lower than the minimum critical concentration in an optimized plutonium water system.

The parameter of primary importance in this evaluation is the plutonium concentration in the solid phase. The sludge samples clearly indicate the highest plutonium concentration is in the solid phase. In the waste solids, the plutonium is diluted with neutron absorbing materials, and the average dilution will remain unchanged when the waste is mixed. Mixing will tend to lower the plutonium concentrations where it is high and to increase the concentration where it is lower. This will reduce the probability of there being a region with high plutonium concentration.

\subsubsection{MACROSCOPIC ABSORPTION CROSS SECTION}

A good parameter to use for the measure of plutonium dilution is the mass ratio of waste solids to plutonium. When the typical waste solids to plutonium mass ratio exceeds 476 , criticality is not possible in homogeneous waste (Rogers 1994). The presence of solids ensures that settling of suspended material and evaporation of liquid do not allow the plutonium concentration to increase to an unsafe level.

When the composition of the solids is known, then the subcritical mass ratios of specific elements, such as iron, aluminum or manganese, can be used to demonstrate a margin of subcriticality. If the plutonium in a solids matrix is diluted with a specific component such that the subcritical mass ratio is satisfied, the matrix will be subcritical regardless of the other components in the solid provided the specific component is homogeneously mixed in the 
waste. However, a comparison of the solids to plutonium mass ratio is not complete without a comparison of the total absorption of the solids in tank 101-AZ with the total absorption of the waste model (Rogers 1993). This comparison is given in Tables 5-1 and 5.2.

Table 5-1. Total Absorption of the Solids in Core 1.

\begin{tabular}{|c|c|c|c|c|c|c|}
\hline \multirow{2}{*}{$\left(\frac{1}{2}\right)$} & \multirow{2}{*}{ 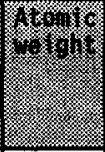 } & \multirow{2}{*}{ 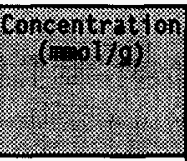 } & \multirow{2}{*}{ (n) } & \multirow{2}{*}{ (196) } & \multicolumn{2}{|c|}{ (1960) } \\
\hline & & & & & 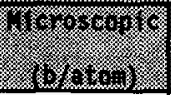 & 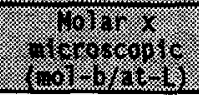 \\
\hline $\begin{array}{l}\text { Sodium } \\
\text { (Na) }\end{array}$ & 22.99 & 3.42 & 6.156 & 141.53 & 0.5300 & 3.263 \\
\hline $\begin{array}{l}\text { Aluminum } \\
\text { (AT) }\end{array}$ & 26.982 & 1.46 & 2.628 & 70.91 & 0.2350 & 0.618 \\
\hline $\begin{array}{l}\text { Iron } \\
\text { (Fe) }\end{array}$ & 55.847 & 1.5 & 2.700 & 150.79 & 2.2350 & 6.035 \\
\hline $\begin{array}{l}\text { Chromium } \\
\text { (Cr) }\end{array}$ & 51.996 & 0.055 & 0.099 & 5.15 & 3.1000 & 0.307 \\
\hline $\begin{array}{l}\text { Nickel } \\
(\mathrm{Ni})\end{array}$ & 58.71 & 0.06 & 0.108 & 6.34 & 4.8000 & 0.518 \\
\hline $\begin{array}{l}\text { Manganese } \\
(\mathrm{Mn})\end{array}$ & 54.938 & 0.086 & 0.155 & 8.504 & 13.2000 & 2.046 \\
\hline \multicolumn{3}{|c|}{ Hor } & 60 & 3ron & 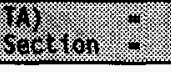 & 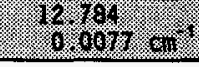 \\
\hline
\end{tabular}

Table 5-2. Total Absorption of the Solids in Core 2.

\begin{tabular}{|c|c|c|c|c|c|c|}
\hline \multirow[t]{2}{*}{ 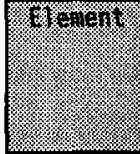 } & \multirow[t]{2}{*}{ 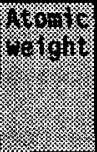 } & \multirow[t]{2}{*}{ Fon } & \multirow[t]{2}{*}{ (6) } & \multirow[t]{2}{*}{ Hoplow } & \multicolumn{2}{|c|}{ 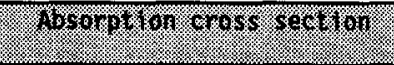 } \\
\hline & & & & & (6.) & 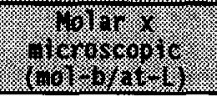 \\
\hline $\begin{array}{l}\text { Sodium } \\
\text { (Na) }\end{array}$ & 22.99 & 3.89 & 6.730 & 154.723 & 0.5300 & 3.567 \\
\hline $\begin{array}{l}\text { Aluminum } \\
\text { (A1) }\end{array}$ & 26.982 & 0.733 & 1.268 & 34.213 & 0.2350 & 0.298 \\
\hline $\begin{array}{l}\text { Iron } \\
(\mathrm{Fe}) \\
\end{array}$ & 55.847 & 2.500 & 4.325 & 241.538 & 2.2350 & 9.666 \\
\hline $\begin{array}{l}\text { Chromium } \\
(\mathrm{Cr})\end{array}$ & 51.996 & 0.0163 & 0.028 & 1.456 & 3.1000 & 0.087 \\
\hline $\begin{array}{l}\text { Nickel } \\
\text { (Ni) }\end{array}$ & 58.71 & 0.112 & 0.194 & 11.390 & 4.8000 & 0.931 \\
\hline $\begin{array}{l}\text { Manganese } \\
(M n)\end{array}$ & 54.938 & 0.0375 & 0.065 & 3.571 & 13.2000 & 0.858 \\
\hline Wort & 15. & 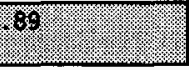 & $180.1 \%$ & Wroros. & (M) & Y. 007, \\
\hline
\end{tabular}


The macroscopic absorption cross section for the selected analytes in core sample 1 calculates to $0.0077 \mathrm{~cm}^{-1}$ and the cross section for core sample 2 calculates to $0.00928 \mathrm{~cm}^{-1}$. The total macroscopic absorption cross section (XS) must exceed $0.01096 \mathrm{~cm}^{-1}$ for the absorption of the waste to be bounded by the calculations used in the model.

The macroscopic absorption cross section of the waste appears to be less than the cross section of the composition of waste used in the conservative waste model, but the opposite is true. The problem lies with the gross quantity of analytes, on a liter basis, used for the comparison. The quantity of solid material used for core 1 is 383 grams and for core 2 the selected analytes totaled 447 grams. The amount of solid material per liter used in the conservative waste model is 1,200 grams. So, if the absorption cross section is calculated on a gram basis, then the model has a cross section of $0.01516 \mathrm{~cm}^{-1} / \mathrm{g}$, while core 1 has $0.0334 \mathrm{~cm}^{-1} / \mathrm{g}$ and core 2 has $0.0344 \mathrm{~cm}^{-1} / \mathrm{g}$. The calculations indicate the absorption cross section for the waste in tank 101-AZ is more than double the cross section of the model per unit mass.

The difficulty in comparing real waste to a model lies in converting the rea] waste analysis to the same conditions used in the model. The model used a solids composition based on dry solids with a density of 1,200 g solids/L; however, the centrifuged solids in tank 101-AZ includes about 40\% 1iquids with a combined density of $1,800 \mathrm{~g} / \mathrm{L}$ for core 1 and $1,730 \mathrm{~g} / \mathrm{L}$ in core 2 . With $40 \%$ liquids, the samples only contained a little over $1,000 \mathrm{~g}$ of solids and only a portion of those solids were used to calculate the macroscopic cross section. In fact, less than half of the solids in the samples are included among the analyzed components (analytes). Therefore, the actual macroscopic absorption cross section would be expected to be at least twice that found above.

Because the comparison is based on a theoretical dry solids matrix used in the model, the sample must be converted to the same dry solid bases. A comparison of absorption cross sections can be done using the assumption that the water content of each sample is removed and replaced with solid material of the same composition as the sample. The solids would fill the void space left by removing the water. The result would be dry solids densities of about $2,500 \mathrm{~g} / \mathrm{L}$ for the samples. In reality, the compaction of the solids would probably not be as great as the volume of the water removed. Nevertheless, the density of dry solids would be expected to be greater than the density in the original wet sample, and it would have a very high probability of exceeding $1,200 \mathrm{~g} / \mathrm{L}$. In any case, the higher neutron absorption per unit mass would ensure a greater macroscopic cross section than that assumed in the conservative waste model.

An equitable comparison of absorption cross sections could have been done with the assumption that the water content of each sample is removed and replaced with solid material of the same composition as the sample. The result would be sample densities of about $2,500 \mathrm{~g} / \mathrm{L}$ and the molarity of each analyte would increase about $40 \%$. The follow on assumption is that the solids would fill the void space left by removing the water. But, because the comparison is based on a theoretical dry solids matrix used in the model, the sample must be converted to the same theoretical dry solid bases. Converting the macroscopic absorption cross section to a per gram basis satisfies the requirement to compare the sample and model on the same basis. 


\subsubsection{SUBCRITICAL MASS RATIOS}

An important characteristic of using mass ratios to show subcriticality is that conclusions remain valid for all densities of solids. It does not matter if the solids are suspended in water, are compacted in a centrifuge or calculated on a dry basis. Subcriticality is assured when the limiting subcritical mass ratios are exceeded throughout the waste. The subcritical mass ratio limit for selected components are listed in Table 5-3 (Rogers 1994).

Table 5-3. Mass Ratio Subcritical Limit.

\begin{tabular}{|c|c|}
\hline (2) & 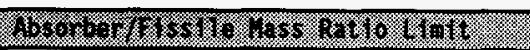 \\
\hline Aluminum (Al) & 910 \\
\hline Chromium (Cr) & 135 \\
\hline Nickel (Ni) & 105 \\
\hline Nitrate $\left(\mathrm{NO}_{3}\right)$ & 270 \\
\hline Sodium (Na) & 360 \\
\hline Iron $(\mathrm{Fe})$ & 160 \\
\hline Manganese (Mn) & 32 \\
\hline Gross solids & 476 \\
\hline
\end{tabular}

Based on the sludge composition in tank 101-AZ obtained from sample analysis, a comparison of the mass ratio of gross solids to plutonium and mass ratios of specific elements to plutonium can be used to draw conclusions about the margin of subcriticality. The mass ratios of specified absorbers in the solid-phase and water-washed solids sludge are given in Table 5-4. The plutonium concentration for the mass ratio calculations in the water-washed solids and the sludge is taken from Tables 4-2 and 4-3.

Table 5-4. Mass Ratios of Absorber-to-Plutonium.

\begin{tabular}{|c|c|c|c|c|}
\hline & \multicolumn{2}{|c|}{ (1) } & \multicolumn{2}{|c|}{ W0 } \\
\hline 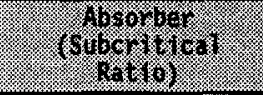 & 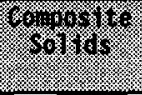 & 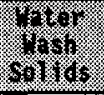 & 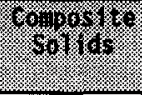 & 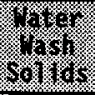 \\
\hline Aluminum $(910)$ & 555 & 587 & 196 & 218 \\
\hline Chromium (135) & 40 & 33 & 8 & 5 \\
\hline Nicke1 (105) & 50 & $<9$ & 65 & 105 \\
\hline Sodium $(360)$ & 1,108 & 1,387 & 886 & 178 \\
\hline Iron $(160)$ & 1,180 & 1,600 & 1,383 & 1,463 \\
\hline Manganese (32) & 67 & 72 & 20 & 22 \\
\hline Gross Solids (476) & 14,091 & 78,481 & 9,904 & 25,941 \\
\hline
\end{tabular}


HNF-SD-W151-CSA-001, Rev. 1

A review of the mass ratios in Table 5-4 indicate the ratios of the analytes to plutonium are about the same for the composite and the water-wash solids.

The reason these ratios are in good agreement is because these analytes are in the solid phase. As a result, the quantity of each analyte did not change with the water wash, centrifuge, and tumbling so the mass ratios of plutonium did not change significantly.

There is a significant difference in the mass ratio of gross solids to plutonium between the composite and the water-wash solids. One possible explanation for this difference is that the soluble salts were washed from the composite and replaced with lighter water so the density was decreased from $1,800 \mathrm{~g} / \mathrm{L}$ to $1,400 \mathrm{~g} / \mathrm{L}$ (about $20 \%$ ) for core 1 and $1,730 \mathrm{~g} / \mathrm{L}$ to $1,140 \mathrm{~g} / \mathrm{L}$ (about 30\%) for core 2. The quantity of plutonium per liter of water-washed solids was decreased by $86 \%$ for core 1 and $62 \%$ for core 2 as a result of diluting the composite solids portion of the sample with water. The laboratory analysis does not provide an explanation for the decrease in concentration of plutonium or the other insoluble analytes in the water-wash solids. Because the mass ratios of the insoluble analytes to plutonium remained fairly constant, the reason for the decrease is considered the same for all the specified analytes.

\subsection{CHEMICAL CONSIDERATIONS}

A discussion of the potential for mechanical mixing of the waste to separate the plutonium from the absorbers is not complete without reviewing the chemical aspects. Although all the plutonium could reside in either the solids or liquids and the waste would be highly subcritical. The solids sample preparation in the laboratory supports the contention that the plutonium is primarily a precipitate in the caustic environment of the waste. The transition of plutonium from the solid phase to the liquid phase would require increasing the plutonium solubility of the supernate. Significant changes in plutonium solubility can only be achieved with extreme changes in the chemical makeup of the waste. This would require adding significant quantities of organic or inorganic plutonium complexants, a change in the redox potential of the solution by adding oxidants or reductants, or acidifying the solution. None of these waste changes are planned nor are they part of the scope of the mixer pump operations.

The other half of the chemical consideration scenario is the subsequent precipitation of plutonium after the transition from solid phase to liquid phase. The operations planned under the scope of the mixer pump operations do not include the chemistry changes necessary to facilitate the transition of plutonium between phases and is not considered credible, so further discussion is not necessary. Suffice to conclude that after the waste is thoroughly mixed and the solids suspended, any precipitated plutonium would not be confined to settle out in an area small enough to achieve the minimum critical areal density, even if all the plutonium settled out in the sludge layer. 


\subsection{PUMP TEST AMD SOLIDS DISTRIBUTION}

The operational goal of the functional test of the mixer pumps is to achieve 90\% mobilization of solids which have settled to the tank bottom and to demonstrate that a slurry suitable for transfer to the treatment facility can be maintained within the tank. Previous mixer pump tests and studies have shown that more than one mixer pump is required to achieve mobilization of a large fraction of the solids. The two $300 \mathrm{hp}$ pumps will be orientated on the north and south of the tank centerline. The estimated ECR for each pump is $9.8 \mathrm{~m}(32 \mathrm{ft})$.

The minimum critical areal density in tank waste is $2,582 \mathrm{~g} / \mathrm{m}^{2}\left(240 \mathrm{~g} / \mathrm{ft}^{2}\right)$ (Carter 1969). For plutonium spread evenly over the entire area of the tank, this correlates to a mass of slightly greater than 1,000 kgs of plutonium. The minimum critical mass at $4.0 \mathrm{~g} \mathrm{Pu} / \mathrm{L}$ of waste solids is $215 \mathrm{~kg}$ of plutonium and the minimum critical mass at $10.0 \mathrm{~g} \mathrm{Pu} / \mathrm{L}$ of waste solids requires $3.0 \mathrm{~kg}$ of plutonium (Rogers 1994). In a plutonium-pure water system the minimum critical plutonium concentration is $7.2 \mathrm{~g} \mathrm{Pu} / \mathrm{L}$ (Rogers 1994). The presence of neutron absorbers in the waste supernate ensures that the reactivity of the plutonium in the supernate is less than it is in pure water.

At $23,203 \mathrm{~g}$ of plutonium, the areal density, assuming the plutonium is dispersed homogeneously around the tank, calculates to $56.8 \mathrm{~g} / \mathrm{m}^{2}$

$\left(5.3 \mathrm{~g} \mathrm{Pu} / \mathrm{ft}^{2}\right)$, which is extremely subcritical. Concern arises from the possibility of a localized area with a high concentration of plutonium. The concentration of plutonium in the solids in core 1 was $0.128 \mathrm{~g} \mathrm{Pu} / \mathrm{L}$ and in core 2 was $0.175 \mathrm{~g} \mathrm{Pu} / \mathrm{L}$, both of which are highly subcritical. To approach the minimum critical concentration in waste solids of $2.6 \mathrm{~g} \mathrm{Pu} / \mathrm{L}$ the concentration in the core samples 1 and 2 would need to be increased by a factor of 20 and 15, respectively.

The rigorous laboratory procedure for analyzing plutonium strongly supports the conclusion that the plutonium remains in the solid phase after the water wash, agitation, and centrifuging, and most likely will continue to be a solid-phase material after mixing in the tank with the mixer pumps. Also, the solid phase will contain sufficient quantities of iron, manganese and other solid neutron absorbing material to ensure the mixture is highly subcritical. Any geometry, pile or configuration of solid material with the composition of the core samples will be highly subcritical regardless of the total quantity of plutonium. Consequently, discussions of possible concentrating mechanisms must include the assumption that the plutonium is separated from other absorbers as a result of the hydraulic dynamics of mixing.

The reasonable postulated scenario considers the suspension of $90 \%$ of the solids, which settle on top of the 10\% unsuspended solids. Assume the unsuspended solids are in a flat slab on the bottom of the tank. The areal density and plutonium concentration will be exactly the same as indicated in the core samples. If the $10 \%$ solids, which are not suspended, are in one area of the tank, then the area would cover a minimum of $10 \%$ of the tank floor. Of course, this means that all the plutonium in the tank is settled into an area equivalent to $10 \%$ of the floor area. The resulting areal density would be $567.6 \mathrm{~g} \mathrm{Pu} / \mathrm{m}^{2}\left(52.7 \mathrm{~g} \mathrm{Pu} / \mathrm{ft}^{2}\right)$. A value which is highly subcritical. For all the plutonium to settle in an area of the tank which exceeds the minimum 
critical areal density the area would need to be no larger than $9.0 \mathrm{~m}^{2}$ ( $96.7 \mathrm{ft}^{2}$ ) which is about $2 \%$ of the floor area. No mechanism which promotes the settling of solids into localized areas has been identified.

If the action of the mixer pumps actually separate the plutonium from the other solid-phase material, then a pile of plutonium in any desired geometry at any concentration can be contemplated. For this to happen, the mechanical forces of the pump must exceed the bonding forces which maintain the plutonium and the solid absorber material together in the solid phase. Without extensive research into the bonding forces of the coprecipitated solid material the discussion must suppose the separation takes place. The accumulation of $23 \mathrm{kgs}$ of pure plutonium in a small area of the tank will certainly have the potential to go critical. Therefore, the discussion must investigate the possibility that the small area can be achieved.

The pumps are installed in risers 01A and 01C which are located about half way between the tank center and the tank wall north and south of the tank centerline. If the ECR of the pumps is $9.8 \mathrm{~m}$ (32 ft) then "dead zones" of unsuspended solids will exist at the east and west sides of the tank. The unsuspended material will be the same composition as the core samples because the solids are undisturbed. Any separated plutonium which settles on top of the undisturbed solids will settle in a flat slab the same as if it settled on the tank floor with some minor commingling with the undisturbed solids. The size of each "dead zone" will be about $13.9 \mathrm{~m}^{2}$ (147 $\mathrm{ft}^{2}$ ) which is about $6.6 \%$ of the floor area. This volume of undistributed solids would be expected to contain $766 \mathrm{~g}$ of plutonium in each "dead zone". If al1 other plutonium is suspended, the quantity of suspended plutonium will be $21,672 \mathrm{~g}$. If al1 the suspended plutonium settles in one "dead zone" the areal density will be $1,643 \mathrm{~g} / \mathrm{m}^{2}$ (153 g/ $\left.\mathrm{ft}^{2}\right)$ which is still subcritical. If all the suspended plutonium settles on top of one "dead zone" at a concentration of $8 \mathrm{~g} \mathrm{Pu} / \mathrm{L}$, the height of plutonium rich material will be $20.5 \mathrm{~cm}(8.1 \mathrm{in.})$. The waste is subcritical for waste thicknesses up to $38 \mathrm{~cm}$ (15 in.) at a plutonium concentration of $8 \mathrm{~g} \mathrm{Pu} / \mathrm{L}$.

Consider the case where all the solids are suspended, the plutonium particulate separates from the absorbers and has a faster settling velocity than the absorber material. The plutonium would settle in a flat slab over the floor of the tank after the pumps are turned off. The areal density for this case is equivalent to the core samples, $56.8 \mathrm{~g} / \mathrm{m}^{2}\left(5.3 \mathrm{~g} \mathrm{Pu} / \mathrm{ft}^{2}\right)$. If the plutonium is concentrated in a layer of waste at the bottom of the tank to $8 \mathrm{~g}$ $\mathrm{Pu} / \mathrm{L}$, the waste would be subcritical for waste thicknesses up to $38 \mathrm{~cm}$ (15 in.) (Braun et a1. 1994). If the plutonium inventory in tank 101-AZ did separate and concentrate to $8 \mathrm{~g} \mathrm{Pu} / \mathrm{L}$ at the bottom of the tank, the slab would only be $0.7 \mathrm{~cm}(0.28 \mathrm{in.})$ thick, which is highly subcritical.

Without extensive computer modeling, an increase in plutonium concentration can only be speculated. The first requirement includes the separation of plutonium from the other solid materials. If the plutonium settles in a flat slab at the bottom of the tank and additional mixing takes place, the plutonium could be moved along the tank floor instead of being suspended. This action could create a pile of plutonium rich material at the tank wall on the east and west side of the tank. With half of the plutonium inventory, $11,602 \mathrm{~g} \mathrm{Pu}$, in each pile and the objective of the test is met, i.e, $90 \%$ of 
HNF-SD-W151-CSA-001, Rev. 1

the solids are suspended, then each pile will have $5 \%$ the of the unsuspended solid material. The plutonium may be pushed and mixed with these solids resulting in a plutonium concentration as high as $1.8 \mathrm{~g} \mathrm{Pu} / \mathrm{L}(11,602 \mathrm{~g}$ in $5 \%$ of the solids or $6,624 \mathrm{~L}$ ). This concentration of plutonium is about 10 fold higher than the core samples. However, the system would remain subcritical for any geometry of solids, because the minimum critical concentration is $2.6 \mathrm{~g} \mathrm{Pu} / \mathrm{L}$.

Al1 the plutonium in the tank must settle in no more than $8,924 \mathrm{~L}(2,358 \mathrm{gal})$ of waste solids to achieve a plutonium concentration of $2.6 \mathrm{~g} \mathrm{Pu} / \mathrm{L}$ of solids. This is only $6.7 \%$ of the solid material in tank 101-AZ. The design of this scenario requires the plutonium to separate from the other solid-phase material. As the plutonium concentration increases, the mass ratio of any absorber to plutonium decreases. The enriched plutonium solids would need to settle in a localized area of the tank at a concentration greater than $2.6 \mathrm{~g} \mathrm{Pu} / \mathrm{L}$, while the plutonium depleted solids settle in another area of the tank. The plutonium also must not settle in a flat slab, but accumulate in a spherical geometry.

A 300-L sphere has a diameter of about $83 \mathrm{~cm}(32.7 \mathrm{in.})$. A sphere of this size requires a plutonium concentration of at least $10 \mathrm{~g} \mathrm{Pu} / \mathrm{L}$ or $3,000 \mathrm{~g}$. To achieve a plutonium concentration of $10 \mathrm{~g} \mathrm{Pu} / \mathrm{L}$ and a plutonium mass of $3,000 \mathrm{~g}$ before criticality is possible. To achieve, a plutonium concentration of $10 \mathrm{~g} \mathrm{Pu} / \mathrm{L}$, the plutonium content in core sample 2 would need to increase over 57 times. Also, because the solids volume in the tank calculates to an average height of $32.3 \mathrm{~cm}$ (12.7 in.) its unlikely the suspended solids will settle into a pile in a localized area of the tank to a height greater than the average. If the agitation of the tank supernate created an area of fluid flow conducive to the settling of plutonium particulate while the pumps are operating, the area would most likely be at the "dead zones". The undisturbed solids layer is $32.2 \mathrm{~cm}$ (12.7 in.) high and the settled plutonium-rich material would create a mound on top of these solids. If the mound is equivalent to the $300 \mathrm{~L}$ sphere it would increase the height of the undisturbed solids by $83 \mathrm{~cm}$ ( 32.7 in.) which would be about three times higher than the original solids layer. If the "dead zones" accumulate a slab of solids with the $300 \mathrm{~L}$ sphere contained inside, the volume of solids would be $31,495 \mathrm{~L}$ $(8,321 \mathrm{gal})$, which is $24 \%$ of all the solids in the tank.

The above scenarios include some assumptions that are considered extremely unlikely if not impossible. The plutonium concentration of the solids material as determined from sample analysis $(0.175 \mathrm{~g} \mathrm{Pu} / \mathrm{L})$ is at least 57 times less than the concentration of $10 \mathrm{~g} \mathrm{Pu} / \mathrm{L}$ required to make $3,000 \mathrm{~g}$ of plutonium critical under optimum conditions. The plutonium concentration in the supernate as determined from sample analysis $(0.000019 \mathrm{~g} \mathrm{Pu} / \mathrm{L})$ is at least 378,947 times less than the minimum critical concentration in water of $7.2 \mathrm{~g} \mathrm{Pu} / \mathrm{L}$. 


\subsection{BASIC PARAMETERS}

The following discussion provides supporting evidence for the conclusions contained in this CSER.

\subsection{SOLUBILITY OF PLUTONIUN IN HASTE}

This discussion is provided verbatim (with the permission of the author) from WHC-SD-SQA-CSA-20368, CSER 94-004: Criticality Safety of Double-Shell Tank Waste Storage Tanks, (Rogers 1994). The reader is encouraged to review the Rogers (1994) for a more extensive discussion.

An important parameter for criticality safety is the solubility of plutonium in high-level waste. The higher the solubility the more difficult it is to control the distribution of the plutonium. If the plutonium can be dissolved, for example, separation of the plutonium from other components might be possible by preferentially dissolving the plutonium. When plutonium is in solution, there are mechanisms, such as evaporation of liquid, settling, and precipitation, that are capable of increasing the concentration.

Perhaps the main problem associated with having a large fraction of the plutonium in solution would be the difficulty in estimating how much plutonium is in each tank. When plutonium is dissolved, the quantity transferred when waste is pumped between tanks is increased, and it becomes more difficult to estimate the distribution of the plutonium. It is therefore desirable to ensure a low solubility for plutonium to keep it combined with solids and to make it less mobile. Because plutonium is less soluble in an alkaline solution, the pH of the waste is controlled to ensure alkalinity.

\section{Concentration of Dissolved Plutonium}

Four documents were examined that discuss the solubility of plutonium under the conditions present in high-level waste. C. H. Delegard is the primary author for two of these studies, and D. T. Hobbs is the primary author of the other two.

Hobbs investigated the influence of hydroxide, nitrate, nitrite, aluminate, sulfate, carbonate, and temperature on the solubility of plutonium and uranium in alkaline salt solutions and reached the following conclusion:

For salt solutions within the range considered by this study, upper 95\% tolerance limits for $P u$ and $U$ solubilities, estimated from analytically measured specie concentrations, are $1.68 \mathrm{mg} / \mathrm{L}(6.36 \mathrm{mg} / \mathrm{gal})$ and $17.1 \mathrm{mg} / \mathrm{L}$ $(64.7 \mathrm{mg} / \mathrm{gal})$, respectively. The alkaline salt solutions considered in this study should bound those that will be treated in the in-tank precipitation process (Hobbs et al. 1993). 
Hobbs also concluded that:

"Conditions which increase the plutonium solubility do not necessarily increase the uranium solubility. Maximum plutonium solubility is predicted at high nitrate, high hydroxide, high carbonate, and high sulfate concentrations. Maximum uranium solubility is predicted at high hydroxide, high aluminate and high sulfate concentrations and low nitrate, low nitrite, and low carbonate concentrations (Hobbs et a1. 1993)."

\section{Effects of Haste Components on Solubility}

Hobbs makes the following observation concerning the effect of other waste components on solubility:

- The solubilities reported in this document may be higher than those which will be observed in actual waste caused by the coprecipitation of the plutonium and the uranium with iron, manganese, and aluminum during neutralization of fresh waste. In a single experiment in which the plutonium and uranium were coprecipitated with iron, the solubility of plutonium was decreased by a factor of about five, and that of uranium increased by about a factor of two (Hobbs et al. 1993).

- Although the common understanding is that plutonium precipitates in alkaline solution, this simple understanding does not fully describe the complex nature of the chemistry involved in waste. Delegard shows that the solubility of plutonium increases for increasing $\mathrm{NaOH}$.

- The solubility of $\mathrm{Pu}$ (IV) hydrous oxide, $\mathrm{PuO}_{2} \cdot \mathrm{xH}_{2} \mathrm{O}$, in air-equilibrated, synthetic, Hanford Site high-leve? waste (HLW) solutions was determined as a function of $\mathrm{NaOH}, \mathrm{NaAl}(\mathrm{OH})_{4}, \mathrm{NaNO}_{3}$, $\mathrm{NaNO}_{2}$, and $\mathrm{Na}_{2} \mathrm{CO}_{3}$ concentrations. The solubility was found to increase with the square of the $\mathrm{NaOH}$ chemical activity. The components $\mathrm{NaNO}_{3}$ and $\mathrm{NaNO}_{2}$ increased $\mathrm{PuO}_{2} \cdot \mathrm{xH}_{2} \mathrm{O}$ solubility by increasing $\mathrm{NaOH}^{3}$ activity (Delegard 1985).

Although the plutonium solubility is found to increase with addition of $\mathrm{NaOH}$, the solubility nevertheless remains low. Delegard (1985) studied the solubility of plutonium in $\mathrm{NaOH}$ solutions over the range of $\mathrm{NaOH}$ concentration between 1 and 15 molar.

For typical waste, Delegard (1985) states that the $\mathrm{NaOH}$ concentration is 4 molar. At this concentration the maximum plutonium concentration is found to be about $0.0005 \mathrm{~g} / \mathrm{L}\left(0.0019 \mathrm{~g} / \mathrm{gal}\right.$ or $\left.2 \times 10^{-6} \mathrm{molar}\right)$. When allowed to set for a long time, the plutonium concentration in solution decreases to a value about 8 times smaller. When the $\mathrm{NaOH}$ is increased from 4 molar to 7 molar, the concentration of dissolved plutonium increases by about 10 times, and at 11 molar it is about 100 times greater than at 4 molar. At the high $\mathrm{NaOH}$ concentration of 11 molar, the plutonium concentration in solution should not exceed $0.05 \mathrm{~g} / \mathrm{L}(0.19 \mathrm{~g} / \mathrm{gal})$ (Delegard 1985). 
HNF-SD-W151-CSA-001, Rev. 1

\subsection{DEMSITY OF SOLIDS}

The following discussion provides supporting evidence for the conclusions about the density of solids and liquid content the contained in this CSER. This discussion is provided verbatim from Rogers (1994).

\section{Importance of Solids}

The presence of solids greatly increases the difficulty of achieving a critical configuration. Solids not only increase the neutron absorption, but also limit the ability of the plutonium to become more concentrated. After all liquids have been drained from the waste, the remaining solids ensure that the average plutonium concentration remains low.

The total mass of solids in all waste tanks is known to greatly exceed what is required to maintain subcriticality for the total quantity of plutonium available. However, the components of tank waste are not uniformly distributed among the various tanks, and the possibility must be considered that a localized region of high plutonium concentration and relatively low solids concentration might exist.

The conservative waste model defines a waste for which the neutron absorption is less than for any actual waste. Any homogenized real waste cannot be made critical when the mass ratio of waste solids to plutonium exceeds 476 . This is the same as stating that the plutonium must be less than $2.1 \mathrm{~g} / \mathrm{kg}$ of solids.

Many waste components are good absorbers of neutrons. For each of these components there is a corresponding absorber/plutonium mass ratio above which criticality is impossible. When the ratio of one particular absorber is decreased, it is likely that there will be other absorbers in the waste capable of ensuring subcriticality.

\section{Total Quantity of Settled Plutonium}

Settling of solids and evaporation of liquid can result in a layer of waste in which the plutonium concentration has increased. However, criticality is not possible unless the plutonium areal density exceeds $240 \mathrm{~g} / \mathrm{ft}^{2}\left(2,582 \mathrm{~g} / \mathrm{m}^{2}\right)$. This areal density over the area of a storage tank would require more than $1,000 \mathrm{~kg}$ of plutonium. There is a low probability that the inventory of any tank exceeds $10 \%$ of this quantity. Therefore, criticality would not be possible within a layer of settled waste, regardless of the solids content.

\section{Density of Solids}

Waste solids provide an effective way of controlling the plutonium concentration. When the plutonium is mixed with a high proportion of solids, it is difficult, if not impossible, to separate the plutonium from the solids by mechanical means. Stirring, mixing, pumping, or any other operation performed on the waste tends to more completely mix the plutonium with the solids. 
When waste contains a large fraction of liquid, it is possible for solids to be suspended in the liquid. Removal of liquid may cause the density of the solids to increase. The highest density for the solids is obtained by removing all of the liquid to obtain dry solids. The volume of dry solids provides a lower limit on the volume of waste. When all plutonium is assumed confined to the dry solids, an upper limit is obtained on the plutonium concentration. Because the maximum possible plutonium concentration is determined by the minimum density of solids, the dry solids density is an important parameter for criticality safety.

\section{Liquid Content}

The high water content of the waste ensures that fissile material is highly overmoderated. However, there are operations designed to remove water from waste, such as saltwell pumping and passing waste through an evaporator. Although the degree of overmoderation decreases as liquid is removed, the low plutonium concentration ensures that the waste will remain overmoderated after completion of evaporation or pumping. If all water were to be removed, the scattering properties of the large fraction of material in the waste that is not fissile would provide appreciable moderation and absorption.

This evaluation assumes that optimal moderation of waste is possible. Therefore, the actual volume of liquid in the waste tank does not affect conclusions reached. No restrictions need be placed on the water content of tank waste, either as to how little or how much is allowed to be present.

\subsection{PLUTONIUN CRITICAL PARAMETERS}

The following discussion provides support for the critical parameters in different mediums that is cited in this CSER. This discussion is provided verbatim from Rogers (1994).

\section{Plutonium in Water}

Criticality is not possible for plutonium in a plutonium-water mixture unless the plutonium concentration exceeds $7.2 \mathrm{~g} / \mathrm{L}$.

When certain materials are present whose neutron absorption cross sections are small, in addition to water, criticality becomes possible at lower concentrations. For tank waste, criticality is possible at a lower plutonium concentration when the total macroscopic absorption cross section per plutonium atom is less than for water.

\section{Plutonium in Waste}

For criticality to be possible in tank waste, it is necessary for the plutonium concentration to be at least $2.6 \mathrm{~g} / \mathrm{L}(9.84 \mathrm{~g} / \mathrm{gal})$ over a large volume. This value is based on the conservative waste model and occurs at an hydrogen/plutonium (H/Pu) atom ratio of about 100 . Alternately, criticality is possible with a higher plutonium concentration over a smaller volume. 
HNF-SD-W151-CSA-001, Rev. 1

To achieve criticality with waste having a plutonium concentration of $4.0 \mathrm{~g} / \mathrm{L}$ requires a $4.7-\mathrm{m}(15.4-\mathrm{ft})$ diameter, $53,750-\mathrm{L}(14,200-\mathrm{ga} 1)$ sphere containing $215 \mathrm{~kg}$ of plutonium. Optimal moderation occurs for an hydrogen/plutonium atom ratio of 500 .

The minimum critical areal density of plutonium in water is conservative when applied to waste. $2,582 \mathrm{~g} \mathrm{Pu} / \mathrm{m}^{2}\left(240 \mathrm{~g} \mathrm{Pu} / \mathrm{ft}^{2}\right)$ is the lowest areal density that can be made critical (Carter et al. 1969). The areal density includes all plutonium above a unit area of floor, including plutonium located all the way to the top surface.

\subsection{MIXING MECHANISHS}

The following discussion provides support for the conclusions about the dispersing of plutonium due to mixing waste. Rogers (1994) states the following about the dispersing tendency of mixing waste.

The only operation performed for many waste storage tanks is the pumping of new waste into the tank. The incoming solids from each batch of waste settle into a layer and the liquid portion mixes with the already present supernatant liquid. In these tanks the configuration of the waste should remain relatively unchanged over long periods of time.

Mixing tends to disperse a region of higher plutonium concentration. The concentration of each component in waste types that have been mixed together tends to become closer to an average value. Regions containing both higher and lower concentrations tend to become smaller. The overall waste mixture becomes increasingly uniform in composition as the mixing continues. Although the waste is initially well subcritical, mixing is expected to increase the margin of safety even farther by dispersing the plutonium and reducing the regions of higher plutonium concentration.

Although scenarios have been postulated in which mixing might lead to an increase in plutonium concentration, the conditions of waste in tank 101-AZ are such as to make it unlikely to occur. The extremely low plutonium concentration would require a highly efficient process of separating plutonium from other waste in order to even begin to approach the concentration at which criticality is possible. No such process can be postulated. 
HNF-SD-W151-CSA-001, Rev. I

This page intentionally left blank.

6-6 
HNF-SD-W151-CSA-001, Rev. 1

\subsection{REFERENCES}

Braun, D. J., L. D. Muhlestein, T. B. Powers, and M. D. Zentner, 1994, High Level Waste Tank Subcriticality Safety Assessment, WHC-SD-WM-SARR-003, Westinghouse Hanford Company, Richland, Washington.

Brevick, C. H., L. A. Gaddis, and S. D. Consort, 1995, Supporting Document for the Southeast Quadrant Historical Tank Content Estimate Report for AZ-Tank Farm. Volume I, WHC-SD-WM-ER-318, Westinghouse Hanford Company, Richland, Washington.

Brevick, C. H., L. A. Gaddis, and E. D. Johnson, 1995, Tank Waste Source Term Inventory Validation, WHC-SD-WM-ER-400, Westinghouse Hanford Company, Richland, Washington.

Carter, R. D., G. R. Kiel, and K. R. Ridgway, 1969, Criticality Handbook, ARH-600, Vol.II, p. III.A.8.100-3, Atlantic Richfield Hanford Company, Richl and, Washington.

Delegard, C. H., 1985, Solubility of $\mathrm{PuO}_{2} \cdot \mathrm{xH}_{2} \mathrm{O}$ in A7kaline Hanford High-Level Waste Solution, RHO-RE-SA-75 P, Rockwell International, Richl and, Washington.

Gray, W. J., M. E. Peterson, R. D. Scheele, and J. M. Tingey, 1993 (DRAFT), Characterization of The Second Core Sample of Neutralized Current Acid Waste From Double-Shell Tank 101-AZ, Pacific NorthWest Laboratory, Richland, Washington.

Hanlon, B. M., 1995, Tank Farm Surveillance and Waste Status Summary Report for February 1996, WHC-EP-0182-95, Westinghouse Hanford Company, Richland, Washington.

Herting, D. L., 1994, Characterization of Sludge Samples From Tank 241-AN-107, I.L. 8E110-PCL94-064, Westinghouse Hanford Company, Richl and, Washington.

Hobbs, D. T., T. B. Edwards, and S. D. Fleischman, 1993, Solubility of Plutonium and Uranium in Alkaline Salt Solutions (U), WSRC-TR-93-056, Savannah River Technology Center, Westinghouse Savannah River Company, Aiken, South Carolina.

Hodgson, K. M., and T. T. Tran, 1995, Tank Characterization Report for Double-Shell Tank 241-AZ-101, WHC-SD-WM-ER-410, Westinghouse Hanford Company, Richland, Washington.

Peterson, M. E., R. D. Scheele, and J. M. Tingey, 1989, Characterization of The First Core Sample of Neutralized Current Acid Waste From Double-Shell Tank 101-AZ, PNL-7758, Battelle, Pacific Northwest Laboratory, Richland, Washington. 
Rogers, C. A., 1993, CSER 92-009: An Analytical Model For Evaluating Subcritical Limits for Waste in Hanford Site Storage Tanks, WHC-SD-SQA-CSA-20356, Westinghouse Hanford Company, Richl and, Washington.

Rogers, C. A., 1994, CSER 94-004: Criticality Safety of Doub7e-Shell Tank Waste Storage Tanks, WHC-SD-SQA-CSA-20368, Westinghouse Hanford Company, Richland, Washington.

Symons G. A., 1996, Mixer Pump Test Plan For Double-Shell Tank AZ-101, WHC-SD-WM-PTP-027, Westinghouse Hanford Company, Richland, Washington.

Vai1, 1995, Waste Storage Tanks and Associated Equipment, CPS-T-149-00010, Rev. G-0, Westinghouse Hanford Company, Richland, Washington. 
HNF-SD-W151-CSA-001, Rev. 1

\section{APPENDIX A}

ORIGINAL DATA AND CALCULATIONS

A-1 
HNF-SD-W151-CSA-001, Rev. 1

This page intentionally left blank. 


\section{A.1 APPENDIX DESCRIPTION}

Tables in the appendix correlate with tables in the text of the document. The appendix tables will be identified with an "A" designator (i.e., Table A-4-1) contains original data for Table 4-1 and is in the appendix. There is no relevant need to include Table 5-3 in the appendix.

\section{A.2 ORIGINAL DATA AND UNIT CONVERSION FOR SUPERNATE ANALYSIS}

The units for values in Table 4-1 for core 1 are the same as the units reported in Peterson et a7. (1989), except ${ }^{239 / 260} \mathrm{Pu}$ which is reported as $\mathrm{mCi} / \mathrm{g}$. The units for values in Table 4-1 for core 2 are $\mathrm{mmol} / \mathrm{g}$ and are reported in Gray et al. (1993) Table 9, as umol/g, except for ${ }^{239 / 240} \mathrm{Pu}$ which is reported in Gray et al. (1993) as ug/g in Table 11. The original data as reported in the two documents are in Table A-4-1. The unit conversions are detailed below the table.

Table A-4-1. Selected Analyte Analys is of Centrifuged Supernate.

\begin{tabular}{|l|c|c|}
\hline & (1) & ( \\
\hline $\mathrm{pH}$ & 13.7 & 13.5 \\
\hline $\mathrm{Al}$ & 0.332 & 81.6 \\
\hline $\mathrm{Ni}$ & $<0.0002$ & 0.043 \\
\hline $\mathrm{Fe}$ & 0.0002 & 0.351 \\
\hline $\mathrm{Cr}$ & 0.013 & 8.29 \\
\hline $\mathrm{K}$ & 0.088 & 52.1 \\
\hline $\mathrm{Mn}$ & 0.00002 & 0.008 \\
\hline $\mathrm{Na}$ & 3.76 & 2,020 \\
\hline Density $\mathrm{g} / \mathrm{mL}$ & 1.2 & 1.22 \\
\hline $239 / 240 \mathrm{Pu}$ & $4.3 \mathrm{E}-7 \mathrm{mCi} / \mathrm{g}$ & $0.0154 \mathrm{ug} / \mathrm{g}$ \\
\hline
\end{tabular}

Notes:

${ }^{1}$ Peterson et al. (1989)

'Gray et al. (1993)

The conversion of core 2 data from umol/g to $\mathrm{mmol} / \mathrm{g}$ of supernate is as follows:

$$
\text { Conc. }\left(\frac{\text { umol }}{g}\right) \times\left[\frac{\text { mol }}{1000 \text { umol }}\right]=\text { Conc. }\left[\frac{m m o l}{g}\right]
$$


The conversion ${ }^{239 / 240} \mathrm{Pu}$ in core 1 from $\mathrm{mCi} / \mathrm{g}$ to $\mathrm{uCi} / \mathrm{g}$ is as follows:

$$
\text { Pu Conc. }\left[\frac{m C i}{g}\right] \times\left(\frac{1000 u C i}{m C i}\right]=P u \text { Conc. }\left(\frac{u C i}{g}\right)
$$

The conversion ${ }^{239 / 240} \mathrm{Pu}$ in core 2 from $u g / g$ to $\mathrm{uCi} / \mathrm{g}$ is as follows:

$$
\text { Pu Conc. }\left(\frac{u g}{g}\right) \times\left(\frac{g}{1 E+6 u g}\right) \times\left[\frac{0.062 C i}{g}\right] \times\left(\frac{1 E+6 u C i}{C i}\right)=P u \text { Conc. }\left(\frac{u C i}{g}\right)
$$

\section{A.3 ORIGINAL DATA AND UNIT CONVERSION FOR SLUDGE ANALYSIS}

The units for the values in Table 4-2 are mnol/g of sludge. The original data documented in Peterson et al. (1991), Table 2, is, also in units of mmol/g sludge, except the density, which is $\mathrm{g} / \mathrm{mL}$ and $239 / 240 \mathrm{Pu}$ which is reported as units of $\mathrm{mC} i / g$ in Table 7 . The Table A-4-2 below contains the original data as found in Peterson et al. (1991). No unit conversions are necessary, the Table A-4-2 is included for completeness.

Table A-4-2. Selected Analyte Analysis of Core 1 Sludge. Results reported by Peterson et al. (1991)

\begin{tabular}{|c|c|c|c|}
\hline mingors & .0901149 & (40010) & soritis \\
\hline $\mathrm{Na}$ & 3.42 & 1.53 & 0.769 \\
\hline Al & 1.46 & 0.0739 & 0.277 \\
\hline $\mathrm{Fe}$ & 1.5 & $4.98 \mathrm{E}-6$ & 0.365 \\
\hline $\mathrm{Cr}$ & 0.055 & 0.00553 & 0.00803 \\
\hline Mn & 0.086 & $<2 . \mathrm{E}-6$ & 0.0166 \\
\hline $\mathrm{Ni}$ & 0.06 & $<2 . E-5$ & $<0.002$ \\
\hline Density $\mathrm{g} / \mathrm{mL}$ & 1.8 & 1.08 & 1.04 \\
\hline${ }^{239 / 240} \mathrm{Pu}, \mathrm{mCi} / \mathrm{g}$ & 0.0044 & $6.4 E-8$ & 0.00079 \\
\hline
\end{tabular}

(all values in $\mathrm{mmol} / \mathrm{g}$, except as noted).

Notes: 
The units for the values in Table 4-3 are mol/g of sludge. The original data documented in Gray et al. (1993), Table 9, is in units of umol/g sludge, except the density, which is $\mathrm{g} / \mathrm{mL}$ (Table 8 ) and $239 / 240 \mathrm{Pu}$ which is reported in units of $\mathrm{ug} / \mathrm{g}$ in Table 11 . The Table A-4-3 below contains the original data as found in Peterson et a1. (1991). The only required unit conversion is for plutonium and is below the table.

Table A-4-3. Selected Analyte Analysis of Core 2 Sludge. Results reported by Gray et al. (1993) (all values in umol $/ \mathrm{g}$, except as noted).

\begin{tabular}{|c|c|c|c|}
\hline ( ) & y.r. & 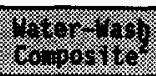 & 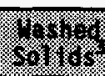 \\
\hline $\mathrm{Na}$ & 3,890 & 769 & 299 \\
\hline A1 & 733 & 34.4 & 312 \\
\hline Fe & 2,500 & 0.004 & 1,010 \\
\hline $\mathrm{Cr}$ & 16.3 & 2.77 & 3.54 \\
\hline$M n$ & 37.5 & 0.001 & 15.5 \\
\hline $\mathrm{Ni}$ & 112 & $<0.002$ & 68.8 \\
\hline Density $\mathrm{g} / \mathrm{mL}$ & 1.73 & $1.22^{4}$ & 1.14 \\
\hline${ }^{239 / 260} \mathrm{Pu}$, ug/g & 101 & 0.00488 & 38.6 \\
\hline
\end{tabular}

Notes:

'Centrifuged solids from the core composite

${ }^{2}$ Combined supernate from washed solids

Water-washed solids

Density of the water wash was not reported, the density of the supernate will be used.

For plutonium, the unit conversion from ug $\mathrm{Pu} / \mathrm{g}$ of sludge to $\mathrm{mCi} \mathrm{Pu} / \mathrm{g}$ of sludge is as follows.

$\mathrm{Pu}$ Conc. $\left(\frac{\mathrm{ug}}{\mathrm{g}}\right) \times\left(\frac{\mathrm{g}}{\mathrm{IE}+6 \mathrm{ug}}\right) \times\left(\frac{0.062 \mathrm{Ci}}{\mathrm{g}}\right) \times\left(\frac{1000 \mathrm{mCi}}{\mathrm{Ci}}\right)=\mathrm{Pu}$ Conc. $\left(\frac{\mathrm{mCi}}{\mathrm{g}}\right)$

\section{A. 4 CALCULATIONS FOR ABSORPTION CROSS SECTION}

The unit conversions and calculations for the absorption cross sections are below Table A-5-2. The original concentration data for each analyte is from Tables 4-2 and 4-3. 
Table A-5-1. Total Absorption of the Solids in Core 1.

\begin{tabular}{|c|c|c|c|c|c|c|}
\hline \multirow{2}{*}{ U: } & \multirow{2}{*}{ 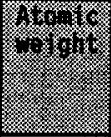 } & \multirow{2}{*}{ for } & \multirow{2}{*}{ 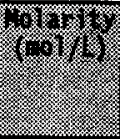 } & \multirow{2}{*}{ 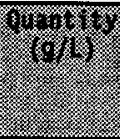 } & \multicolumn{2}{|c|}{ 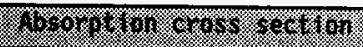 } \\
\hline & & & & & 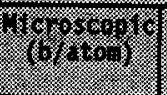 & (1) \\
\hline $\begin{array}{l}\text { Sodium } \\
\text { (Na) }\end{array}$ & 22.99 & 3.42 & 6.156 & 141.53 & 0.5300 & 3.263 \\
\hline $\begin{array}{l}\text { Al uminum } \\
\text { (A1) }\end{array}$ & 26.982 & 1.46 & 2.628 & 70.91 & 0.2350 & 0.618 \\
\hline $\begin{array}{l}\text { Iron } \\
\text { (Fe) }\end{array}$ & 55.847 & 1.5 & 2.700 & 150.79 & 2.2350 & 6.035 \\
\hline $\begin{array}{l}\text { Chromium } \\
(\mathrm{Cr})\end{array}$ & 51.996 & 0.055 & 0.099 & 5.15 & 3.1000 & 0.307 \\
\hline $\begin{array}{l}\text { Nickel } \\
\text { (Ni) }\end{array}$ & 58.71 & 0.06 & 0.108 & 6.34 & 4.8000 & 0.518 \\
\hline $\begin{array}{l}\text { Manganese } \\
(\mathrm{Mn})\end{array}$ & 54.938 & 0.086 & 0.155 & 8.504 & 13.2000 & 2.046 \\
\hline \multicolumn{3}{|c|}{ How } & \multicolumn{2}{|c|}{ W. W } & \% & (1) \\
\hline
\end{tabular}

Table A-5-2. Total Absorption of the Solids in Core 2.

\begin{tabular}{|c|c|c|c|c|c|c|}
\hline \multirow{2}{*}{ (4) } & \multirow{2}{*}{ 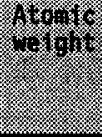 } & \multirow{2}{*}{ 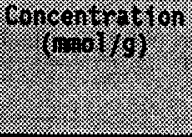 } & \multirow{2}{*}{ (6) } & \multirow{2}{*}{ (4) } & \multicolumn{2}{|c|}{ 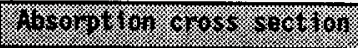 } \\
\hline & & & & & W & (1) \\
\hline $\begin{array}{l}\text { Sodium } \\
\text { (Na) }\end{array}$ & 22.99 & 3.89 & 6.730 & 154.723 & 0.5300 & 3.567 \\
\hline $\begin{array}{l}\text { Aluminum } \\
\text { (A1) }\end{array}$ & 26.982 & 0.733 & 1.268 & 34.213 & 0.2350 & 0.298 \\
\hline $\begin{array}{l}\text { Iron } \\
\text { (Fe) }\end{array}$ & 55.847 & 2.500 & 4.325 & 241.538 & 2.2350 & 9.666 \\
\hline $\begin{array}{l}\text { Chromium } \\
\text { (Cr) }\end{array}$ & 51.996 & 0.0163 & 0.028 & 1.456 & 3.1000 & 0.087 \\
\hline $\begin{array}{l}\text { Nickel } \\
(\mathrm{Ni})\end{array}$ & 58.71 & 0.112 & 0.194 & 11.390 & 4.8000 & 0.931 \\
\hline $\begin{array}{l}\text { Manganese } \\
\left(M_{n}\right)\end{array}$ & 54.938 & 0.0375 & 0.065 & 3.571 & 13.2000 & 0.858 \\
\hline Hol 6 & $6 \%$ & & Wo & 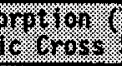 & 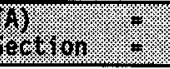 & 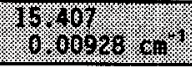 \\
\hline
\end{tabular}


The unit conversion for each analyte from mol/g to molarity is as follows.

$$
\text { Conc. }\left(\frac{m \mathrm{~mol}}{\mathrm{~g}}\right) \times\left(\frac{\mathrm{mol}}{1000 \mathrm{mmol}}\right) \times \text { density }\left(\frac{\mathrm{g}}{\mathrm{L}}\right)=\text { Conc. }\left(\frac{\mathrm{mol}}{\mathrm{L}}\right)
$$

The unit conversion for each analyte from mol/g to $\mathrm{g} / \mathrm{L}$ is as follows.

$$
\text { Conc. }\left[\frac{\mathrm{mmol}}{\mathrm{g}}\right] \times\left[\frac{\mathrm{mol}}{1000 \mathrm{mmol}}\right] \times \text { density } \times\left[\frac{\mathrm{g}}{\mathrm{L}}\right] \times \text { atomic wt }\left(\frac{\mathrm{g}}{\mathrm{mol}}\right]=\text { Conc. }\left(\frac{\mathrm{g}}{\mathrm{L}}\right)
$$

The TOTAL ABSORPTION (TA) for the sample is calculated by multiplying each analyte in units of molarity by the microscopic cross section for each analyte and adding all the microscopic cross sections.

The sample macroscopic absorption cross section (XS) is calculated as follows:

XS $=$ total absorption (TA) $\times$ Avogadro's Number

$=\quad T A(m o l e-b / a t o m-L) \times(6.023 \mathrm{E} 23$ atom/mole $) \times 1 E-27 \mathrm{~L} / \mathrm{b}-\mathrm{cm}$

$=6.023 \mathrm{E}-04 \times \mathrm{TA} \mathrm{cm}^{-1}$

The macroscopic absorption cross section for core 1 calculates to $0.0077 \mathrm{~cm}^{-1}$ and core 2 calculates to $0.00928 \mathrm{~cm}^{-1}$. The calculation of absorption per gram of sample is determined by dividing the macroscopic cross section by the grams of analytes used to calculate the total absorption.

For core 1 the absorption per gram is:

$$
\frac{\text { TA } 12.784 \mathrm{~cm}^{-1}}{383.22 \mathrm{~g}}=0.0334 \frac{\mathrm{cm}^{-1}}{\mathrm{~g}}
$$

For core 2 the absorption per gram is:

$$
\frac{\text { TA } 15.407 \mathrm{~cm}^{-1}}{446.89 \mathrm{~g}}=0.0344 \frac{\mathrm{cm}^{-1}}{\mathrm{~g}}
$$

For the conservative waste model (Rogers 1993) the absorption per gram is:

$$
\frac{T A 18.197 \mathrm{~cm}^{-1}}{1200 \mathrm{~g}}=0.01516 \frac{\mathrm{cm}^{-1}}{\mathrm{~g}}
$$




\section{A.5 UNIT CONVERSION CALCULATION MASS RATIOS}

The values in Table 5-4 are unitless ratios of the mass of plutonium to the specified analytes. Therefore, the units of the original data for each analyte must be consistent with the units of plutonium. The original data documented in Peterson et al. (1991) and Gray et al. (1993), for each phase of the sludge is given in Tables A-4-2 and A-4-3. The method of calculating mass ratios is to convert the analytes and plutonium concentration into $\mathrm{g} / \mathrm{L}$. The unit conversions are given below.

For core 1 the units are in mmol/g, so the conversion to $\mathrm{g} / \mathrm{L}$ is:

Conc. $\left[\frac{\mathrm{mmol}}{\mathrm{g}}\right] \times\left(\frac{\mathrm{mol}}{1000 \mathrm{mmol}}\right] \times$ atomic wt $\left[\frac{\mathrm{g}}{\mathrm{L}}\right] \times$ density $\left[\frac{\mathrm{g}}{\mathrm{L}}\right]=$ Conc.

The conversion of plutonium from $\mathrm{mCi} / \mathrm{g}$ to $\mathrm{g} \mathrm{Pu} / \mathrm{L}$ is:

${ }^{239 / 240} \mathrm{Pu}$ Conc. $\left(\frac{\mathrm{mCi}}{\mathrm{g}}\right) \times\left(\frac{\mathrm{Ci}}{1000 \mathrm{mCi}}\right) \times\left(\frac{\mathrm{g}}{0.062 \mathrm{Ci}}\right) \times \operatorname{density}\left(\frac{\mathrm{g}}{\mathrm{L}}\right)={ }^{239 / 240} \mathrm{Pu}$ Conc. $\left(\frac{\mathrm{g}}{\mathrm{L}}\right)$

For core 2 the units are in umol $/ \mathrm{g}$, so the conversion to $\mathrm{g} / \mathrm{L}$ is:

Conc. $\left(\frac{\mathrm{umol}}{\mathrm{g}}\right) \times\left(\frac{\mathrm{mol}}{\mathrm{lE} 6 \mathrm{umol}}\right) \times$ atomic wt $\left(\frac{\mathrm{g}}{\mathrm{Mol}_{0}}\right) \times$ density $\left(\frac{\mathrm{g}}{\mathrm{L}}\right]=$ Conc. $\left(\frac{\mathrm{g}}{\mathrm{L}}\right)$

The conversion of plutonium from $u g / g$ to $\mathrm{g} \mathrm{Pu/L}$ is:

${ }^{239 / 240} \mathrm{Pu}$ Conc. $\left(\frac{\mathrm{ug}}{\mathrm{g}}\right) \times\left(\frac{\mathrm{g}}{\mathrm{lE} 6 \mathrm{ug}}\right) \times$ density $\left(\frac{\mathrm{g}}{\mathrm{L}}\right)={ }^{239 / 240} \mathrm{Pu}$ Conc. $\left(\frac{\mathrm{g}}{\mathrm{L}}\right)$ 
HNF-SD-W151-CSA-001, Rev. I

APPENDIX B

REVIEWER' S CONMENTS

B-1 
HNF-SD-W151-CSA-001, Rev. 1

This page intentionally left blank.

B-2 


\section{B. 1 APPENDIX DESCRIPTION}

The following comments were received by the individuals indicated. All comments were appropriately resolved and incorporated into the document.

\section{B.2 INDEPENDENT REVIEW}

An independent review was completed by $C$. A. Rogers. Editorial comments were provided on a marked up copy of the evaluation.

Only a limited amount of analytical data is available on the composition of waste in tank 101-AZ. This data indicates a high degree of subcriticality. All available information on tank waste indicates that separation of the plutonium from the waste matrix is extremely unlikely. The nature of mixing itself has a strong tendency towards dispersal of waste components, rather than concentration. This report provides good justification that operation of the two mixer pumps would be very unlikely to produce any localized pockets in which the plutonium concentration would be much increased. A concentrating mechanism of very high efficiency would be required to bring together most of the available plutonium into a volume of less than $6 \%$ of the waste volume. Convincing arguments are provided that no such mechanism exists.

The following from page 4-7 provides important information showing criticality safety.

Also, the plutonium was not washed out of the solid phase by the water as evidenced by the low plutonium values of the water-washed supernate fraction of the samples. The rigorous laboratory procedure that centrifuged and tumbled the sample for several hours failed to dislodge the plutonium from the solid phase. The centrifuge and tumbling of the sludge is considered similar to the mixing action of the mixer pump.

This evaluation should discuss the accuracy of the two core samples and whether the associated uncertainty influences the conclusions of this report.

Some of the equations which show how to convert from one set of units to another do not balance. The formatting of some equations is not correct. These discrepancies are pointed out on a copy of the report.

The following specific comments are made.

1. (Page 2-2, Paragraph 3, Sentence 3) Suggest following rewrite of the discussion of calculating the absorption cross section per gram of waste.

When the absorption cross section is calculated for one gram of waste material, it is found to be $0.01516 \mathrm{~cm}^{-1} / \mathrm{g}$ for the model composition. This can then be compared to $0.0334 \mathrm{~cm}^{-1} / \mathrm{g}$ for core 1 and to $0.0345 \mathrm{~cm}^{-1} / \mathrm{g}$ for core 2. The absorption cross section for the waste in 101-AZ is therefore found to be more than double the cross section of the model, when they are compared on the basis of the same mass per liter. Since the analyzed components of the waste samples comprise only about onethird of the total material in the waste, the total neutron absorption 
per liter of waste is expected to be more than twice that obtained for the analyzed components. The neutron absorbing qualities of the actual waste is therefore found to be greater than that of the waste composition used to calculate the minimum critical parameters.

2. (Page 4-2, Paragraph 4, Line 6) The sentence beginning with "The Tank solids contained 74 vol\%" is not clearly written.

3. (Page 5-1, Section 5.1, Paragraph 1) 42,000 in the next paragraph appears to be wrong. Is 4,200 the correct number?

4. Page 5-3, Bottom Paragraph) Suggest deleting last sentence in first paragraph and adding:

In fact, less than half of the solids in the samples are included among the analyzed components (analytes). Therefore, the actual macroscopic absorption cross section would be expected to be at least twice that found above.

(Page 5-4, top paragraph) Suggest replacing paragraph with something like:

Since the comparison is based on a theoretical dry solids matrix used in the model, the sample must be converted to the same dry solid bases. A comparison of absorption cross sections can be done using the assumption that the water content of each sample is removed and replaced with solid material of the same composition as the sample. The solids would fill the void space left by removing the water. The result would be dry solids densities of about $2500 \mathrm{~g} / \mathrm{L}$ for the samples. In reality, the compaction of the solids would probably not be as great as the volume of the water removed. Nevertheless, the density of dry solids would be expected to be greater than the density in the original wet sample, and it would have a very high probability of exceeding $1,200 \mathrm{~g} / \mathrm{L}$. In any case, the higher neutron absorption per unit mass would ensure a greater macroscopic cross section than that assumed in the conservative waste model.

5. (Page 5-4, bottom paragraph) The reference to Table 4-7 is incorrect. Probably Table 5-4 is intended.

6. (Page 5-5) First paragraph is not clear. Suggest deleting it.

7. (Page 5-5) Bottom paragraph is not clear. A lower solids density in water-washed solids implies to me that the soluble solids are heavier than the insoluble. 
HNF-SD-W151-CSA-001, Rev. 1

\section{B.3 AUTHOR OF THE CRITICALITY SAFETY ACCIDENT ANALYSIS FOR THE FSAR.}

Mr. Robert M. Marusich provided the following comments.

1. I have a concern of using 478 as the solids to Pu subcriticality ratio without explicitly showing that the solids used have more absorption than Chuck's (Rogers 1993).

I also have a "sales" concern in that all reviewers have their own pet solids group. Use of this begs them to ask questions concerning low absorption solids, etc. It seems easier to me not to use the solids ratio.

2. Page 4-11,12 - While it is nice to speak in generalities, I think you need to get the dual mixer pump data from Greg Whyatt or Jeff Serne, determine the size of the dead zone, put the $P_{u}$ in that zone(s) (plural as due to symmetry there may always be two zones or 4 zones) and show that the volume is subcritical. This is needed based on the topical's: assertion that dual mixer pumps pose a criticality problem because of the dead zones.

The same comment applies to page 5-5 - paragraph 3 and the last paragraph. The dead zone is the mechanism to increase concentration. You cannot get off the hook by saying that it does not look like the Pu can concentrate that much.

3. page $5-2$, If the tank has carbonate in it, even down to $0.001 \mathrm{M}$, the solubility is much greater per the Topical. I did not see $\mathrm{CO}_{3}$ in the listing, but the list was anions not cations.

\section{B.4 CRITICALITY AND SHIELDING}

Mr. Ed M. Miller provided the following verbal comments.

1. The SUMMARY AND CONCLUSIONS section should include a much more detailed discussion of the evaluation of the "dead zones" created by the two mixer pumps. The conclusions about the plutonium concentration in those dead zones should be clearly discussed in the summary sections.

2. The discussion about the rigorous laboratory procedure which prepared the solid sample for analysis should be expanded to explain the difference between the mechanical and chemical treatment of the sample. Not everyone understands what "fusion" is or how it relates to the conclusions.

3. The highest plutonium concentration of the two core samples was used to calculate the plutonium inventory and draw conclusions about that inventory. Using the highest plutonium concentration should be emphasized so that it is very clear to the reader that this evaluation is conservative. 
Also, some attempt should be made to quantify the conservativeness or accuracy of the plutonium inventory in tank 101-AZ. There should be other samples, tanks, inventory or transfer sheets which could be used to quantify or at least provide a qualitative assessment of the accuracy of the plutonium inventory.

4. Page 4-9, primary criticality parameters, the discussion about why the mass ratio of water-washed solids to plutonium is significantly higher than the mass ratio for the composite is not clear. The value of the discussion is apparent, so the text should not be deleted only reworded to clarify the evaluation.

\section{B.5 PROJECT H-151}

The following comments were received from Mr. Edward M. Nordquist the Project Manager for Project W-151, representing DST Retrieval Projects.

1. Page 1-1, the last sentence, the objective is to resuspend the solids not mix and settle as that is a by-product of the resuspension.

2. Page 2-1, 3rd paragraph, suggest adding reference for statement in last sentence (i.e., for the Fissile Material Tracking System).

3. Page 2-2, first paragraph on page (carryover from previous page), the last sentence talks to dramatic chemical change but there's no mention of the heat input or material shearing. Would either of these mechanisms account for plutonium separation?

4. Page 2-3, 2nd paragraph last sentence, "... will not impact criticality safety, ..."

5. Page 3-1, is the third paragraph really needed? I'm not sure it adds any value to your analysis. If it stays, the first sentence needs to refer to construction, not Phase I activities.

6. Page 3-2, fifth paragraph need to delete fifth sentence. Also, the pumps are installed in riser $01 \mathrm{~A}$ and $01 \mathrm{C}$ (don't add 241-AZ).

7. Page 4-1, first paragraph suggest you be consistent with kgal, not Mgal. Also, last paragraph suggest measured in 1980 (drop "about").

8. Page 4-5, first equation looks like a tab is missing for the denominators.

9. Page 4-7, first sentence change to "was" and "is". Similar comment page 4-8, first full sentence.

10. Page 4-10, first sentence in Section 4.7, shouldn't we convert the $135 \mathrm{kgal}$ to $x \times$ " of sludge? 
HNF-SD-W151-CSA-001, Rev. 1

11. Page 4-11, last paragraph refer to the risers without the $A Z$ on them, that is $01 \mathrm{~A}$ and $01 \mathrm{C}$.

12. Page 5-I, you only referenced one of each of the authors quoted in the Concentration section. Should you add the other references in Section 6.0?

13. Page 5-3, second paragraph you mention that the possibility of a localized region of high plutonium concentration and relatively low solids concentration must be considered. Do the following paragraphs discuss and refute the possibility?

14. Page 5-4, second paragraph under Plutonium in water you mention that criticality is possible for tank waste when the total macroscopic absorption cross-section per plutonium atom is less than for water. Is this asked and answered? It seems you leave the reader hanging. 
HNF-SD-W151-CSA-001, Rev. 1

This page intentionally left blank. 
HNF-SD-W151-CSA-001, Rev. I

APPENDIX C

AN EVALUATION OF LAYERS OF WASTE IN 241-AZ-101

WITH THE HIGHEST CONCENTRATION OF PLUTONIUM

C-1 
HNF-SD-W151-CSA-001, Rev. 1

This page intentionally left blank.

C-2 


\section{1 APPENDIX DESCRIPTION}

An estimate is provided of the plutonium concentration in layers of waste inside tank 241-AZ-101 (AZ-101). The vertical heterogeneity of the solid waste with respect to plutonium is the result of variations in waste batch characteristics. The Pu concentration and quantity in each batch of waste sent to 101-AZ was identified in an effort to establish the highest $\mathrm{Pu}$ concentration that could potentially reside in a layer of solid waste. The $\mathrm{Pu}$ concentration in each layer of solids was then increased by a factor of three to account for the potential that discrete $\mathrm{Pu}$ particles may segregate from neutron absorbers. Criticality safety of pumping the layer with the highest Pu concentration through the mixer pump housing is evaluated.

The chemistry of plutonium in alkaline salt solutions similar to tank waste is we11 documented. Recently Whyatt et a1. (1996) and Serne et al. (1996) provide justification that Pu mainly resides in the solid phase of tank waste. This appendix discusses their conclusions and justification.

Core samples are mixed and homogenized before analysis and thus will not detect high $\mathrm{Pu}$ concentration layers within the sludge. If a high $\mathrm{Pu}$ concentration layer is formed and drawn into the mixer pump housing, the possibility exists that a more favorable geometry with respect to criticality might be achieved. This appendix addresses the following questions, 1) what is the highest possible concentration of plutonium in a waste layer, and 2) will that concentration of plutonium be critical inside the mixer pump housing?

\section{2 SUMMARY AND CONCLUSIONS}

Since 1981 more than 235 transfers of plutonium bearing waste have been received into tank 101-AZ. The transferred volume of the waste batches range from 2,000 L (528 gal.) to over $15,000 \mathrm{~L}(3,963 \mathrm{gal}$.). The Pu concentration in the batches ranges from 0 to $0.0242 \mathrm{~g} \mathrm{Pu} / \mathrm{L}$ of solid Tiquid mixture. The total quantity of $\mathrm{Pu}$ in the batches range from 0 to $242 \mathrm{~g}$. These volumes do not include the addition of $\mathrm{NaOH}$ (caustic) for corrosion control or the flush water used to prevent transfer line plugging. The $\mathrm{NaOH}$ and flush water were typicałly in excess of $3,785 \mathrm{~L}(1,000 \mathrm{gal}$.) per batch.

The variation in $\mathrm{Pu}$ concentration and quantity of each waste batch transferred to 101-AZ provides the justification to expect that some vertical heterogeneity may exist within the sludge layer. Although the vertical heterogeneity is concluded to exist the variation is not sufficient to allow a reasonable scenario to be postulated in which criticality is achieved within the mixer pump housing.

The waste batch transfer data clearly indicate that a high concentration of plutonium can be estimated but only in a very thin layer. For 10l-AZ the highest concentration of plutonium found, assuming uniform waste distribution over the entire area of the tank, is $0.63 \mathrm{~g} \mathrm{Pu} / \mathrm{L}$ in a layer $0.037 \mathrm{in}$. thick. Given the scenario evaluated, this layer is located 7.9 in. from the tank bottom and 6.9 in. from the top of the solids. In reality, the layer could be located in any vertical position of the solids and the conclusions will not be 
impacted. This Pu concentration is at least 4 times less than the minimum critical Pu concentration in waste tank solids of $2.6 \mathrm{~g} \mathrm{Pu} / \mathrm{L}$.

The layering of the $\mathrm{Pu}$ bearing solids as they were discharged into the tank is clearly subcritical, however the potential for preferential segregation of $\mathrm{Pu}$ from neutron absorbers was investigated. The conclusion established by Whyatt et al. (1996) is that the plutonium primarily resides in the solid phase of the tank waste. The addition of $\mathrm{NaOH}$ to waste batches prior to discharge into the waste storage tanks most likely formed the solubility controlling solid $\mathrm{PuO}_{2} \bullet \mathrm{xH}_{2} \mathrm{O}$ and the hydroxides of the metals 1 ike aluminum and iron. The predominate aqueous solution species expected in 101-AZ is less certain, but the likely candidate is $\mathrm{Pu}(\mathrm{OH})_{2}\left(\mathrm{CO}_{3}\right)_{2}{ }^{2-}$ or $\mathrm{Pu}(\mathrm{OH})_{2}\left(\mathrm{CO}_{3}\right)_{2}{ }^{4-}$ depending on the $\mathrm{pH}$ and total carbonate concentration. Whyatt et al. (1996) provides the solubility considerations to conclude the $\mathrm{Pu}$ solution concentrations are thousands to about 30 times lower than the values needed to support a criticality in supernate solutions.

The exact mechanism which holds the plutonium in the 101-AZ solids is not known, but it is reasonable to suggest that many different mechanisms contribute (i.e. precipitation, adsorption, agglomerated solids, etc.). The preferential segregation of $\mathrm{Pu}$ from the other hydroxides is most likely prevented by solid agglomerates containing $\mathrm{Pu}$ at very large absorber to $\mathrm{Pu}$ ratios. Whyatt et al. (1996) explains that hot-cell settling tests and flocculation calculations leads to the conclusion that particles are flocculated under normal waste tank conditions and interaction potentials promote a very rapid flocculation rate even after the agglomerates are broken up by hydraulic forces such as mixer pumps. The investigation into $\mathrm{Pu}$ chemistry in waste tank environments does not lead to any scenario which suggests a criticality in the solid phase of the waste is possible.

An evaluation of the criticality safety aspects of mixing the waste in 101-AZ must also investigate the consequences of $\mathrm{Pu}$ segregation due to the waste containing discrete particles of $\mathrm{PuO}_{2}$. Serne et a1. (1996) provides "...calculations that show, for the most realistic cases, that the level of segregation of fissiles from neutron absorbers was about a factor of 2.5." This value is the result of particle segregation predictions using the Transient Energy Momentum and Pressure Equations solutions in Three Dimensions (TEMPEST) Fluid Dynamic Model, the STOMP code, a simplified one-dimensional stagnant settling model and mixing experiments which assess particle segregation due to size. For the evaluation in this appendix, a plutonium concentration increase by a factor of 3 was chosen because it bounds the 2.5. The highest plutonium concentration for the increased Pu concentration condition is $1.889 \mathrm{~g} \mathrm{Pu} / \mathrm{L}$ in a layer $0.012 \mathrm{in.} \mathrm{thick.}$

Two variations of two different settling conditions or scenarios, which are assumed to take place as the waste batches are discharged into the tank, were evaluated and described as follows:

1.a A11 the Pu bearing solids are dispersed over the entire area of the tank floor and layered at the Pu concentration of each batch as it was discharged.

1.b The Pu concentration in each layer was increased by a factor of 3 . 
HNF-SD-W151-CSA-001, Rev. 1

2.a The Pu bearing solids are layered in a pile directly under the discharge pipe and accumulate over an area equal to $1 / 3$ of the tank floor surface area.

2.b The Pu concentration in each layer of the pile is increased by a factor of 3 .

The Pu concentration in each layer modeled in condition 1.a and 2.a is identical since the mass of solids entering the tank from each waste batch is the same for both conditions. The difference in the two scenarios is that the areal density for condition $2 . \mathrm{a}$ is increased by a factor of 3 , from $23.9 \mathrm{~g}$ $\mathrm{Pu} / \mathrm{m}^{2}\left(2.22 \mathrm{~g} \mathrm{Pu} / \mathrm{ft}^{2}\right)$ to $71.8 \mathrm{~g} \mathrm{Pu} / \mathrm{m}^{2}\left(6.67 \mathrm{~g} \mathrm{Pu} / \mathrm{ft}^{2}\right)$. Both these areal densities are subcritical since the minimum critical areal density is $2,582 \mathrm{~g}$ $\mathrm{Pu} / \mathrm{m}^{2}\left(240 \mathrm{~g} \mathrm{Pu} / \mathrm{ft}^{2}\right)$, Carter et al. (1968).

The $\mathrm{Pu}$ concentration in each layer modeled in condition $1 . \mathrm{b}$ and 2.b is identical since quantity the Pu bearing solids is identical. The quantity of solids transferred to the tank must be modeled as either associated with the $\mathrm{Pu}$ or disassociated from the Pu, but they must always be modeled as contained in the tank.

For the calculations which assume the plutonium concentration is increased by a factor of three, condition 1.6 and 2.6 , the highest plutonium concentration is $1.889 \mathrm{~g} \mathrm{Pu} / \mathrm{L}$. The difference in the scenarios is that the solids layer which covers only $1 / 3$ of the tank floor area is thicker by a factor of 3 $(0.037 \mathrm{in}$. versus $0.012 \mathrm{in.})$. The similarities and differences between the two conditions provides an interesting point of review, however no condition establishes a concentration of plutonium which poses a criticality safety concern.

The minimum critical concentration of $\mathrm{Pu}$ in solid tank waste is $2.6 \mathrm{~g} \mathrm{Pu} / \mathrm{L}$ of solids, Rogers (1993). Plutonium concentrations less than this value are subcritical regardless of the quantity of waste or Pu. The minimum critical mass of $\mathrm{Pu}$ in an idealized Pu-Water system with full water reflection is $520 \mathrm{~g}$, (Carter et al. (1968), III.A.9(100)-4). The minimum critical areal density for $\mathrm{Pu}$ is $2,582 \mathrm{~g} \mathrm{Pu} / \mathrm{m}^{2}\left(240 \mathrm{~g} \mathrm{Pu} / \mathrm{ft}^{2}\right)$, Carter et a1. (1968). The modeling of waste layers with the concentration of $\mathrm{Pu}$ as received and at concentrations increased by a factor of 3 indicate that the conditions of the model do not result in any waste that violates these minimum critical parameters.

This final aspect of this evaluation includes a determination of the consequences of pulling waste with the highest Pu concentration into the mixer pump. The expectation is that the waste layer with $1.889 \mathrm{~g} \mathrm{Pu} / \mathrm{L}$ will mix with layers of lower $P u$ concentration resulting in an overall lower average, but the conservative approach is an evaluation which assumes that only the high $\mathrm{Pu}$ concentration waste is in the pump. The volume of the mixer pump housing is estimated to be $134 \mathrm{~L}$. So at the highest plutonium concentration of $1.889 \mathrm{~g} \mathrm{Pu} / \mathrm{L}$ only $253 \mathrm{~g}$ of plutonium can reside in the pump at any one time. The $\mathrm{Pu}$ concentration is less than the minimum critical concentration of $2.6 \mathrm{~g} \mathrm{Pu} / \mathrm{L}$ and the total mass of $\mathrm{Pu}$ in the pump is less than the minimum critical mass of plutonium of $520 \mathrm{~g}$. Since the pump has no identified mechanisms for separating and accumulating $\mathrm{Pu}$ and the hydraulics of mixing the 
waste should not separate and accumulate plutonium this quantity and concentration of plutonium is subcritical. There is an added layer of conservativeness to this conclusion since the quantity of $240 \mathrm{Pu}$ in the waste was not subtracted from the highest $\mathrm{Pu}$ concentration, but ${ }^{240} \mathrm{Pu}$ has a substantial neutron capture cross section so will decrease the reactivity of the waste.

\section{C.3 DISCUSSION}

An evaluation of criticality safety requires knowledge of the system contents, configuration and geometry. In addition to core sample data which provides a vertically averaged $\mathrm{Pu}$ concentration, transfer data can be used to assess the degree of variation that may exist in the tank as a result of variations in the waste stream composition as it was discharged.

The plutonium bearing waste stored in tank 101-AZ is the result of the most recent PUREX separations operations which occurred between 1983 and 1989 . The waste batches sent to 101-AZ took place during the first three of the six campaigns between 1983 and 1986. The waste volume, plutonium concentration and content of each batch, Table $\mathrm{C}-2$ and Table $\mathrm{C}-3$, was taken from the PUREX Nuclear Material Control (NMC) process records. Most of the batches were sampled while the waste was held in tank F-15, was very acidic and was agitated. The plutonium and other metals are quite soluble in an acid medium so the laboratory analysis is considered representative of each batch.

The waste was transferred into tank $\mathrm{F}-16$ which contained an amount of $\mathrm{NaOH}$ required to meet the tank farms corrosion specifications. The alkalinity of the mixture resulted in the precipitation of the plutonium and other heavy metals. Since the Tank Farms Criticality Prevention Specifications (CPS) required the concentration of plutonium to be less than $0.013 \mathrm{~g} \mathrm{Pu} / \mathrm{L}(0.05 \mathrm{~g}$ $\mathrm{Pu} / \mathrm{gal}$ ) of mixtures routed to 101-AZ, verification of compliance with the CPS took credit for the dilution of plutonium by the addition of the caustic and flush water. This evaluation disregards the dilution of the plutonium since the precipitated plutonium and metals settled out and resides in the sludge layer in the tank.

The tank currently contains 14.8 in. $(40,700 \mathrm{gal}$.$) of solids as measured in$ August 1990. The summation of the plutonium in each waste batch sent to the tank totals $9,782 \mathrm{~g} \mathrm{Pu}(21.5$ lbs.), see Table C.2 for a listing of the transfers. The official Pu inventory for $101-\mathrm{AZ}$ is $19,249 \mathrm{~g} \mathrm{Pu}$ based strictly on core sample data. The data for each batch of waste transferred to the tank provides insight on the possible stratification of $\mathrm{Pu}$.

\section{4 NASTE HISTORY OF TANK 241-AZ-101}

Tank 241-AZ-101 (101-AZ) began service by receiving evaporator waste in the fourth quarter of 1976. The tank continued to receive evaporator waste until fourth quarter of 1977. From the first quarter of 1978 until September 1980, the tank received complexed waste, double-shell slurry feed waste, non-complexed waste, water, evaporator waste residual liquor, and complexant concentrate. From the first quarter of 1981 until the third quarter 1983 the 
tank received dilute, noncomplexed waste from PUREX miscellaneous streams. The bulk of transfers into 101-AZ between 1977 and 1983 came from other waste tanks. These transfers contain very small amounts of plutonium since the intratank transfers primarily consist of supernate with small quantities of entrained flocculent solids.

During the fourth quarter of 1983 the tank began receiving Aging Waste from PUREX. The aging waste stream was transferred into 101-AZ until the first quarter of 1986. Prior to receiving the PUREX neutralized acid waste in 1983 the waste in 101-AZ was transferred into several other tanks. The cleanout of 101-AZ, in late 1981 and early 1982, removed some suspended solids but the settled solids remained since there was no way of suspending the material sufficiently for pumping. The tank currently receives only condensate from other aging waste tanks.

\section{5 PLUTONIUM CHEMISTRY}

The criticality safety concerns of mixing the waste in 101-AZ are nonexistent if the plutonium is shown to be intimately associated with sufficient neutron absorbers both before and after mixing in both the aqueous and solid phases of the waste. Whyatt et al. (1996) and Serne et al. (1996) provide evaluations which investigate the potential for segregation of fissile material creating locally concentrated regions within a tank that could cause a criticality. The evaluations conclude that the low solubility of plutonium in the high $\mathrm{pH}$ supernates results in very low plutonium inventories in the supernate and salt cake. Thus, of the three waste types, supernate, saltcake and sludge, only the sludge poses a potential criticality safety concern.

\section{C.5.1 PLUTONIUM SOLUTION CHEMISTRY}

Whyatt et a1. (1996) takes the approach that a full discussion of the chemistry of plutonium in aqueous solutions must precede conclusions about the physical phase of plutonium in the Hanford waste tanks. Whyatt et a1. (1996) cites numerous research reports which demonstrate that the plutonium in the High Level Waste (HLW) exists mainly in the tetravalent oxidation state. A review of the redox status, hydrolysis, complexation, ionic strength effects, temperature effects and radiolysis effects support the assertion that the typical solution composition of HLW in Hanford Site tanks probably includes $\mathrm{Pu}(\mathrm{IV})-\mathrm{OH}-\mathrm{CO}_{3}$ mixed ligand complexes as the dominate aqueous species.

However, none of the research or tests cited in whyatt et al. (1996) suggest the plutonium concentration in the supernate phase of the HLW will exceed $0.13 \mathrm{~g} \mathrm{Pu} / \mathrm{L}(0.49 \mathrm{~g} \mathrm{Pu} / \mathrm{gal})$ which is a factor of 55 less than the minimum critical aqueous concentration of plutonium of $7.8 \pm 0.3 \mathrm{~g} / \mathrm{L}$ where $\mathrm{H} / \mathrm{Pu}=3392 \pm 100$, Carter et a1. (1968), III.A-2. Whyatt et a1. (1996) concludes "...the plutonium in the Hanford Site tanks, based on proposed retrieval activities or continued safe storage, will not be found in the supernate or salt cake at high enough concentrations to cause a criticality. Also, the tank supernate will always have enough neutron absorbers to promote subcriticality." 
HNF-SD-W151-CSA-001, Rev. 1

\section{C.5.2 PRECIPITATION}

The distribution of plutonium between the solution phase and the solid phase can be addressed by the concept of solubility/precipitation. The upper bound concentration of dissolved plutonium, $0.13 \mathrm{~g} \mathrm{Pu} / \mathrm{L}(0.49 \mathrm{~g} \mathrm{Pu} / \mathrm{gal})$ in a solution as discussed in section C.5.a is subcritical regardless of the quantity or geometry. A review of the solid forming mechanisms provides the basis for continued discussion of the species of plutonium as it resides in the solid phase of the waste.

The waste from the chemical separations process was generated as acidic solutions containing low concentrations of plutonium and high concentrations of dissolved metals such as aluminum, iron, chromium, manganese, etc. When the waste batches were neutralized and made caustic with $(\mathrm{NaOH})$, large amounts of oxyhydroxide solids were formed. When the batches were discharged into the tank, particle segregation could have resulted from different particle settiing velocities. If plutonium particles have a density and settling velocity much different than other solid particles then the plutonium will segregate and the result is layers of high plutonium concentration. Even so, the quantity of nonfissile bearing solids exceeds the quantity of Pu and these solids would have to settle on top of the Pu, creating thick layers of neutron absorbers between thin layers of Pu. However, if a plutonium particle flocculates with other particles of sludge, the plutonium density and settling characteristics will be masked by the properties of the floc. Whyatt et al. (1996) explains that the results of hot-cell settling tests and flocculation calculations, leads to the conclusion that the particles are flocculated under normal tank conditions. Therefore, the discharge composition of the waste streams is considered to include agglomerates of solids materials with a very large mass ratio of absorbers to Pu.

The quantity of plutonium sent to 101-AZ is overwhelmed by the quantity of nonfissile solid materials which were al so sent to the tank. There are $14.8 \mathrm{in}$. or $154,050 \mathrm{~L}(40,700 \mathrm{gal})$ total solids in the tank and only $9,782 \mathrm{~g}$ of plutonium, so with a solids density of $1800 \mathrm{~g} / \mathrm{L}$ and assuming uniform distribution of $\mathrm{Pu}$, the ratio of bulk solids to plutonium is 28,347 . However, the prevailing issue to be addressed is the mechanism by which the plutonium is held in those solids and the impact that operating mixer pumps will have on the assurance that a subcritical distribution is maintained.

If agglomeration is investigated as a mechanism which may prevent segregation of fissile material the parameter of choice is particle size. Agglomeration is expected to occur since Transmission Electron Microscopy (TEM) measurements indicate the primary particles of sludge are submicron, but particle sizing information indicate much larger particles. TEM characterization data for sludge samples from 10 double-shell and single-shell tanks indicate the most probable primary sludge particle size is between 0.010 and $0.050 \mu \mathrm{m}$, with over $90 \%$ of the particles characterized smaller than $1 \mu \mathrm{m}$, whyat et al. (1996). The more common primary particles are usually agglomerated to form clusters which occasionaliy reach sizes of tens of microns to a few hundred microns and appear somewhat non-selective regarding other primary particles. The non-selective nature of the aggregate of sludge particles provides the 


$$
\text { HNF-SD-W151-CSA-001, Rev. I }
$$

foundation to infer that Pu-laden particles will be distributed throughout the flocs and, hence, unable to concentrate via any of the various hypothesized mechanisms.

The mixer pumps in 101-AZ are likely to breakup agglomerates, but they are expected to reform under conditions suitable for settling solids. The selective agglomeration of specific particles can be controlled, but only in environments where chemical reactions are aggressively controlled to cement chemically-similar particles together. Plutonium bearing waste is not expected to exhibit this type of behavior. Therefore, based on the TEM data the plutonium will be agglomerated with other materials and will not segregate from neutron absorbers.

Although $\mathrm{PuO}_{2}$ is not believed to exist as super micron, discrete, non-agglomerated particles, the potential for segregation of this particle has been evaluated. The fluid dynamics of segregation was modeled using simplified 1-dimensional models as well as full 3-dimensional Transient Energy Momentum and Pressure Equations solutions in Three Dimensions (TEMPEST) models, Whyatt et al. (1996). For the 1-dimensional case when the Pu is assumed to be smaller, monodisperse particles the minimum critical concentration of $2.6 \mathrm{~g} \mathrm{Pu} / \mathrm{L}$ could be achieved, but in only very thin layers at the top of the solid layer. Since these layers are very thin, the total mass of $\mathrm{Pu}$ is insufficient to create a criticality even if the layer could be skimmed off the top and rolled into a sphere. The full 3 -dimensional modeling indicated the largest degree of enrichment in fissile content was less than a factor of 2.5. This degree of segregation does not pose a criticality concern since the $\mathrm{Pu}$ was introduced to the tank at very low concentrations.

The dimensions of the tank combined with the hazardous nature of the waste material preclude the ability to readily observe the actual conditions in the waste. The discussion on plutonium chemistry provides confidence that the $\mathrm{Pu}$ mainly resides in the solid phase of the waste with copious amounts of metal oxyhydroxides, which provide significant neutron absorbing capability. The mechanism by which the plutonium is held in the solid phase can not be established with quantified accuracies, but the margin of criticality safety can be inferred with the knowledge that the plutonium resides primarily in the solid phase at very low concentrations.

\section{6 SOLIDS BUILDUP}

The buildup of solids in 101-AZ is important to the determination of plutonium concentration. Table $\mathrm{C}-\mathrm{l}$ contains solids measurements taken from the six identified risers between October 5, 1984 and August 24, 1990. The location of the risers are depicted in Figure $\mathrm{C}-1$.

The measured solids level on October 5, 1984 is slightly higher than the measurements taken in January 1985. One possible explanation for the decrease, is the suspension of solids by the air lift circulators. Also, accurate solids measurements are difficult when the waste is being agitated by the ALCs. Based on the solids measurements, a solids level of 6 in. is assumed for a solids volume of $62,453 \mathrm{~L}(16,500 \mathrm{gal})$ at the start of the PUREX campaign in November 1983. Since these solids accumulated from primarily 
evaporator discharges and intratank transfers the plutonium concentration is assumed to be zero. Actually, the $51 \mathrm{~g}$ of plutonium, indicated in the Double-Shell Tank Plutonium Inventory System is added to the first transfer of the campaign on November 15, 1983. With the current solids level, measured on August 24, 1990, of $14.8 \mathrm{in.,}$ a solids accumulation of 8.8 in. is assigned for the PUREX transfers of aging waste into 101-AZ.

Table C-1. Solids Measurements in 101-AZ (all values in inches).

\begin{tabular}{|c|c|c|c|c|c|}
\hline (2) & $214 \times 4 \%$ & 340 & $646 \% 5$ & Wy 10 & $9 \% 80$ \\
\hline 24-B & 11 & 9 & 9 & 10.5 & 17 \\
\hline $24-C$ & 0 & 0.75 & 3.5 & 4.5 & 10.5 \\
\hline 24-D & 12.5 & 13 & 16 & 16 & 25.5 \\
\hline 24-E & 4.5 & 4.25 & 8 & 10.5 & 18 \\
\hline $24-F$ & 2.5 & 3.25 & 7 & 9 & 16.25 \\
\hline 24-G & 5.5 & 5 & 9 & 9 & 18 \\
\hline Average & 7.2 & 5.9 & 8.8 & 9.9 & 16.9 \\
\hline $3(5)+1)$ & 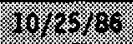 & 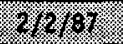 & 2 & 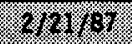 & 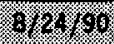 \\
\hline 24-B & 18.25 & 18.25 & 18.75 & 18.25 & 15.75 \\
\hline $24-C$ & 11.75 & 11.25 & 11.25 & 12.75 & 9.75 \\
\hline 24-D & 25.25 & 24.25 & 24.25 & 25.25 & $25.0^{*}$ \\
\hline $24-E$ & 22.25 & 16.75 & 17.0 & 17.25 & 13.75 \\
\hline $24-F$ & 16.0 & 14.75 & 15.25 & 15.75 & 11.25 \\
\hline $24-G$ & 17.75 & 16.75 & 18.0 & 17.75 & 13 \\
\hline Average & 18.5 & 17.0 & 17.4 & 17.8 & 14.8 \\
\hline
\end{tabular}

Note:

* Solids level from Riser 24-D could not be measured on $8 / 24 / 90$, so an average value was used. 
Figure C-1. Tank 101-AZ S7udge Level Riser Locations.

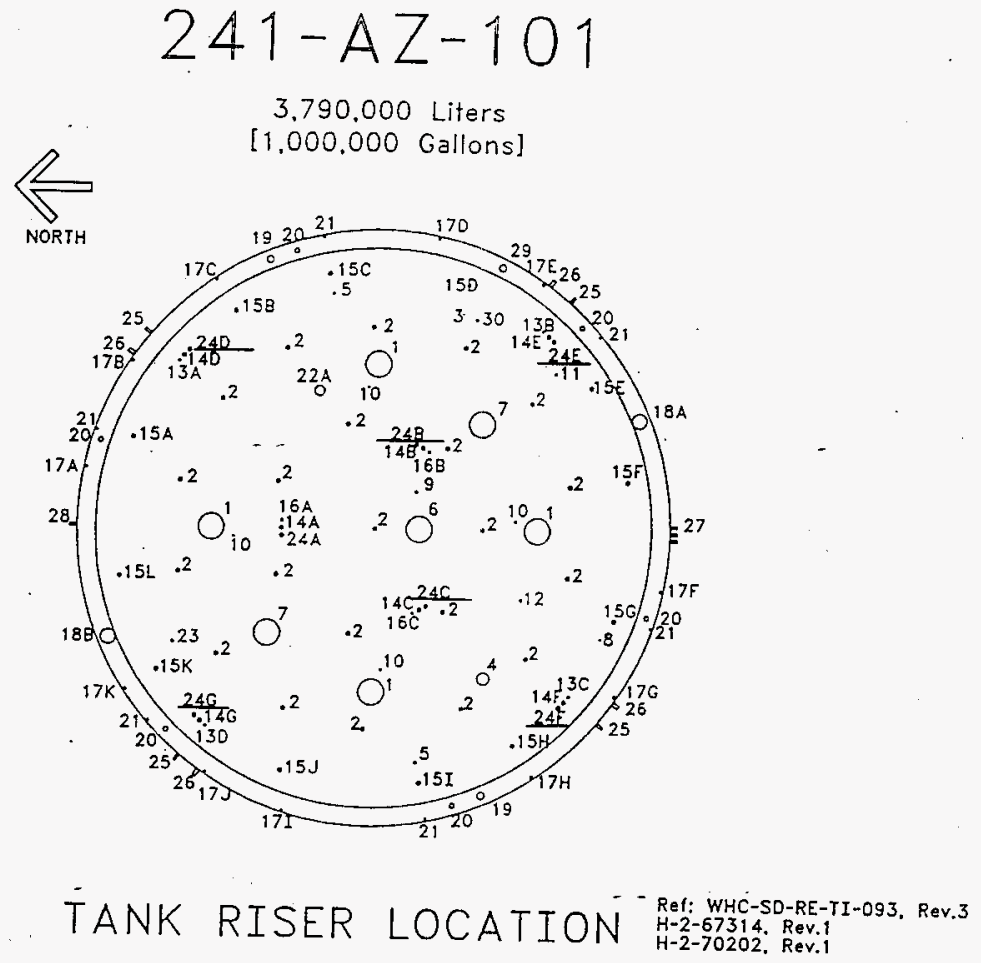




\section{C.7 PLUTONIUH ACCUMULATION}

A listing of applicable transfers of plutonium bearing waste into 101-AZ is contained in Table C-2. The waste transfer information obtained from two sources were compared; 1) the PUREX Nuclear Material Control (NMC) process records, and 2) the Double-Shell Tank Plutonium Inventory Tracking System. Both sources of information contain the concentration and amount of plutonium in each batch before the caustic, sodium nitrite and flush water is added. The quantity of plutonium sent to 101-AZ is the summation of the quantity of plutonium in each batch and is calculated in the DST Plutonium Inventory Tracking System and reproduced in Table $\mathrm{C}-2$. The total quantity of plutonium in the tank $9,782 \mathrm{~g}$. For comparison purposes the plutonium inventory derived by Los Alamos National Laboratory (LANL) is $10.4 \mathrm{~kg}$ and documented in WHC-SD-WM-ER-318, Rev. 0, Supporting Document for the Historical Tank Content Estimate for AZ Tank Farm, Volume II. The LANL inventory values were derived from the tons of fuel processed versus an average exposure rate for that fue 1 and calculated process efficiencies.

\section{C.8 TRANSFER DATA PROFILE}

The data for the following discussion are located in Table $C-2$, columns 6,7 , and 8 .

Figure $\mathrm{C}-2$ is a graphic representation of the $\mathrm{Pu}$ concentration of each waste batch transferred into 101-AZ. The plutonium bearing solid waste layer is $8.8 \mathrm{in.}$ thick covering the entire tank floor area. The line graph clearly shows the variation of $\mathrm{Pu}$ concentration in the transferred batches. As expected, layers of solids contain high concentrations of $\mathrm{Pu}$, but those layers are very thin. The layer with the highest $\mathrm{Pu}$ concentration of $0.63 \mathrm{~g} \mathrm{Pu} / \mathrm{L}$ is on $7 y 0.04 \mathrm{in}$. thick and only $242 \mathrm{~g}$ Pu was transferred into 101-AZ in that batch. The profile of the line graph will remain constant regardless of the assumed increase or decrease of the Pu concentration. The mathematical manipulation of the $\mathrm{Pu}$ concentration is achieved by varying the nonfissile material solids in each layer. The overall effect will be to make the layers thicker or thinner and the line graph will be linearly shifted up or down.

Figure $\mathrm{C}-2$ also graphs an average Pu concentration of 10 transfers (the bar graph). As expected any averaging of transfers will lower the highest $\mathrm{Pu}$ concentration and increase the lowest $P u$ concentration. The use of 10 transfers is arbitrary since any number of transfers can be used to calculate an average. One inch of solids are accumulated in the tank for about every 30 transfers. Each bar on the graph represents the average concentration for the 5 transfers before and after that bar. The graph indicates that as the $\mathrm{Pu}$ concentration in multiple transfers are averaged the curve is smoothed out. This trend will continue up to the average of all the transfers which is a straight 1 ine at $0.106 \mathrm{~g} \mathrm{Pu} / \mathrm{L}$. Also, the vertical heterogeneity of the waste is graphically obvious. 
Figure C-2. 101-AZ Plutonium Concentration in Each Layer.

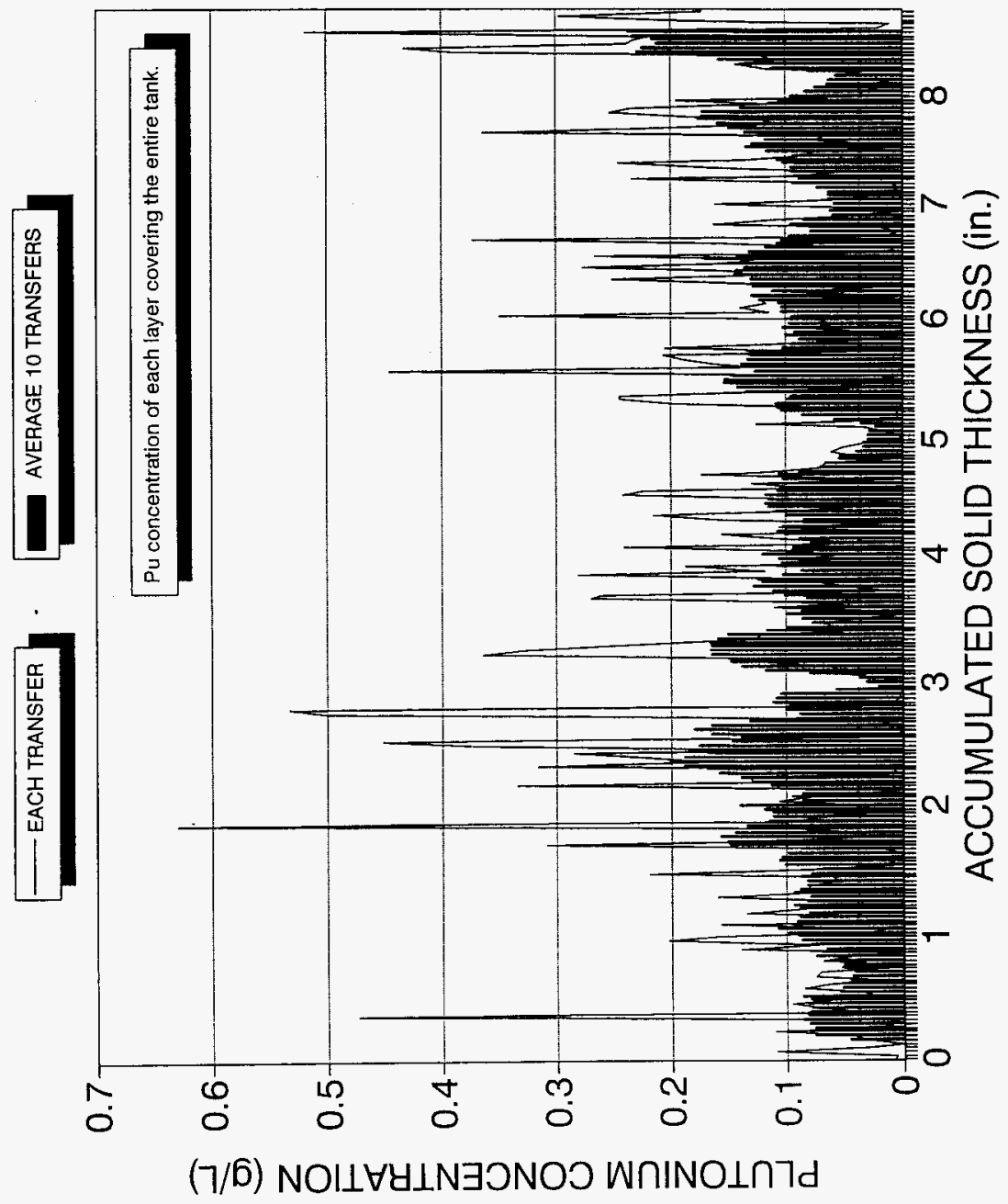


HNF-SD-W151-CSA-001, Rev. 1

Figure $\mathrm{C}-3$ is a graphical representation of the $\mathrm{Pu}$ concentration in each layer increased by a factor of 3 . The particle segregation predictions discussed in Serne et al. (1996) show for the most part that particle segregation due to size may increase the $\mathrm{Pu}$ concentration by a factor of 3 . Columns (9) and 10) in Table $\mathrm{C}-2$ are the calculations which increase the $\mathrm{Pu}$ concentration in each solid layer or transfer by a factor of 3 and these values are used in Figure $\mathrm{C}-3$. As expected the profile of the graph is exactly the same as Figure $\mathrm{C}-2$, the major difference is the Pu bearing solids layer is only $2.93 \mathrm{in}$. thick instead of $\mathbf{8 . 8} \mathrm{in}$. The visual representation of the heterogeneity of the waste layers is more easily captured by the graph versus the columns of values in Table $\mathrm{C}-2$.

The calculated average of 10 transfers increased by a factor of 3 is denoted by the bar graph in Figure $\mathrm{C}-3$. As stated above the value of 10 transfers is arbitrary and in this case about 90 transfers are required to accumulate 1 in. of solids. An interesting note is that the highest values for the 10 transfer batch averages does not include the batch with the highest Pu concentration.

\section{C.9 PLUTONIUN CONCENTRATION}

The solid waste in 101-AZ is known to be heterogeneous with respect to the plutonium concentration as depicted in figures $\mathrm{C}-2$ and $\mathrm{C}-3$. The exact highest localized concentration of plutonium in the tank is unknown, however for criticality safety a reasonable, yet conservative, estimate of the waste composition is used.

Two variations of two settling scenarios or conditions were modeled to achieve a reasonable estimate of the highest plutonium concentration in a layer of solid waste. Modeling parameters which are common to both scenarios are as follows.

- 6 in. of non-plutonium bearing solids is located at the bottom of the tank.

- The quantity of plutonium in the tank is $9782 \mathrm{~g}$, derived by summing a11 the plutonium in each batch of waste transferred to the tank, Table C-2, columns (5) and (6).

- The total volume of waste transferred to the tank between $11 / 15 / 83$ and $3 / 27 / 86$ is $2.39 \mathrm{E} 6 \mathrm{~L}(630,956 \mathrm{gal}$.$) , Table \mathrm{C}-2$, column (3).

- The height of solids currently in the tank is $14.8 \mathrm{in}$.

- The increase in plutonium concentration by a factor of 3 is achieved by removing non-plutonium solids from the plutonium bearing solids.

- The transfer data was obtained from the PUREX Nuclear Material Control (NMC) process records. The transfer date is identified in column (1) and the waste batch number is located in column (2) of both Tables $\mathrm{C}-2$ and $\mathrm{C}-3$. 
Figure C-3. 101-AZ Plutonium Concentration in Each Layer, Increased by a Factor of 3 .

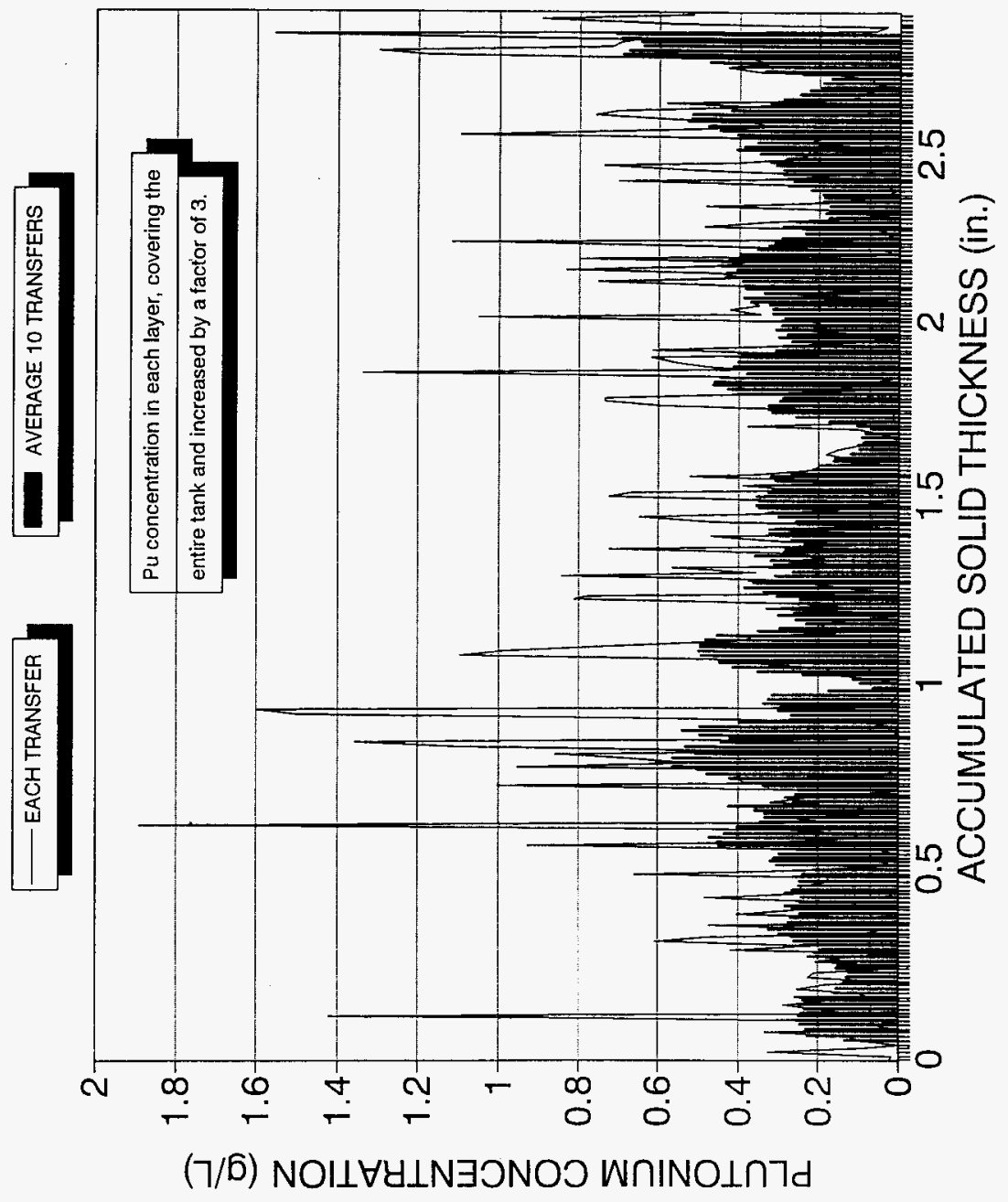


HNF-SD-W151-CSA-001, Rev, 1

- The quantity of plutonium in each waste batch, Table $\mathrm{C}-2$, column (5) and Table $\mathrm{C}-3$, column (3), is calculated by multiplying the plutonium concentration by the batch volume.

\section{C.9.1 CONDITION 1.a}

Condition 1.a models the plutonium bearing solids in a flat slab covering the entire floor area of the tank, Figures $\mathrm{C}-2$ and $\mathrm{C}-4$. Since the solids level in the tank is currently 14.8 in. the plutonium bearing solids discharged to the tank since 1983 must total 8.8 in., considering 6 in. of solids have no Pu. The solids buildup per transfer of waste to the tank is described as follows:

$$
8.8 \text { in. } / 2,388,167.7 \mathrm{~L}=3.68 \mathrm{E}-6 \text { in. } / \mathrm{L}
$$

So, the solids layer was built up at a rate of $3.68 \mathrm{E}-6$ in. per liter of transferred waste. The layer thickness, column (7) of Table C-2, is determined by multiplying the volume of each transfer, column (3) of Table $\mathrm{C}-2$, by the quantity of solids per liter transferred, as follows:

$$
V_{\text {transferred }}(L) \times 3.68 \mathrm{E}-6 \text { in } / L=\text { Layer Thickness (in.) }
$$

The plutonium concentration per layer, column (8) of Table C-2, is calculated by dividing the amount of plutonium per waste batch, column (5) of Table $\mathrm{C}-2$, by the quantity of solids in that batch, as follows:

$\frac{P u(g)}{V_{\text {transferred }}(L) \times 3.68 E-6 \text { in. } / \mathrm{L} \times 10,409 \mathrm{~L} / \mathrm{in} .}=\mathrm{Pug} / \mathrm{L}$

The highest concentration of plutonium is calculated to be $0.63 \mathrm{~g} \mathrm{Pu} / \mathrm{L}$ in a layer $0.037 \mathrm{in}$. thick. For this scenario that layer is located 7.9 in. from the tank bottom and 6.9 in. from the top of the solids. This waste batch was transferred into 101-AZ on June $30,1984$.

\section{C.9.2 CONDITION 1.b}

Condition 1.b takes all the information calculated in condition 1.a and increased the Pu concentration by a factor of 3 , Figures $C-3$ and $C-5$. Actually, the layered Pu concentration is determined by decreasing the solids quantity of each transfer. So, instead of having 6 in. of non-plutonium bearing solids, the tank is assumed to have 11.8 in. and the Pu bearing solids is only 2.93 in. thick. This condition is calculated in column (9) of Table $C-2$ and is depicted in Figures $C-3$ and $C-5$. Figure $C-5$ is drawn with the enriched layer at the top of the measured solids level, however this layer can be placed at any vertical location throughout the solids. The highest plutonium concentration is $1.889 \mathrm{~g} \mathrm{Pu} / \mathrm{L}$ in a layer $0.012 \mathrm{in}$. thick. For this condition this layer is located $12.5 \mathrm{in}$. from the bottom of the tank and $2.3 \mathrm{in}$. from the top of the solids. 


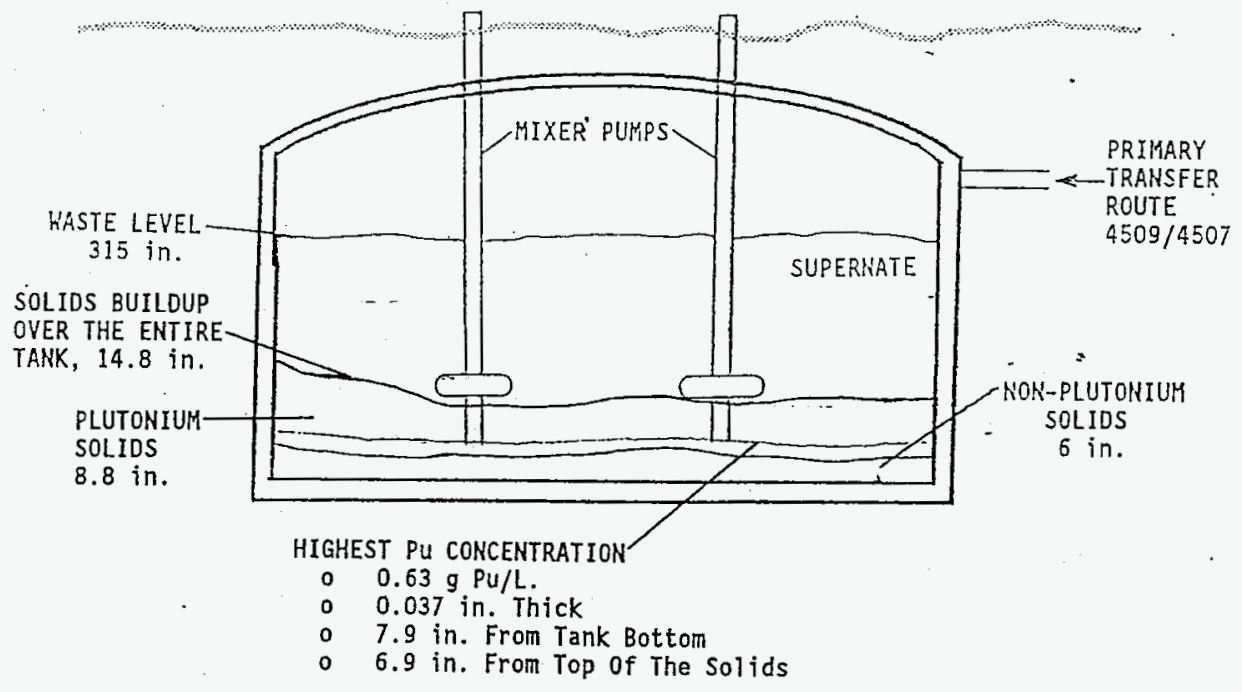

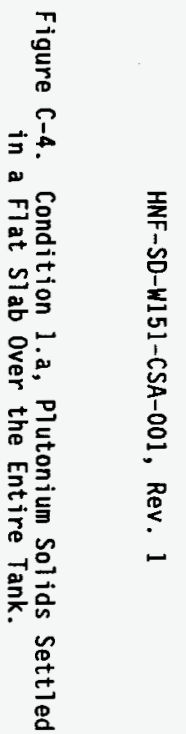




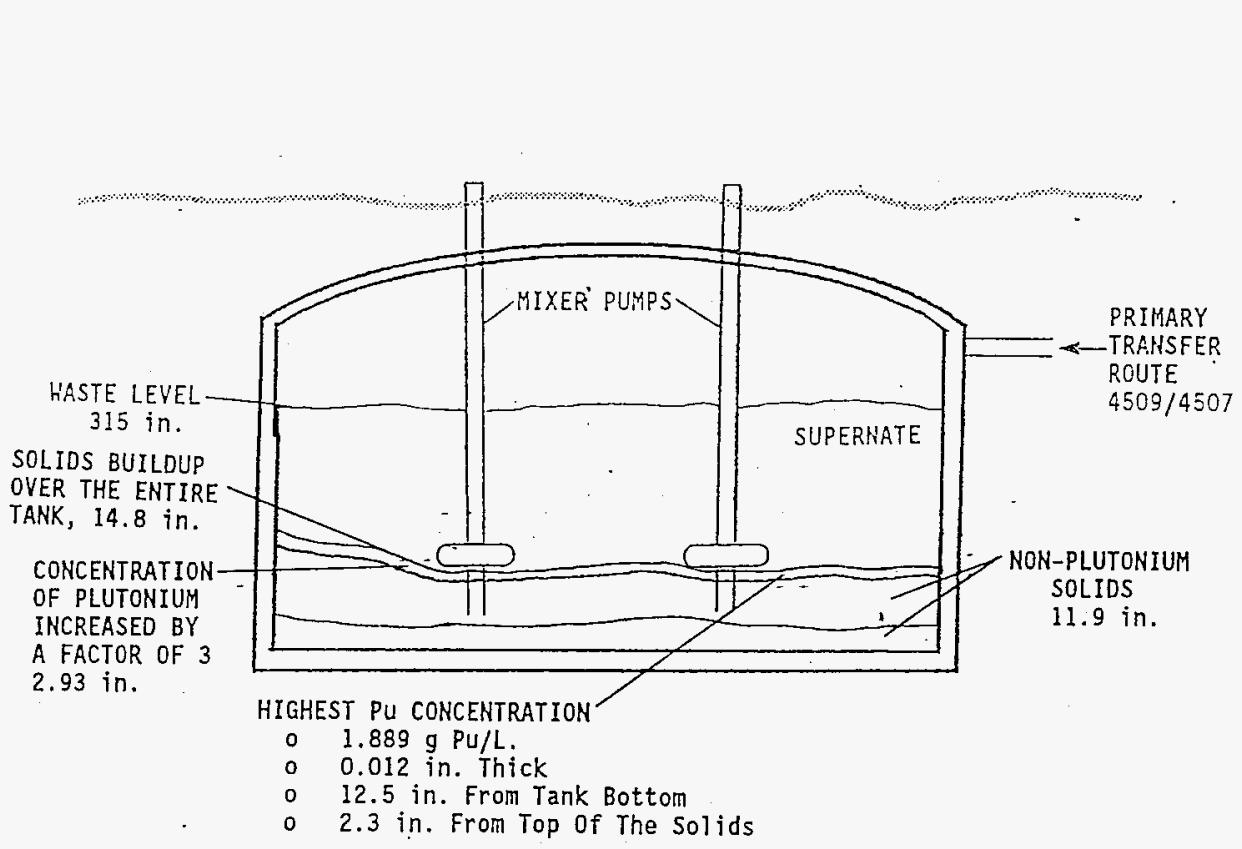

옹

范

要

芆

政 
HNF-SD-W151-CSA-001, Rev. 1

Table C-2, column (10) is a calculation of the average Pu concentration for each incremental 10 transfers immediately preceding each data point. The layered $\mathrm{Pu}$ concentration used for this calculation is the case where the $\mathrm{Pu}$ concentration is increased by a factor of 3 . Ten transfers is an arbitrary value which was used because the accumulation of solids for 10 transfers is small, about 0.10 in., and consideration of layers less than 0.10 in. is not meaningful from a criticality standpoint since too little material is involved.

The average $\mathrm{Pu}$ concentrations were calculated as a matter of interest since the average will be less than the highest value and greater than the lowest value, in other words the curve is "smoothed" out. The intent was to determine the highest $\mathrm{Pu}$ concentration which could be expected to exist for a stratified layer. The average plutonium concentration for the 10 transfer layers range from $0.062 \mathrm{~g} \mathrm{Pu} / \mathrm{L}$ to $0.710 \mathrm{~g} \mathrm{Pu} / \mathrm{L}$. An interesting note is that the highest averaged layer does not include the transfer with the highest plutonium concentration. This can be seen in Figure $\mathrm{C}-3$, where the highest average of the 10 transfers includes the last couple transfers of Pu bearing waste made into the tank.

\section{C.9.3 CONDITION 2.a}

Condition 2 models the plutonium bearing solids piled over an area of the tank equal to $1 / 3$ of the tank floor area, Figure $C-6$. The area of the tank floor covered by this model, one third, is arbitrary. It's reasonable to expect that if the waste solids piled up instead of fan out as the waste was discharged to the tank then an area equivalent to $1 / 3$ of the tank area is expected to be required to support the pile. Table $C-3$, column (1) and (2) provide the waste batch transfer date and batch number, while column (3) contains the quantity of $\mathrm{Pu}$ transferred in each batch. Since the total mass of solids must be conserved, the Pu bearing solids will pile to a height of 26.4 in. above the original 6 in. of non-Pu solids and cover an area of $136.3 \mathrm{~m}^{2}\left(1,467 \mathrm{ft}^{2}\right)$, Figure $\mathrm{C}-6$. The height of each layer is provided in column (4) of Table $\mathrm{C}-3$ and is calculated the same as previousiy discussed. The concentration of $\mathrm{Pu}$ in each layer, column (5) of Table $\mathrm{C}-3$, is calculated the same as previously discussed and as expected the Pu concentration of each layer is the same as condition 1 . However, because the layers are spread over a smaller area the layer thickness is increased by a factor of 3 . So, the highest $\mathrm{Pu}$ concentration is $0.63 \mathrm{~g} \mathrm{Pu} / \mathrm{L}$ in a layer $0.11 \mathrm{in}$. thick, and for this condition, located $11.6 \mathrm{in}$. from the tank bottom and $20.7 \mathrm{in}$. from the top of the solids layer. The significant aspect of this scenario is the increase in areal density from $23.9 \mathrm{~g} \mathrm{Pu} / \mathrm{m}^{2}\left(2.22 \mathrm{~g} \mathrm{Pu} / \mathrm{ft}^{2}\right)$ to $71.8 \mathrm{~g} \mathrm{Pu} / \mathrm{m}^{2}$ $\left(6.67 \mathrm{~g} \mathrm{Pu} / \mathrm{ft}^{2}\right)$. 
Figure $\mathrm{C}-6$. Condition 2.a, Plutonium Bearing Solids Piled Over $1 / 3$ of the Tank Floor Area.

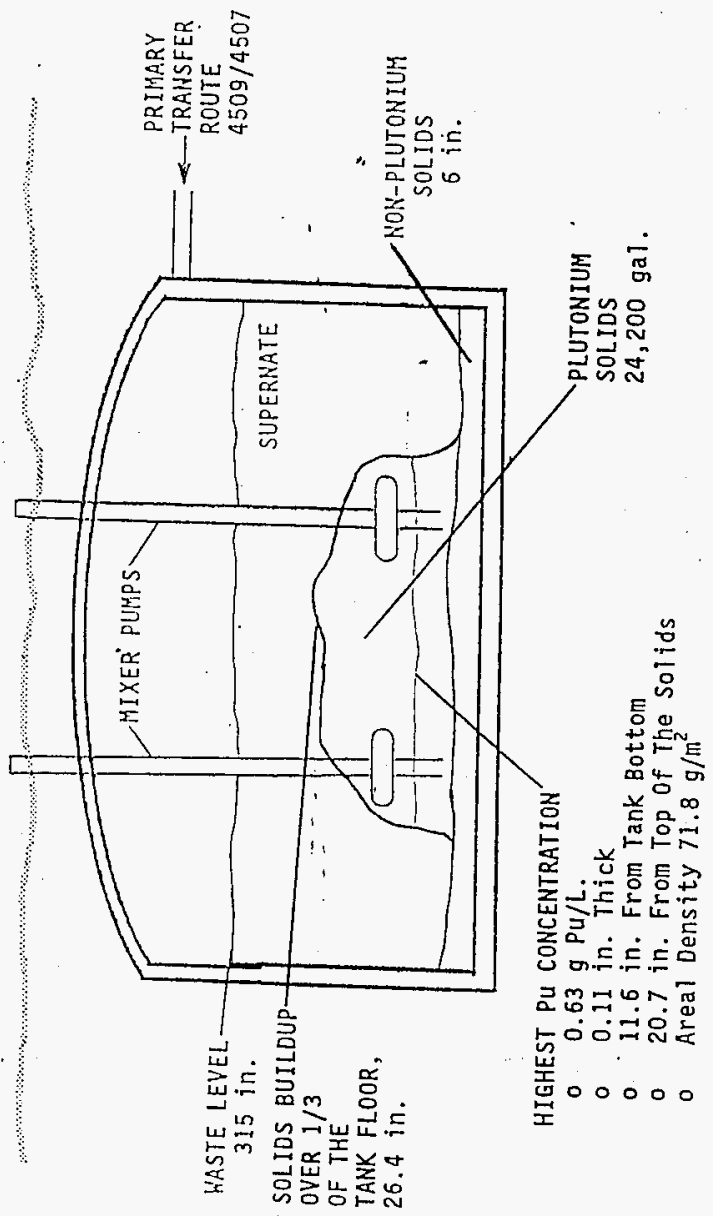


HNF-SD-W151-CSA-001, Rev. 1

\section{C.9.4 CONDITION 2.b}

To maintain consistency with the first condition, the Pu concentration of the solids which cover only $1 / 3$ of the tank floor area are increased by a factor of 3 , Figure $\mathrm{C}-7$. This condition assumes that a combination of discrete $\mathrm{Pu}$ (IV) oxide particles combined with $\mathrm{Pu}$-laden agglomerates have a faster settling velocity then lighter non-Pu bearing floc. As a result, the Pu-bearing solids pile up and the non-Pu solids fan out and settle in the outer areas of the tank. The plutonium bearing solids will be 8.8 in. thick on top of the original 6 in. and cover $1 / 3$ of the tank area. Table $C-3$, column (7) contains the calculations of each layered concentration of plutonium that would result if the all the plutonium is contained in the 8.8 in. of solids covering $1 / 3$ of the tank area. The areal density will not be different from condition 2.a but the plutonium concentration in each layer will increase by a factor of 3 . The results of this calculation, column (7) of Table $\mathrm{C}-3$, is exactly the same as the calculations which assume the plutonium concentration spread over the whole tank is increased by a factor of 3 , column (9) of Table $\mathrm{C}-2$. As expected, the Pu bearing solids layer is thinner than was discussed in condition 2.a, but since all the Pu covers only $1 / 3$ of the tank floor area, each layer is thicker than was determined in condition $1 \mathrm{~b}$. for this case the highest $\mathrm{Pu}$ concentration is $1.889 \mathrm{~g} \mathrm{Pu} / \mathrm{L}$ in a layer $0.04 \mathrm{in}$. thick and for this condition the layer is located 7.9 in. from the tank bottom and 6.9 in. from the top of the solids layer.

Table $C-3$, column $(10)$ is a calculation of the average $P u$ concentration for each incremental 10 transfers immediately preceding each data point. The layered $\mathrm{Pu}$ concentration used for this calculation is the case where the $\mathrm{Pu}$ concentration is increased by a factor of 3 . The average value for the ten transfers is as expected the same as was calculated for condition 2.b. The difference is that the layer of solids accumulated for the 10 transfers in this case is about 0.3 in. versus the 0.1 in. in condition l.b.

The average $\mathrm{Pu}$ concentrations were calculated as a matter of interest since the average value will be less than the highest value and greater than the lowest value. The intent was to determine the highest Pu concentration which could be expected to exist for a stratified layer. The average plutonium concentration for the 10 transfer layers range from $0.062 \mathrm{~g} \mathrm{Pu} / \mathrm{L}$ to $0.710 \mathrm{~g} \mathrm{Pu} / \mathrm{L}$. An interesting note is that the highest averaged layer does not include the transfer with the highest plutonium concentration. This can be seen in Figure $\mathrm{C}-3$, where the highest average of the 10 transfers includes the last several transfers. 


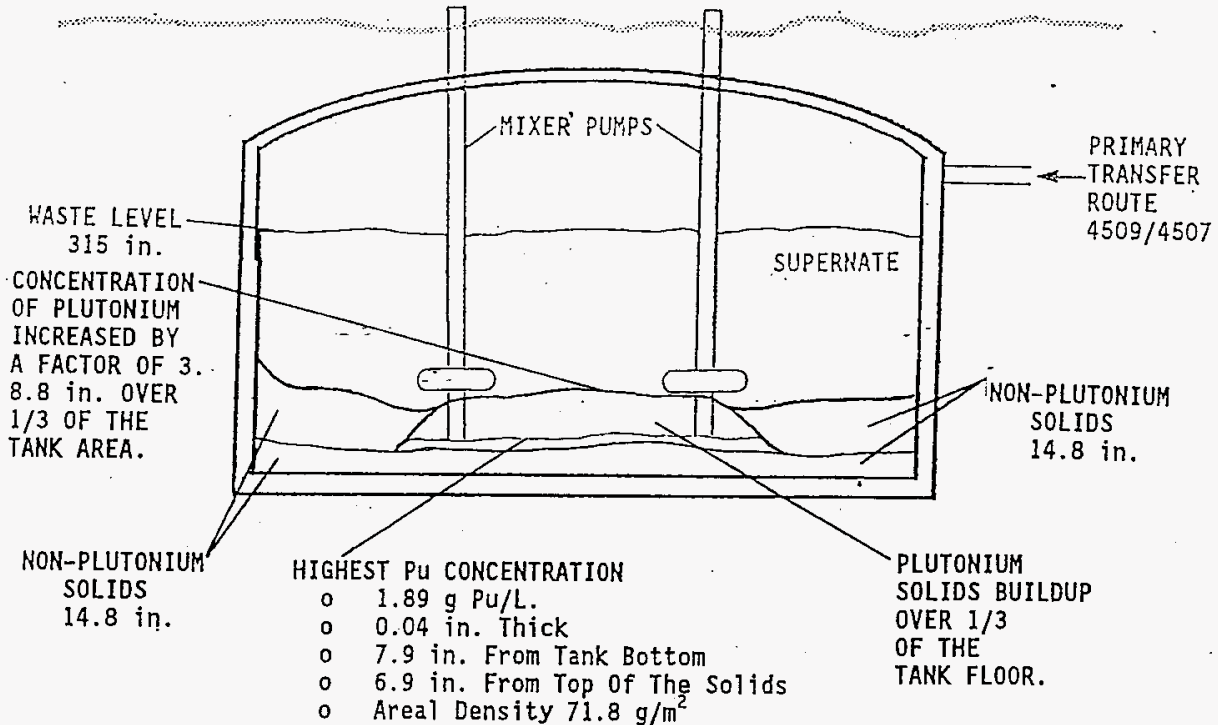


HNF-SD-W151-CSA-001, Rev. 1

\section{C.10 MIXER PUMP INTAKE AND HOUSING}

The mixer pump intake is a cylinder, $13.5 \mathrm{in}$. diameter and $11 \mathrm{in}$. long with a volume of about $25 \mathrm{~L}(6.6 \mathrm{gal}$.). The pump housing approximates a torus, Figure $\mathrm{C}-8$, with an internal volume of approximately $134 \mathrm{~L}$ (35 gal), calculated as follows:

$$
V \approx 19.7392 \mathrm{Rr}^{2}
$$

Where: $R$ is the radius from the center of the pump to the outside wall. $r$ is the radius of the torus.

From Figure $C-8, R=29.21 \mathrm{~cm}(11.5$ in.) and $r=16.51 \mathrm{~cm}(6.0$ in.). Thus, completing the math results in a volume of $133,916 \mathrm{~cm}^{3}(35.38 \mathrm{gal}$.$) .$

The designed flow rate of each of the two nozzles is $19,680 \mathrm{~L} / \mathrm{min}$ $(5,200 \mathrm{gal} / \mathrm{min})$ so at full operation the pump will fill the housing to capacity about every 0.2 seconds.

The highest concentration of $\mathrm{Pu}$ was calculated to be $1.889 \mathrm{~g} / \mathrm{L}$ for the condition where the Pu concentration is increased by a factor of 3 . At this concentration the total amount of plutonium which could possibly be in the pump housing is $253 \mathrm{~g}$. This quantity of $\mathrm{Pu}$ is considerably less then the minimum critical mass of plutonium in an idealized Pu-Water system at 0 wt\% ${ }^{240} \mathrm{Pu}$ with full water reflection of $520 \mathrm{~g}$, Carter et al. (1968), ARH-600, III.A.9(100)-4. Also, any mixing of the waste in the pump housing will decrease the average $\mathrm{Pu}$ concentration. Hence, at the calculated plutonium concentration, the waste in the pump will remain subcritical regardless of the geometry, composition, or dynamics of the system. 
HNF-SD-W151-CSA-001, Rev. 1

Figure C-8. Mixer Pump Configuration and Dimensions.

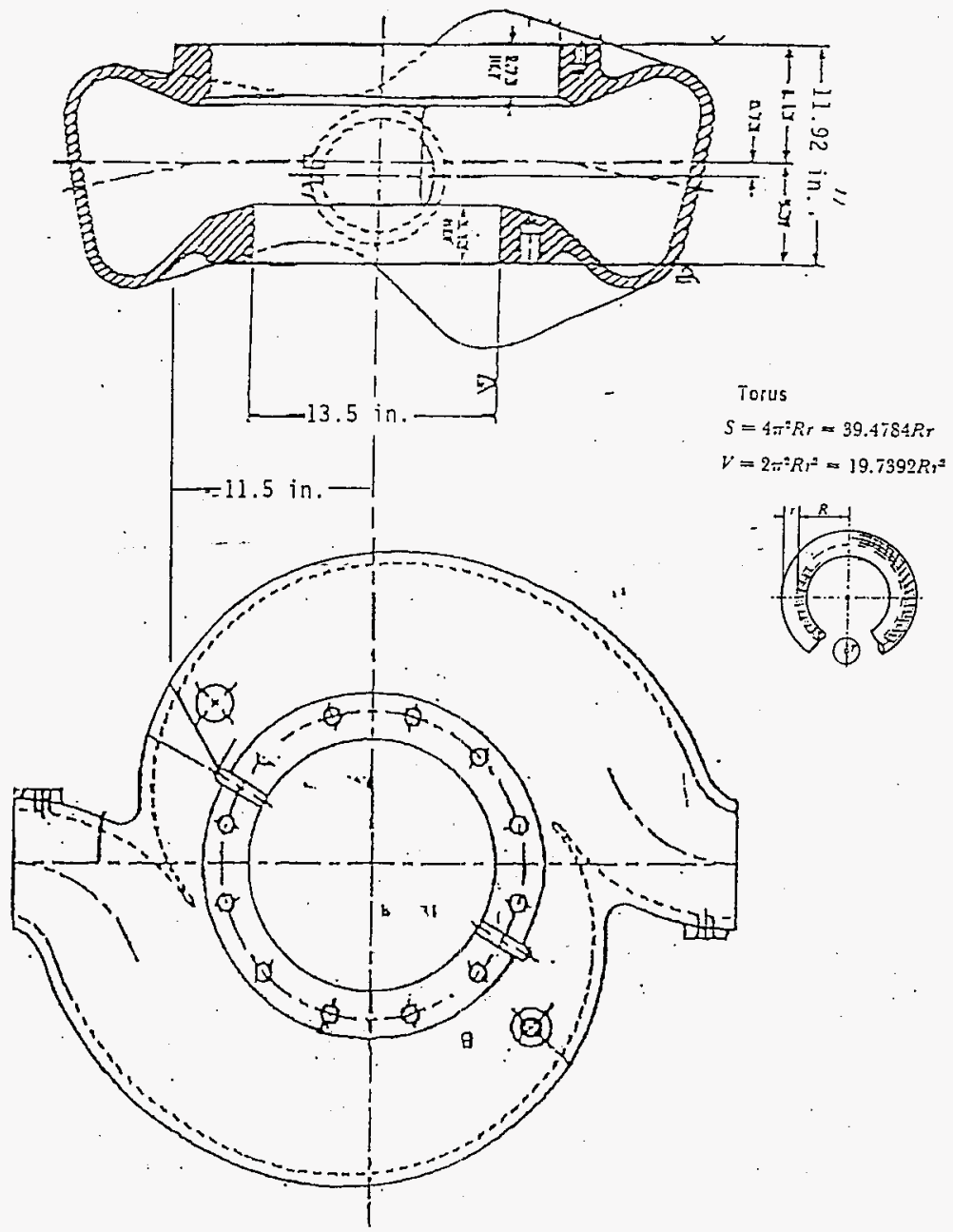


HNF-SD-W151-CSA-001, Rev. 1

Table C-2. Waste Transfer Data and Calculations of Plutonium Concentration for Condition 1.a and l.b. (9 sheets)

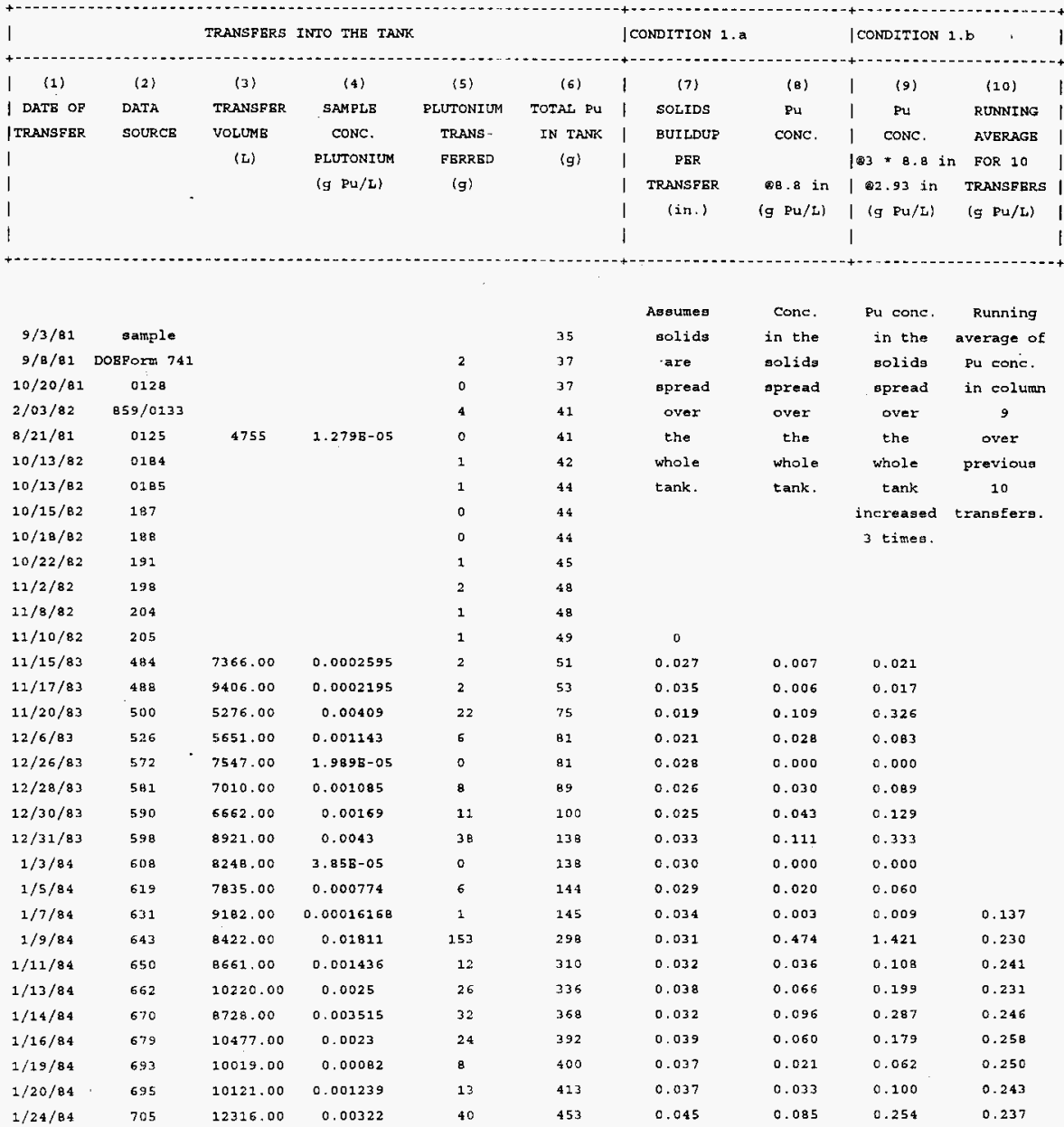


HNF-SD-W151-CSA-001, Rev. 1

Table C-2. Waste Transfer Data and Calculations of Plutonium Concentration
for Condition 1.a and 1.b. ( 9 sheets)

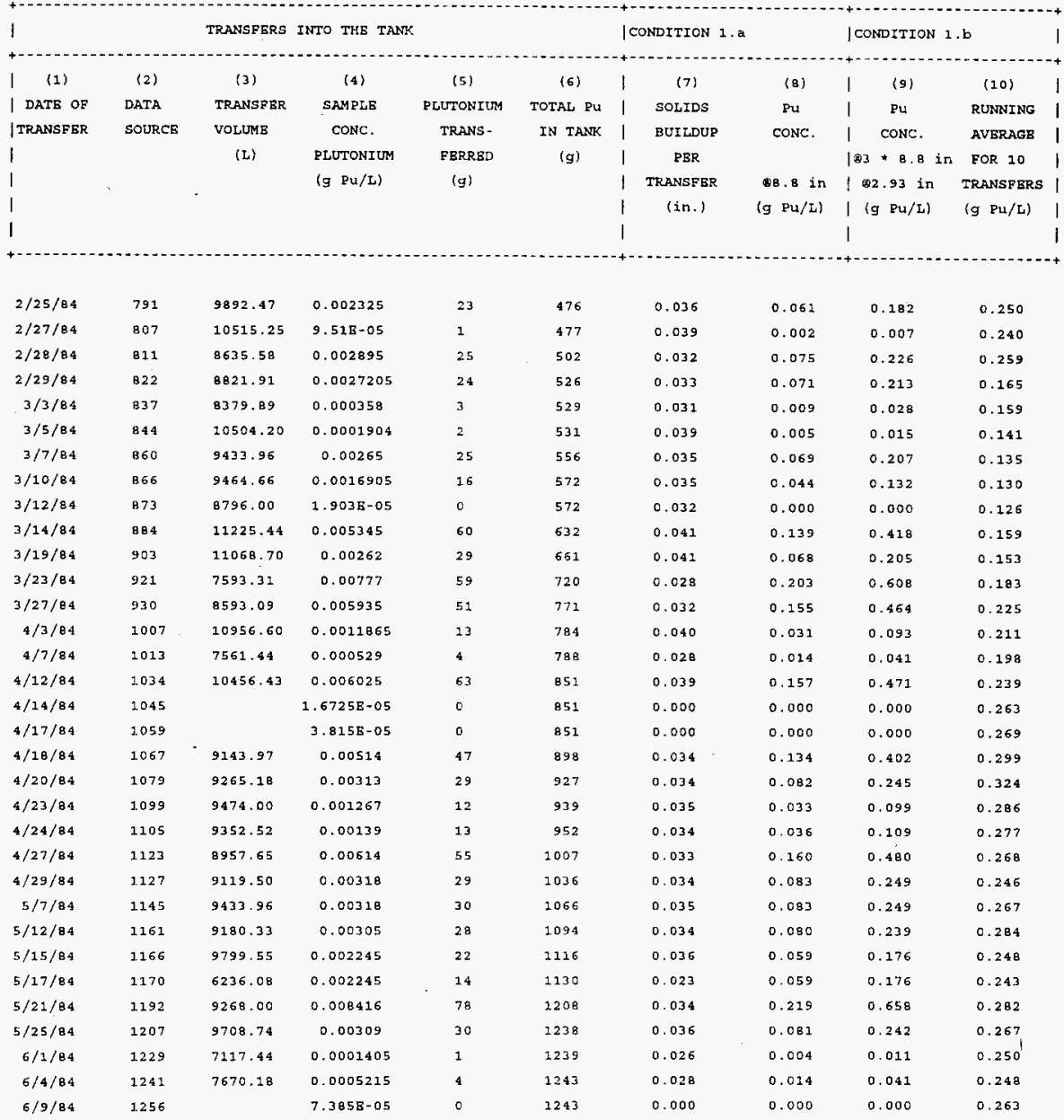


HNF-SD-W151-CSA-001, Rev. I

\section{Table C-2. Waste Transfer Data and Calculations of Plutonium Concentration for Condition $1 . a$ and $1 . b$. (9 sheets)}

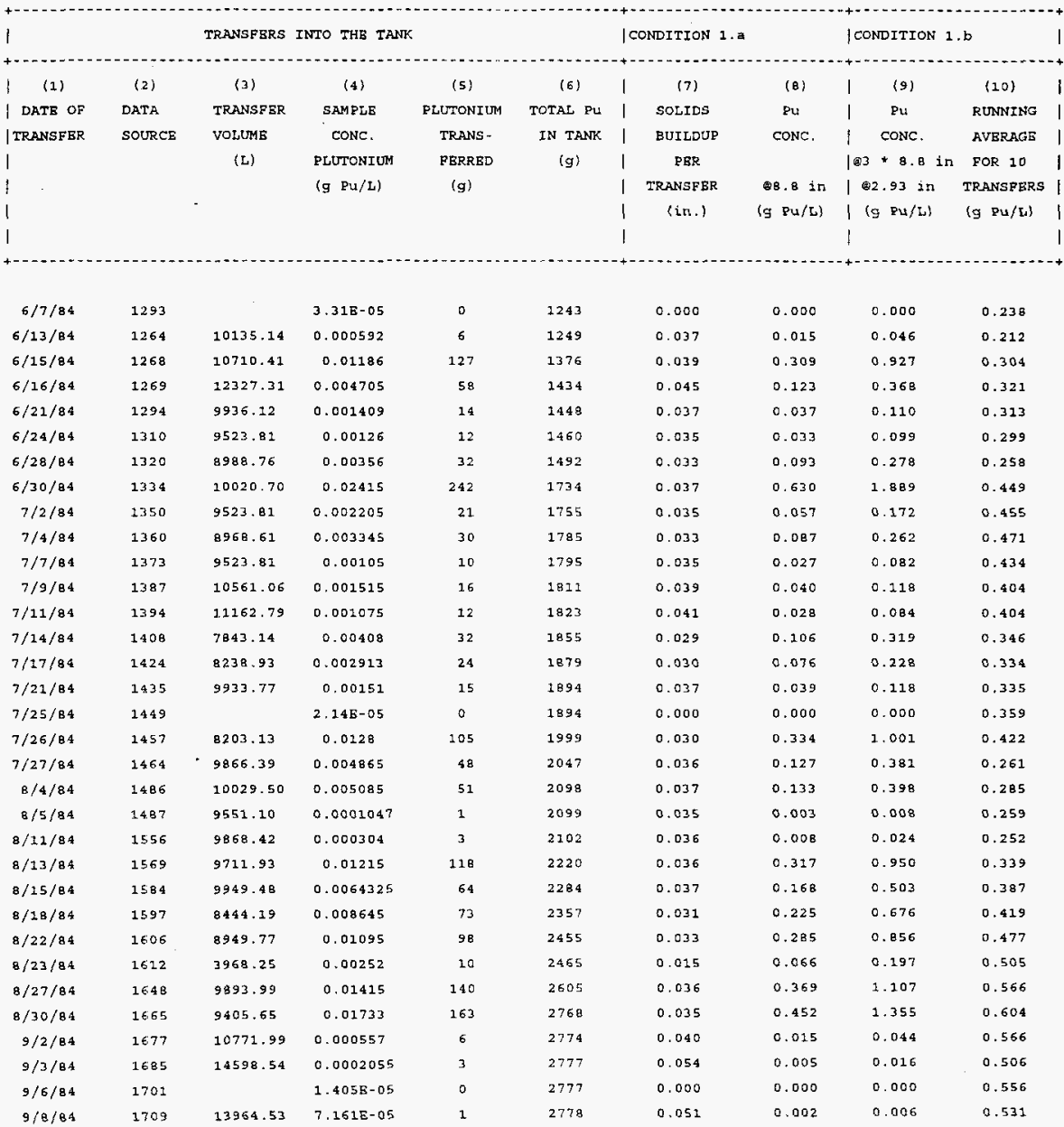




\section{Table C-2. Waste Transfer Data and Calculations of Plutonium Concentration for Condition 1.a and 1.b. ( 9 sheets)}

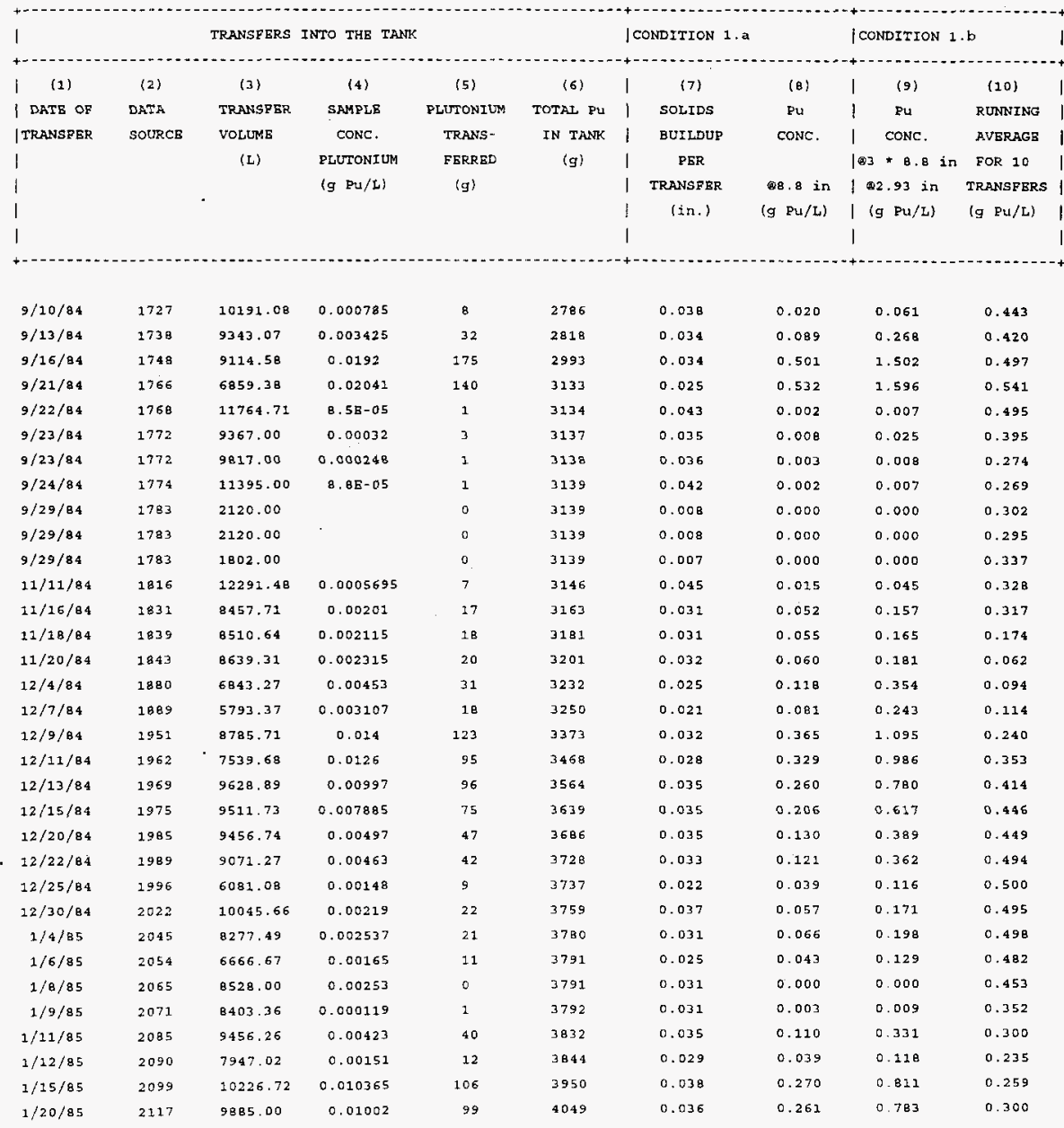


Table C-2. Waste Transfer Data and Calculations of Plutonium Concentration for Condition 1.a and 1.b. (9 sheets)

\begin{tabular}{|c|c|c|c|c|c|c|c|c|c|}
\hline I & & TRANSFERS & NTO THE TAN & & & |CONDITION 1 & & |CONDITION 1.1 & \\
\hline I (1) & (2) & (3) & (4) & (5) & (6) & (7) & (8) & (9) & $(10)$ \\
\hline I DATE OF & DATA & TRANSFER & SAMPLE & PLUTONIUM & TOTAL PU & SOLIDS & $\mathrm{Pu}$ & Pu & RUNNING \\
\hline |TRANSEBR & SOURCE & VOLUMB & CONC. & TRANS- & IN TANK & EUILDUP & CONC. & I CONC. & AVBRAGE \\
\hline I & & (L) & PLUTONIUM & FERRED & $(g)$ & PER & & $103 * 8$ in & FOR 10 \\
\hline I & & & (g Pu/L) & (g) & & TRANSFER & B. $\mathrm{\theta}$ in & $182.93 \mathrm{in}$ & TRANSFER \\
\hline 1 & & & & & & (in.) & $(g \mathrm{Pu} / \mathrm{L})$ & I (g Pu/L $)$ & (g Pu/L) \\
\hline 1 & & & & & & 1 & & 1 & \\
\hline $1 / 22 / 85$ & 2126 & 11820.33 & 0.000423 & 5 & 4054 & 0.044 & 0.011 & 0.033 & 0.262 \\
\hline $1 / 23 / 85$ & 2130 & 8695.65 & 0.00161 & 14 & 4068 & 0.032 & 0.042 & 0.126 & 0.259 \\
\hline $1 / 25 / 85$ & 2145 & 8572.43 & 0.0028 & 24 & 4092 & 0.032 & 0.073 & 0.219 & 0.265 \\
\hline $1 / 28 / 85$ & 2156 & 9090.91 & 0.00011 & 1 & 4093 & 0.033 & 0.003 & 0.009 & 0.247 \\
\hline $1 / 31 / 85$ & 2165 & 8703.70 & 0.0108 & 94 & 4187 & 0.032 & 0.282 & 0.845 & 0.306 \\
\hline $2 / 3 / 85$ & 2174 & 9691.63 & 0.00454 & 44 & 4231 & 0.036 & 0.118 & 0.355 & 0.336 \\
\hline $2 / 8 / 85$ & 2190 & 9431.35 & .0 .00721 & 68 & 4299 & 0.035 & 0.188 & 0.564 & 0.383 \\
\hline $2 / 12 / 85$ & 2218 & 20000.00 & 0.0013 & 13 & 4312 & 0.037 & 0.034 & 0.102 & 0.361 \\
\hline $2 / 15 / 85$ & 2230 & 9641.87 & 0.00363 & 35 & 4347 & 0.036 & 0.095 & 0.284 & 0.372 \\
\hline $2 / 17 / 85$ & 2244 & 9803.92 & 0.00204 & 20 & 4367 & 0.036 & 0.053 & 0.160 & 0.310 \\
\hline $2 / 19 / 85$ & 2251 & 8838.38 & 0.00396 & 35 & 4402 & 0.033 & 0.103 & 0.310 & 0.265 \\
\hline $2 / 24 / 85$ & 2266 & 6702.70 & 0.00925 & 62 & 4464 & 0.025 & 0.241 & 0.724 & 0.324 \\
\hline $2 / 27 / 85$ & 2273 & 11396.00 & 0.00105 & 12 & 4476 & 0.042 & 0.027 & 0.082 & 0.314 \\
\hline $3 / 13 / 85$ & 2330 & 9644.67 & 0.00394 & 38 & 4514 & 0.036 & 0.203 & 0.308. & 0.321 \\
\hline $3 / 15 / 85$ & 2346 & 8207.71 & 0.00597 & 49 & 4563 & 0.030 & 0.156 & 0.467 & 0.361 \\
\hline $3 / 18 / 85$ & 2356 & 9661.84 & 0.000207 & 2 & 4565 & 0.036 & 0.005 & 0.016 & 0.287 \\
\hline $3 / 20 / 85$ & 2369 & 7055.96 & 0,00411 & 29 & 4594 & 0.026 & 0.107 & 0.321 & 0.283 \\
\hline $3 / 22 / 85$ & 2381 & 7352.94 & 0.000136 & 1 & 4595 & 0.027 & 0.004 & 0.012 & 0.236 \\
\hline $3 / 24 / 85$ & 2388 & 8193.98 & 0.00598 & 49 & 4644 & 0.030 & 0.156 & 0.468 & 0.269 \\
\hline $3 / 26 / 85$ & 2401 & 9903.38 & 0.00828 & 82 & 4726 & 0.036 & 0.216 & 0.648 & 0.307 \\
\hline $3 / 27 / 85$ & 2403 & $8 \times 23.53$ & 0.00408 & 36 & 4762 & 0.033 & 0.106 & 0.319 & 0.323 \\
\hline $3 / 28 / 85$ & 2408 & 6622.52 & 0.00151 & 10 & 4772 & 0.024 & 0.039 & 0.118 & 0.310 \\
\hline $3 / 30 / 85$ & 24.26 & 7420,00 & 0 & 0 & 4772 & 0.027 & 0.000 & 0.000 & 0.256 \\
\hline $3 / 31 / 85$ & 2441 & 10476.19 & 0.00105 & 11 & 4783 & 0.039 & 0.027 & 0.082 & 0.257 \\
\hline $4 / 3 / 85$ & 2458 & 10151.19 & 0.00926 & 94 & 4877 & 0.037 & 0.241 & 0.724 & 0.303 \\
\hline $4 / 6 / 85$ & 2466 & 9801.63 & 0.00857 & 84 & 4961 & 0.036 & 0.223 & 0.670 & 0.326 \\
\hline $4 / 7 / 85$ & 2476 & 10032.36 & 0.00309 & 31 & 4992 & 0.037 & 0.081 & 0.242 & 0.349 \\
\hline $4 / 9 / 85$ & 2486 & 8232.93 & 0.00498 & 41 & 5033 & 0.030 & 0.230 & 0.390 & 0.354 \\
\hline $4 / 12 / 85$ & 2500 & 9074.00 & 0 & 0 & 5033 & 0.033 & 0.000 & 0.000 & 0.347 \\
\hline $4 / 15 / 85$ & 2509 & 9980.24 & 0.00668 & 66 & 5099 & 0.036 & 0.174 & 0.522 & 0.355 \\
\hline $4 / 20 / 65$ & 2532 & 10762.33 & 0.00445 & 48 & 5147 & 0.040 & 0.116 & 0.349 & 0.325 \\
\hline $4 / 22 / 85$ & 2540 & 9523.81 & 0.00273 & 26 & 5173 & 0.035 & 0.071 & $0.2 i_{4}$ & 0.316 \\
\hline $4 / 24 / 85$ & 2556 & $94 B 6.17$ & 0.00253 & 24 & 5197 & 0.035 & 0.066 & 0.198 & 0.317 \\
\hline
\end{tabular}




\section{Table C-2. Waste Transfer Data and Calculations of Plutonium Concentration for Condition 1.a and 1.b. (9 sheets)}

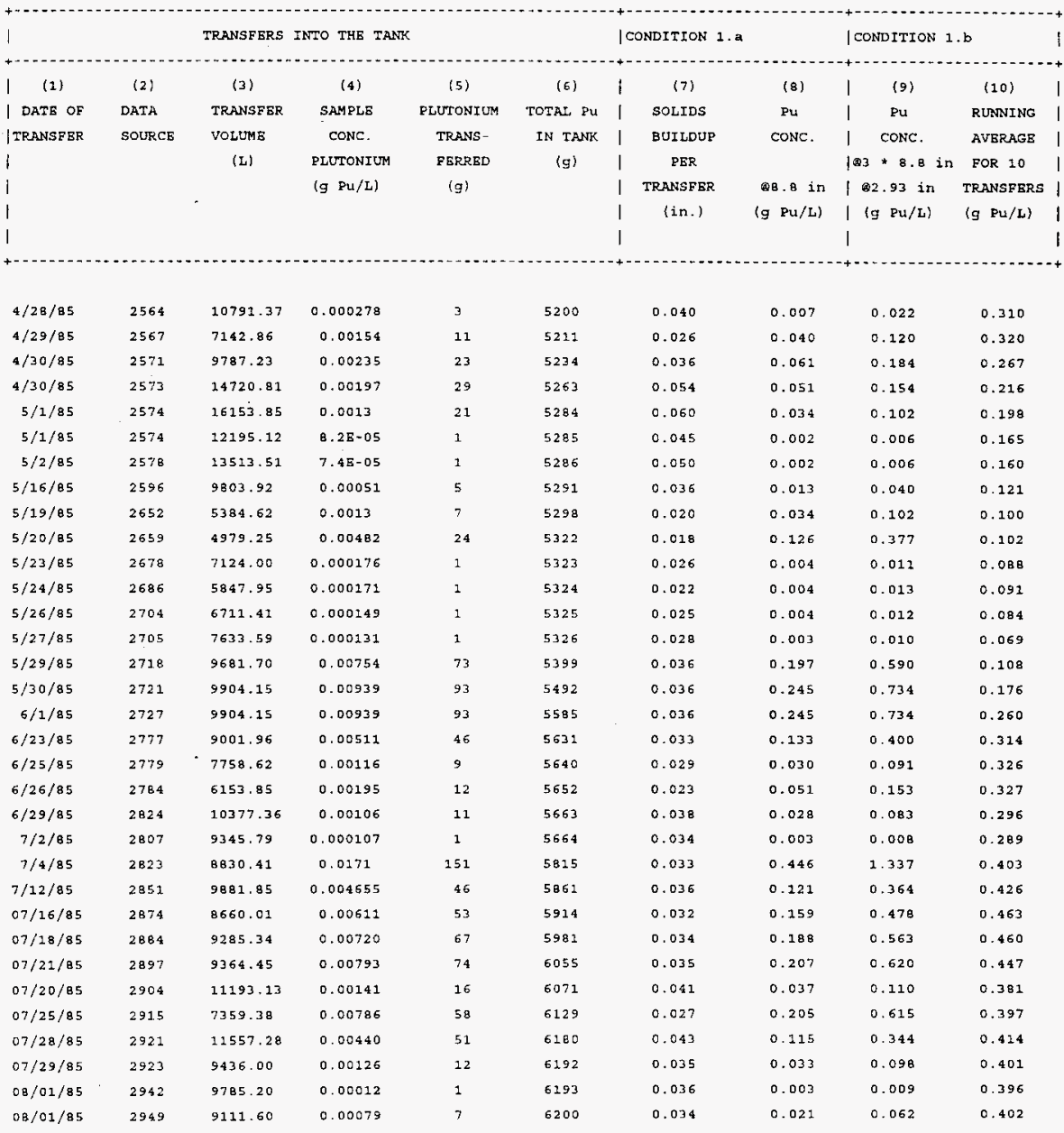




\section{Table C-2. Waste Transfer Data and Calculations of Plutonium Concentration for Condition l.a and l.b. (9 sheets)}

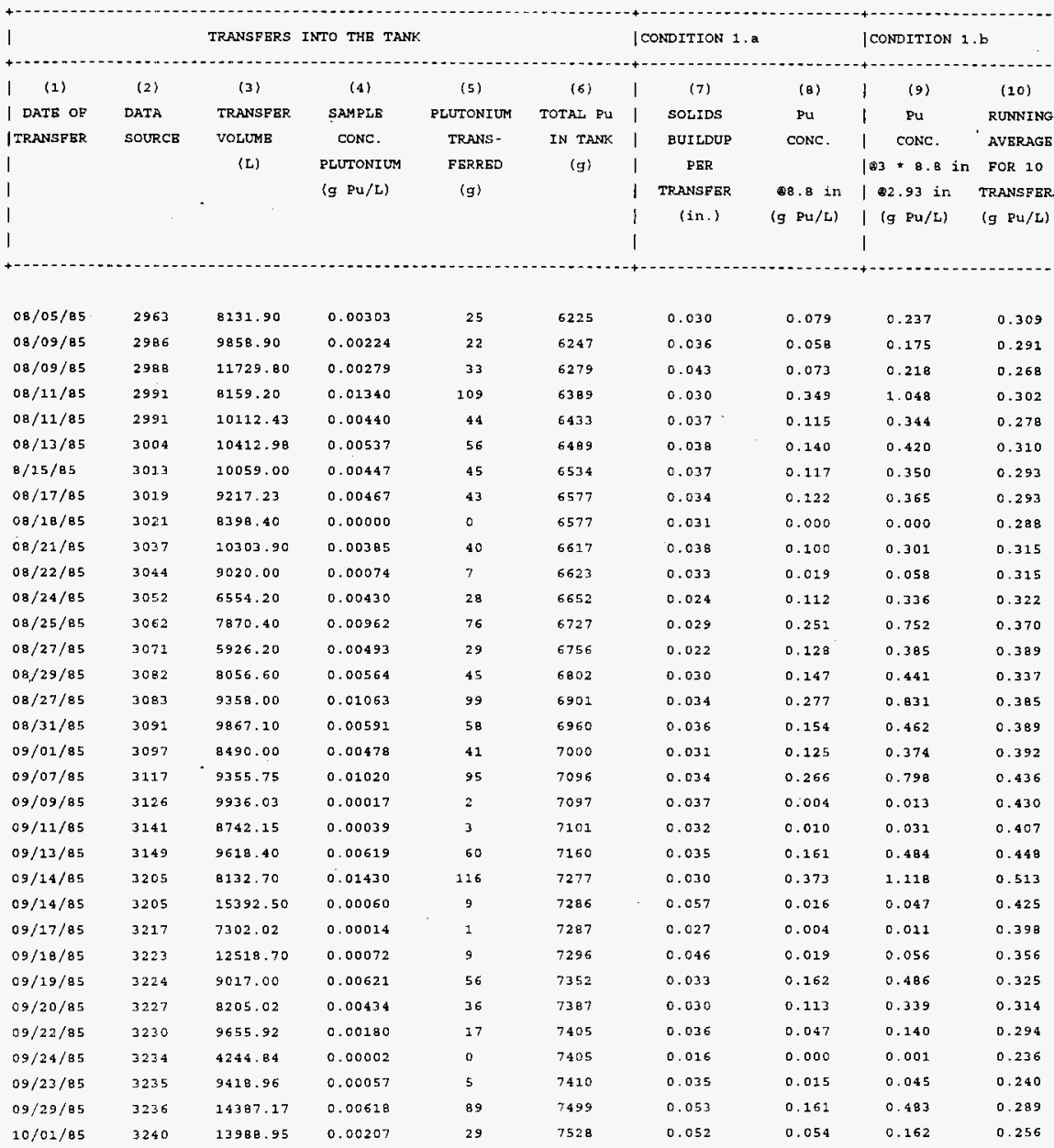


HNF-SD-W151-CSA-001, Rev. I

Table C-2. Waste Transfer Data and Calculations of Plutonium Concentration
for Condition 1.a and 1.b. ( 9 sheets)

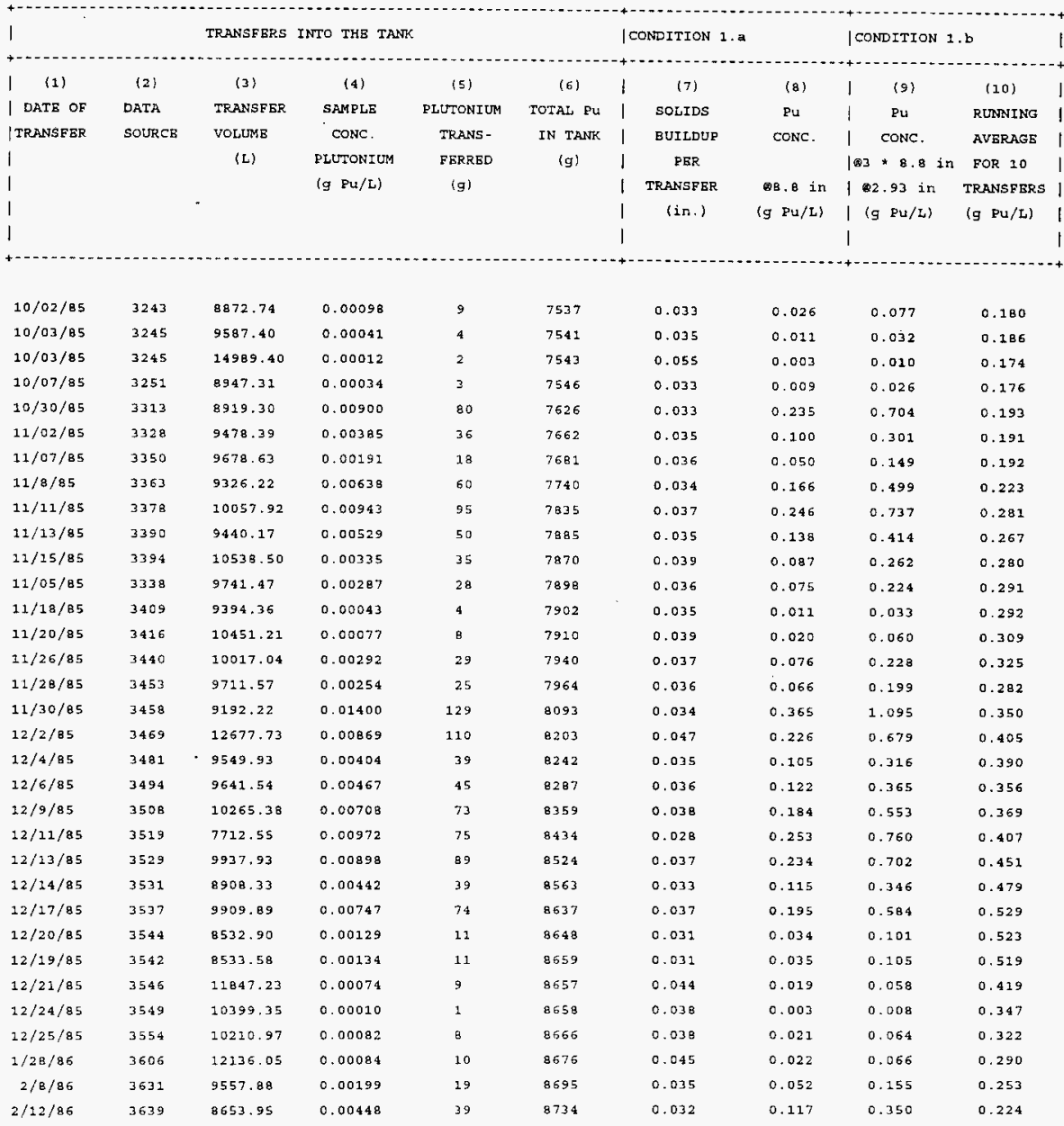


HNF-SD-W151-CSA-001, Rev. I

Table C-2. Waste Transfer Data and Calculations of Plutonium Concentration
for Condition 1.a and 1.b. (9 sheets)

\begin{tabular}{|c|c|c|c|c|c|c|c|c|c|c|}
\hline 1 & & TRANSEBRS & INTO THB TAN & & & & ONDITION 1. A & & | CONDITION 1 & \\
\hline I (1) & (2) & (3) & (4) & (5) & (6) & 1 & (7) & (B) & (9) & (10) \\
\hline I DATB OP & DATA & TRANSFER & SAMPLE & PLUTONIUM & TOTAL Pu & 1 & SOLIDS & Pu & $\mathrm{Pu}$ & RUNNING \\
\hline | TRANSFER & SOURCE & VOLUME & CONC. & TRANS - & IN TANK & 1 & BUILDUP & CONC. & 1 conc. & AVBRAGE \\
\hline 1 & & (L) & PLUTONIUM & FBRRBD & (g) & I & PER & & $183 * 8.8$ in & FOR 10 \\
\hline | & & & $(g \mathrm{Pu} / \mathrm{L})$ & (g) & & I & TRANSEER & 08.8 in & 162.93 in & TRANSFERS \\
\hline 1 & & 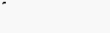 & & & & I & (in.) & $(\mathrm{g} \mathrm{Pu} / \mathrm{L})$ & I (g Fu/L) & (g Pu/L) \\
\hline 1 & & & & & & 1 & & & 1 & \\
\hline $2 / 14 / 86$ & 3648 & 8176.25 & 0.00549 & 45 & 8779 & & 0.030 & 0.243 & 0.429 & 0.196 \\
\hline $2 / 16 / 86$ & 3708 & 8264.07 & 0.00409 & 34 & 8913 & & 0.030 & 0.107 & 0,320 & 0.193 \\
\hline $2 / 19 / 86$ & 3718 & 9394.36 & 0.00472 & 44 & 8857 & & 0.035 & 0.123 & 0.369 & 0.172 \\
\hline $2 / 22 / 86$ & 3728 & 5813.54 & 0.01497 & 102 & 8959 & & 0.025 & 0.390 & 1.171 & 0.243 \\
\hline $3 / 3 / 86$ & 3780 & 8184.95 & 0.01650 & 136 & 9095 & & 0.030 & 0.433 & 1.298 & 0.338 \\
\hline $3 / 4 / 86$ & 3795 & 9880.77 & 0.00914 & 90 & 9185 & & 0.036 & 0.238 & 0.715 & 0.407 \\
\hline $3 / 8 / 86$ & 3805 & 9579.84 & 0.00891 & 85 & 9271 & & 0.035 & 0.232 & 0.697 & 0.476 \\
\hline $3 / 10 / 86$ & 3816 & 9334.55 & 0.00840 & 78 & 9349 & & 0.034 & 0.219 & 0.657 & 0.535 \\
\hline $3 / 17 / 86$ & 3820 & 9268.40 & 0.01990 & 182 & 9531 & & 0.034 & 0.519 & 1.557 & 0.690 \\
\hline $3 / 13 / 86$ & 3842 & 10303.15 & 0.000776 & 8 & 9539 & & 0.038 & 0.020 & 0.061 & 0.676 \\
\hline $3 / 19 / 86$ & 3873 & 9953.41 & 0.000402 & 4 & 9543 & & 0.037 & 0.010 & 0.031 & 0.640 \\
\hline $3 / 25 / 86$ & 3907 & 9082.11 & 0.007157 & 65 & 9608 & & 0.033 & 0.187 & 0.550 & 0.650 \\
\hline $3 / 27 / 86$ & 3925 & 9109.36 & 0.01142 & 104 & 9712 & & 0.034 & 0.298 & 0.893 & 0.699 \\
\hline \multirow[t]{3}{*}{$3 / 27 / 86$} & 3938 & 10619.57 & 0.00659 & 70 & 9782 & & 0.039 & 0.172 & 0.516 & 0.710 \\
\hline & TOTAL Vol. & 2388167.7 & Litera & & & & & & & \\
\hline & & 630955.79 & Gallong & & & & erage $(g / \tau)$ & 0.106 & & \\
\hline
\end{tabular}




\section{Table C-3. Waste Transfer Data and Calculations of Plutonium Concentration} for Condition 2.a and 2.b. (9 sheets)

\begin{tabular}{|c|c|c|c|c|c|c|c|c|}
\hline 1 & & & |CONDITION & $2 \cdot a$ & | CONDITION & $2 . B$ & & | Average \\
\hline & & & $-+--+\infty$ & $--\cdots \cdots-$ & 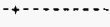 & 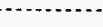 & $\ldots \ldots$ & $b+-1-0-20-2$ \\
\hline (1) & (2) & (3) & 1 (4) & (5) & 16 & (7) & (B) & | (9) \\
\hline DATE OF & DATA & TOTAL & | soLIDS & Pu & | SOLIDS & Pu & ACCUN. & | AVERAGB \\
\hline TRANSFER & SOURCE & PLUTONI UM & | LAYER & CONC. & & CONC. & SOLIDS & | FOR THE \\
\hline & & PBR & | HBIGHT & OVER & | HEIGHT & $1 / 3$ AREA & UP TO & 1 PREVIOUS \\
\hline & & TRANSPER & 1 то & $1 / 3$ AREA & | то & Q3 times & B. B in & 110 \\
\hline & & (g) & $126.4 \mathrm{in}$ & (g Pu/L) & 18.8 in & (g Pu/L) & (in) & | TRANSFERS \\
\hline$\cdot$ & & & I (in) & & $\mid(i n)$ & & & | (g Pu/L) \\
\hline & & & Agoumes & pu cene. & Assumeo & Pu conc. & & Running \\
\hline $9 / 3 / 81$ & sample & & $26.4 \mathrm{in}$ & in $1 / 3$ & B. B in. & in $1 / 3$ & & average of \\
\hline $9 / 8 / 61$ & DOEFOrTh 741 & 2 & of solido & of the & of solids & of the & & Pu cone. \\
\hline $10 / 20 / 81$ & 0128 & 0 & spread & tarik & spread & tank & & in colunr \\
\hline $2 / 03 / 82$ & $859 / 0133$ & 4 & over & area & over & area & & 9 \\
\hline $8 / 21 / 81$ & 0125 & 0 & $1 / 3$ of & pited & $1 / 3$ of & increaged & & over \\
\hline $10 / 13 / 82$ & 0184 & 1 & the & tci & the & by 3 & & previous \\
\hline $10 / 13 / 82$ & 0185 & 1 & tank & a & tank & times & & 10 \\
\hline $10 / 15 / 82$ & 187 & 0 & area. & height & area. & or & & trarsfers. \\
\hline $10 / 18 / 82$ & 188 & 0 & & of & & B.e in. & & \\
\hline $10 / 22 / 82$ & 191 & 1 & & 26.4 in. & & & & \\
\hline $11 / 2 / 82$ & 198 & 2 & & & & & & \\
\hline $11 / 8 / 82$ & 204 & 1 & & & & & & \\
\hline $12 / 10 / 82$ & 205 & 1 & & & & & & \\
\hline $11 / 15 / 83$ & 484 & 2 & 0.08 & $0.0 \mathrm{co}$ & 0.03 & 0.021 & 0.03 & \\
\hline $11 / 17 / 83$ & $48 B$ & 2 & 0.10 & 0,006 & 0.03 & 0.017 & 0.06 & \\
\hline $11 / 20 / 83$ & 500 & 22 & 0.06 & $0.1 \mathrm{c9}$ & 0.02 & 0.326 & 0.08 & \\
\hline $12 / 6 / 83$ & 526 & 6 & 0.06 & 0.028 & 0.02 & 0.083 & 0.10 & \\
\hline $12 / 26 / 83$ & 572 & 0 & 0.08 & 0.000 & 0.03 & 0.000 & 0.13 & \\
\hline $12 / 28 / 83$ & 581 & B & 0.08 & 0.030 & 0.03 & 0.089 & 0.16 & \\
\hline $12 / 30 / 33$ & 590 & 11 & 0.07 & 0.043 & 0.02 & 0.129 & 0.18 & \\
\hline $12 / 31 / 83$ & 598 & 38 & 0.10 & 0.111 & 0.03 & 0.333 & 0.21 & \\
\hline $1 / 3 / 84$ & 608 & 0 & 0.09 & 0.000 & 0.03 & 0.000 & 0.24 & \\
\hline $1 / 5 / 84$ & 619 & 6 & 0.09 & 0.020 & 0.03 & 0.050 & 0.27 & \\
\hline $1 / 7 / 84$ & 631 & 1 & 0.10 & 0.003 & 0.03 & 0.009 & 0.31 & 0.137 \\
\hline $1 / 9 / 84$ & 643 & 153 & 0.09 & 0.474 & 0.03 & 1.421 & 0.34 & 0.230 \\
\hline $1 / 11 / 84$ & 650 & 12 & 0.10 & 0.036 & 0.03 & 0.100 & 0.37 & 0.241 \\
\hline $1 / 13 / 84$ & 662 & 26 & 0.11 & 0.066 & 0.04 & 0.199 & 0.41 & 0.231 \\
\hline $1 / 14 / 84$ & 670 & 32 & 0.10 & 0.096 & 0.03 & 0.287 & 0.44 & 0.246 \\
\hline $1 / 16 / 84$ & 679 & 24 & 0.12 & 0.060 & 0.04 & 0.179 & 0.48 & 0.258 \\
\hline $1 / 19 / 84$ & 693 & 8 & 0.11 & 0.021 & 0.04 & 0.062 & 0.51 & 0.250 \\
\hline $1 / 20 / 84$ & 695 & 13 & 0.11 & 0.033 & 0.04 & 0.100 & 0.55 & 0.243 \\
\hline $1 / 24 / 84$ & 705 & 40 & 0.14 & 0 oes 5 & 0.05 & 0.254 & 0.60 & 0.237 \\
\hline
\end{tabular}


HNF-SD-W151-CSA-001, Rev. 1

Table C-3. Waste Transfer Data and Calculations of Plutonium Concentration for Condition 2.a and 2.b. (9 sheets)

\begin{tabular}{|c|c|c|c|c|c|c|c|c|}
\hline & & & I CONDITIO & $2 . a$ & | CONDITIO & 2.8 & & | Average \\
\hline (1) & (2) & (3) & 1 (4) & (5) & $116)$ & (7) & (a) & (9) \\
\hline DATB OF & DATA & TOTAE & I soLIDS & Pu & | soLIDS & $\mathrm{Pu}$ & Accurs. & I AVERAGE \\
\hline TRANSFER & SOURCE & PLUTONIUM & | LAYSR & CONC. & | LAYER & CONe. & SOLIDS & | FOR THE \\
\hline & & PER & I HEIGHT & OVER & | HEIGHT & 1/3 AREA & UP TO & I PREVIOUS \\
\hline & & TRANSEER & I то & $1 / 3$ AREA & I To & as times & a. in & 10 \\
\hline$\cdot$ & & (g) & $126.4 \mathrm{in}$ & $(\mathrm{g} P \mathrm{~L} / \mathrm{L})$ & 18.8 in & $(g \mathrm{PL} / \mathrm{L})$ & (in) & |TRANSFERS | \\
\hline & & & | (in) & & I (in) & & & $\mid(g \mathrm{Pu} / \mathrm{L}\rangle$ \\
\hline $2 / 25 / 84$ & 791 & 23 & 0.11 & 0.061 & 0.04 & 0.182 & 0.63 & 0.250 \\
\hline $2 / 27 / 84$ & 807 & 1 & 0.12 & 0.002 & 0.04 & 0.007 & 0.67 & 0.240 \\
\hline $2 / 28 / 84$ & 811 & 25 & 0.10 & 0.075 & 0.03 & 0.226 & 0.70 & 0.259 \\
\hline $2 / 29 / 84$ & 822 & 24 & 0.10 & 0.071 & 0.03 & 0.213 & 0.74 & 0.165 \\
\hline $3 / 3 / 84$ & 837 & 3 & 0.09 & 0.009 & 0.03 & 0.028 & 0.77 & 0.159 \\
\hline $3 / 5 / 84$ & 844 & 2 & 0.12 & 0.0 .05 & 0.04 & 0.015 & 0.81 & 0.141 \\
\hline $3 / 7 / 84$ & 860 & 25 & 0.10 & 0.069 & 0.03 & 0.207 & 0.84 & 0.135 \\
\hline $3 / 10 / 84$ & 866 & 16 & 0.10 & 0.044 & $0: 03$ & 0.132 & 0.88 & 0.130 \\
\hline $3 / 12 / 84$ & 873 & 0 & 0.10 & 0.000 & 0.03 & 0.000 & 0.91 & 0.126 \\
\hline $3 / 14 / 84$ & 884 & 60 & 0.12 & 0.239 & 0.04 & 0.418 & 0.95 & 0.159 \\
\hline $3 / 19 / 84$ & 903 & 29 & 0.12 & 0.068 & 0.04 & 0.205 & 0.99 & 0.153 \\
\hline $3 / 23 / 84$ & 921 & 59 & 0.03 & 0.203 & 0.03 & 0.608 & 1.02 & 0.183 \\
\hline $3 / 27 / 84$ & 930 & 52 & 0.09 & 0.155 & 0.03 & 0.464 & \pm .05 & 0.225 \\
\hline $4 / 3 / 84$ & 1007 & 13 & 0.12 & 0.031 & 0.04 & 0.093 & 1.09 & 0.211 \\
\hline $4 / 7 / 84$ & 1013 & 4 & 0.08 & 0.014 & 0.03 & 0.041 & 1.12 & 0.290 \\
\hline $4 / 12 / 84$ & 1034 & 63 & 0.12 & 0.157 & 0.04 & 0.471 & 1.16 & 0.239 \\
\hline $4 / 14 / 84$ & 1.045 & 0 & 0.00 & 0.000 & 0.00 & 0.000 & 1.16 & 0.263 \\
\hline $4 / 17 / 84$ & 1059 & 0 & 0.00 & 0.000 & 0.00 & 0.000 & 1.16 & 0.269 \\
\hline $4 / 18 / 84$ & 1067 & 47 & 0.10 & 0.134 & 0.03 & 0.402 & 1.19 & 0.299 \\
\hline $4 / 20 / 84$ & 1079 & 29 & 0.10 & 0.082 & 0.03 & 0.245 & 1.22 & 0.324 \\
\hline $4 / 23 / 84$ & 1099 & 12 & 0.10 & 0.033 & 0.03 & 0.099 & 1.26 & 0.286 \\
\hline $4 / 24 / 84$ & 1105 & 13 & 0.10 & 0.036 & 0.03 & 0.209 & 1.29 & 0.277 \\
\hline $4 / 27 / 84$ & 1223 & 55 & 0.10 & 0.260 & 0.03 & 0.480 & 1.33 & 0.268 \\
\hline $4 / 29 / 84$ & 1127 & 29 & 0.10 & 0.083 & 0.03 & 0.249 & 1.36 & 0.246 \\
\hline $5 / 7 / 84$ & 1145 & 30 & 0.10 & 0.083 & 0.03 & 0.249 & 1.40 & 0.267 \\
\hline $5 / 12 / 64$ & 1161 & 28 & 0.10 & 0.080 & 0.03 & 0.239 & 1.43 & 0.284 \\
\hline $5 / 15 / 84$ & 1266 & 22 & 0.11 & 0.059 & 0.04 & 0.176 & 1.47 & 0.248 \\
\hline $5 / 17 / 84$ & 1170 & 14 & 0.07 & 0.0 .59 & 0.02 & 0.176 & 1.49 & 0.243 \\
\hline $5 / 21 / 84$ & 1192 & 78 & 0.10 & 0.219 & 0.03 & 0.658 & 2.52 & 0.282 \\
\hline $5 / 25 / 84$ & 1207 & 30 & 0.11 & 0.031 & 0.04 & 0.242 & 1.56 & 0.267 \\
\hline $6 / 1 / 84$ & 2229 & 1 & 0.08 & 0.004 & 0.03 & 0.011 & 2.58 & 0.250 \\
\hline $6 / 4 / 84$ & $\$ 241$ & 4 & 0.08 & 0.014 & 0.03 & 0.041 & 1.61 & 0.246 \\
\hline $6 / 9 / 84$ & 1256 & 0 & 0.00 & 0.000 & 0.00 & 0.000 & 1.61 & 0.263 \\
\hline
\end{tabular}


HNF-SD-W151-CSA-001, Rev. 1

Table C-3. Waste Transfer Data and Calculations of Plutonium Concentration for Condition 2.a and 2.b. (9 sheets)

\begin{tabular}{|c|c|c|c|c|c|c|c|c|}
\hline & & & |CONDITION & $2 a$ & | CONDITIO & N $2 . B$ & & | Average \\
\hline (1) & (2) & (3) & (4) & (5) & (6) & (7) & (B) & (s) \\
\hline DATS OF & DATA & TOTAL & | SOLIDS & E'u & | SOLIDS & $\mathrm{Pu}$ & Accun. & I AVERAGB \\
\hline TRANSFER & SOURCE & ELUTONIUM & I LAYER & Conic. & | LAYER & conc. & SOLIDS & I EOR THE \\
\hline & & PER & | HEIGHT & OVER & | HEIGHT & 1/3 AREA & UP TO & | PREVIOUS \\
\hline & & TRANSEER & I To & $1 / 3$ AREA & 1 TO & Q3 times & 8.8 in & $1 \quad 10$ \\
\hline$*$ & & (g) & $\begin{array}{l}\mid 26.4 \text { in } \\
\mid(i n)\end{array}$ & (g Fu/L) & $\begin{array}{l}\mid 8.8 \text { in } \\
\mid \text { (in) }\end{array}$ & (g Pu/L) & (in) & $\begin{array}{l}\text { |TRANSFERS } \\
\mid \text { (g PU/L) }\end{array}$ \\
\hline $5 / 7 / 84$ & 2293 & 0 & 0.00 & 0.000 & 0.00 & 0.000 & 1.61 & 0.238 \\
\hline $6 / 13 / 34$ & 1264 & 6 & 0.11 & 0.015 & 0.04 & 0.046 & 1.65 & 0.212 \\
\hline $6 / 25 / 94$ & 1268 & 127 & 0.12 & 0.309 & 0.04 & 0.927 & 1.69 & 0.304 \\
\hline $6 / 16 / 34$ & 1269 & 58 & 0.14 & 0.123 & 0.05 & 0.368 & 1.74 & 0.321 \\
\hline $6 / 21 / 84$ & 1294 & 24 & 0.71 & 0.037 & 0.04 & 0.220 & 1.77 & 0.713 \\
\hline $6 / 24 / 04$ & 1310 & 12 & 0.11 & 0.033 & 0.04 & 0.099 & 1. B 1 & 0.299 \\
\hline $6 / 28 / 84$ & 1320 & 32 & 0.10 & 0.093 & 0.03 & $0.27 \mathrm{~B}$ & 1.84 & 0.258 \\
\hline $6 / 30 / 84$ & 1334 & -242 & 0.11 & 0.630 & 0.04 & $2.8 \mathrm{Bg}$ & $1.88=$ & 0.449 \\
\hline $7 / 2 / 84$ & 1350 & 21 & 0.12 & 0.057 & 0.04 & 0.172 & 1.91 & 0.455 \\
\hline $7 / 4 / 84$ & 1360 & 30 & 0.10 & 0.087 & 0.03 & 0.262 & 1.94 & 0.471 \\
\hline $7 / 7 / 84$ & 1373 & 10 & 0.11 & 0.027 & 0.04 & 0.082 & 1.98 & 0.434 \\
\hline $7 / 9 / 84$ & 2387 & 16 & 0.12 & 0.039 & 0.04 & 0.119 & 2.02 & 0.404 \\
\hline $7 / 11 / 84$ & 1394 & 12 & 0.12 & 0.0 .28 & 0.04 & 0.084 & 2.06 & 0.404 \\
\hline $7 / 24 / 84$ & 1408 & 32 & 0.09 & $0.1,36$ & 0.03 & 0.319 & 2,09 & 0.346 \\
\hline $7 / 17 / 84$ & 1424 & 24 & 0.09 & 0.076 & 0.03 & 0.228 & 2.12 & 0.334 \\
\hline $7 / 21 / 84$ & 7435 & 15 & 0.11 & 0.039 & 0.04 & $0.11 \mathrm{~B}$ & 2.16 & 0.335 \\
\hline $7 / 25 / 84$ & 1449 & 0 & 0.00 & 0.000 & 0.00 & 0.000 & 2.16 & 0.359 \\
\hline $7 / 26 / 84$ & 1457 & 105 & 0.09 & 0.334 & 0.03 & 1.001 & 2.19 & 0.422 \\
\hline $7 / 27 / 84$ & 1464 & 48 & 0.21 & 0.127 & 0.04 & 0.382 & 2.22 & 0.261 \\
\hline $8 / 4 / 84$ & 1486 & 57 & 0.11 & 0.133 & 0.04 & 0.398 & 2.26 & 0.285 \\
\hline $8 / 5 / 84$ & 1487 & 1 & 0.11 & 0.003 & 0.04 & 0.008 & 2.29 & 0.259 \\
\hline $8 / 11 / 84$ & 1556 & 3 & 0.11 & 0.008 & 0.04 & 0.024 & 2.33 & 0.252 \\
\hline $1 / 13 / 84$ & 1569 & 118 & 0.12 & $0.3: 7$ & 0.04 & 0.950 & 2.37 & 0.339 \\
\hline$e / 15 / 84$ & $15 B 4$ & 64 & 0.11 & 0.168 & 0.04 & 0.503 & 2.40 & 0.387 \\
\hline $8 / 18 / 84$ & 1597 & 73 & 0.09 & 0.225 & 0.03 & 0.676 & 2.43 & 0.419 \\
\hline $8 / 22 / 84$ & 1606 & $9 B$ & 0.10 & 0.285 & 0.03 & 0.856 & 2.47 & 0.477 \\
\hline $8 / 23 / 84$ & 1612 & 10 & 0.04 & 0.066 & 0.01 & 0.197 & 2.48 & 0.505 \\
\hline $8 / 27 / 84$ & 1648 & 140 & 0.22 & 0.369 & 0.04 & 1.107 & 2.52 & 0.566 \\
\hline $8 / 30 / 84$ & 2665 & 263 & 0.10 & 0.452 & 0.03 & 2.356 & 2.55 & 0.604 \\
\hline $9 / 2 / 04$ & 2677 & 6 & 0.12 & $0 \quad 015$ & 0.04 & 0.044 & 2.59 & 0.566 \\
\hline $9 / 3 / 84$ & 1685 & 3 & 0.16 & 0005 & 0.05 & 0.016 & 2.65 & 0.506 \\
\hline $9 / 6 / 84$ & 1701 & 0 & 0.00 & 0.0010 & 0.00 & 0.000 & 2.65 & 0.556 \\
\hline $9 / 8 / 84$ & 1709 & 1 & 0.15 & 0.0012 & 0.05 & 0.006 & 2.70 & 0.531 \\
\hline
\end{tabular}


HNF-SD-W151-CSA-001, Rev. 1

Table C-3. Waste Transfer Data and Calculations of Plutonium Concentration for Condition 2.a and 2.b. (9 sheets)

\begin{tabular}{|c|c|c|c|c|c|c|c|c|}
\hline I & & & | CONDITIOR & $2 \cdot a$ & | CONDITIO & N $2 . \mathrm{B}$ & & | Average \\
\hline $1 \quad(1)$ & (2) & (3) & (4) & (c) & (6) & (7) & (8) & (9) \\
\hline I DATE OF & DATA & TOTAL & I SOLIDS & $\mathrm{Fu}$ & | SOLIDS & $\mathrm{Pu}$ & ACCUM. & I AVBRAGE \\
\hline I TRANSFER & SOURCE & PLUTONIUM & I LAYBR & CONC. & | LAYER & CONC. & SOLIDS & | FOR THB \\
\hline 1 & & PER & I HEIGHT & OVER & | HEIGHT & $1 / 3$ AREA & UP TO & | PREVIOUS \\
\hline 1 & & TRANSFER & I To & $1 / 3$ AREA & ～то & (4) times & B. 8 in & 110 \\
\hline 1 & & $(g)$ & 126.4 in & $\left\{g \mathrm{~F}^{\mathrm{u}} \mathrm{u} / \mathrm{L}\right\}$ & a.8 in & (g Pu/L) & $(i n)$ & |TRANSFERS \\
\hline I & & & $\mid(i n)$ & & $\mid(i n)$ & & & $|(g \mathrm{Pu} / \mathrm{L}\rangle|$ \\
\hline $9 / 10 / 84$ & 1727 & B & 0.11 & 0.020 & 0.04 & 0.061 & 2.74 & 0.443 \\
\hline $9 / 13 / 84$ & 1738 & 32 & 0.10 & 0.089 & 0.03 & 0.268 & 2.77 & 0.420 \\
\hline $9 / 16 / 84$ & 1748 & 175 & 0.10 & 0.501 & 0.03 & 1.502 & 2.80 & 0.497 \\
\hline $9 / 21 / 84$ & 1766 & 140 & 0.08 & 0.532 & 0.03 & 1.596 & 2.83 & 0.541 \\
\hline $9 / 22 / 84$ & 1768 & 1 & 0.13 & 0.002 & 0.04 & 0.007 & 2.87 & 0.495 \\
\hline $9 / 23 / 84$ & 1772 & 3 & 0.10 & 0.008 & 0.03 & 0.025 & 2.91 & 0.395 \\
\hline $9 / 23 / 84$ & 1772 & 1 & 0.11 & 0.003 & 0.04 & 0.008 & 2.94 & 0.274 \\
\hline $9 / 24 / 84$ & 1774 & 1 & 0.13 & 0.002 & 0.04 & 0.007 & 2.99 & 0.269 \\
\hline $9 / 29 / 84$ & 1783 & 0 & 0.02 & 0.000 & 0.01 & 0.000 & 2.99 & 0.302 \\
\hline $9 / 29 / 84$ & 1783 & 0 & 0.02 & 0.000 & 0.02 & 0.000 & 3.00 & 0.295 \\
\hline $9 / 29 / 84$ & 1783 & 0 & 0.02 & 0.000 & 0.01 & 0.000 & .3 .01 & 0.337 \\
\hline $11 / 11 / 84$ & 1816 & 7 & 0.14 & 0.015 & 0.05 & 0.045 & 3.05 & 0.328 \\
\hline $11 / 16 / 84$ & 1831 & 17 & 0.09 & 0.052 & 0.03 & 0.157 & 3.08 & 0.327 \\
\hline $11 / 18 / 84$ & 1839 & 18 & 0.09 & 0.055 & 0.03 & 0.165 & 3.12 & 0.174 \\
\hline $11 / 20 / 84$ & 1843 & 20 & 0.10 & 0.060 & 0.03 & 0.181 & 3.15 & 0.062 \\
\hline $12 / 4 / 84$ & 1880 & 31 & 0.08 & 0.118 & 0.03 & 0.354 & 3.17 & 0.094 \\
\hline $12 / 7 / 84$ & 1889 & 18 & 0.06 & 0.082 & 0.02 & 0.243 & 3.19 & 0.114 \\
\hline $12 / 9 / 84$ & 1951 & 123 & 0.10 & 0.365 & 0.0 .3 & 1.095 & 3.23 & 0.240 \\
\hline $12 / 11 / 84$ & 1962 & 95 & 0.08 & 0.328 & 0.03 & 0.986 & 3.25 & 0.353 \\
\hline $12 / 13 / 84$ & 1959 & 96 & 0.11 & 0.260 & 0.04 & 0.780 & 3.29 & 0.414 \\
\hline $12 / 15 / 84$ & 1975 & 75 & 0.11 & 0.206 & 0.04 & 0.617 & 3.32 & 0.446 \\
\hline $12 / 20 / 84$ & 1985 & 47 & 0.10 & 0.230 & 0.03 & 0.389 & 3.36 & 0.449 \\
\hline $12 / 22 / 84$ & 1989 & 42 & 0.10 & 0.121 & 0.03 & 0.362 & 3.39 & 0.494 \\
\hline $12 / 25 / 84$ & 1996 & 9 & 0.07 & 0.039 & 0.02 & 0.116 & 3.41 & 0.500 \\
\hline $12 / 30 / 84$ & 2022 & 22 & 0.11 & 0.057 & 0.04 & 0.171 & 3.45 & 0.495 \\
\hline $1 / 4 / 85$ & 2045 & 21 & 0.09 & 0.066 & 0.03 & 0.198 & 3.48 & 0.498 \\
\hline $1 / 6 / 85$ & 2054 & 11 & 0.07 & 0.043 & 0.02 & 0.129 & 3.51 & 0.482 \\
\hline $1 / 8 / 85$ & 2065 & 0 & 0.09 & 0.000 & 0.03 & 0.000 & 3.54 & 0.453 \\
\hline $1 / 9 / 85$ & 2071 & 1 & 0.09 & 0.003 & 0.03 & 0.009 & 3.57 & 0.352 \\
\hline $1 / 11 / 85$ & 2085 & 40 & 0.10 & 0.110 & 0.03 & 0.331 & 3.60 & 0.300 \\
\hline $1 / 12 / 85$ & 2090 & 12 & 0.09 & 0.039 & 0.03 & $0.11 \mathrm{~B}$ & 3.63 & 0.235 \\
\hline $1 / 15 / 85$ & 2099 & 106 & 0.11 & 0.270 & 0.04 & 0.811 & 3.67 & 0.259 \\
\hline $1 / 20 / 85$ & 211.7 & 99 & 0.11 & 0.261 & 0.04 & 0.783 & 3.71 & 0.300 \\
\hline
\end{tabular}


Table C-3. Waste Transfer Data and Calculations of Plutonium Concentration for Condition 2.a and 2.b. (9 sheets)

\begin{tabular}{|c|c|c|c|c|c|c|c|c|}
\hline & & & \multicolumn{2}{|c|}{ |CONDITION $2 . a$} & \multicolumn{3}{|c|}{ |CONDITION 2.B } & | Average | \\
\hline (1) & (2) & (3) & | (4) & (5) & I (6) & (7) & (B) & 1 (9) \\
\hline DATE OF & DATA & TOTAL & I SOLIDS & $\mathbf{P u}$ & I solids & Pu & ACCUM. & I AVBRAGB \\
\hline TRANGFER & SOURCE & PLUTONIUT & | LAYER & CONC. & | LLAYER & Cone. & SOLIDS & | FOR THE \\
\hline & & PER & | HEIGHT & OVER & I HEIGHT & 1/3 AREA & UP TO & | PREVIOUS | \\
\hline & & TRANSFER. & I то & $1 / 3$ AREA & i To & Q3 times & 8.8 in & $1 \quad 10$ \\
\hline & & (g) & 26.4 in & $(g \mathrm{Pu} / \mathrm{L})$ & 18.8 in & (g Pu/L) & (in) & |TRANSFERS | \\
\hline 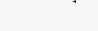 & & & 1 (in) & & I (in) & & & $|(g \mathrm{Pu} / \mathrm{L})|$ \\
\hline $1 / 22 / 85$ & 2126 & 5 & 0.13 & 0.011 & 0.04 & 0.033 & 3.75 & 0.262 \\
\hline $1 / 23 / 85$ & 2130 & 14 & 0.10 & 0.042 & 0.03 & 0.126 & 3.78 & 0.259 \\
\hline $1 / 25 / 85$ & 2145 & 24 & 0.09 & 0.073 & 0.03 & 0.219 & 3.81 & 0.265 \\
\hline $1 / 28 / 85$ & 2156 & 1 & 0.10 & 0.003 & 0.03 & 0.009 & 3.85 & 0.247 \\
\hline $1 / 31 / 85$ & 2165 & 94 & 0.10 & 0.282 & 0.03 & 0.845 & 3.88 & 0.306 \\
\hline $2 / 3 / 85$ & 2174 & 44 & 0.11 & 0.118 & 0.04 & 0.355 & 3.92 & 0.336 \\
\hline $2 / 8 / 85$ & 2190 & 68 & 0.10 & 0.188 & 0.03 & 0.564 & 3.95 & 0.383 \\
\hline $2 / 12 / 85$ & 2218 & 13 & 0.11 & 0.0134 & 0.04 & 0.102 & 3.99 & 0.361 \\
\hline $2 / 15 / 85$ & 2230 & 35 & 0.11 & 0.095 & 0.04 & $0.2 \mathrm{~B} 4$ & 4.02 & 0.372 \\
\hline $2 / 17 / 85$ & 2244 & 20 & 0.11 & 0.053 & 0.04 & 0.160 & 4.06 & 0.310 \\
\hline $2 / 19 / 85$ & 2251 & 35 & 0.10 & 0.103 & 0.03 & 0.310 & 4.09 & 0.265 \\
\hline $2 / 24 / 85$ & 2266 & 62 & 0.07 & 0.242 & 0.02 & 0.724 & 4.12 & 0.324 \\
\hline $2 / 27 / 85$ & 2273 & 12 & 0.13 & 0.027 & 0.04 & 0.082 & 4.16 & 0.314 \\
\hline $3 / 13 / 85$ & 2330 & 38 & 0.11 & 0.103 & 0.04 & 0.300 & 4.19 & 0.321 \\
\hline $3 / 25 / 85$ & 2346 & 49 & 0.09 & 0.156 & 0.03 & 0.467 & 4.22 & 0.361 \\
\hline $3 / 18 / 85$ & 2356 & 2 & 0.11 & 0.005 & 0.04 & 0.016 & 4.26 & 0.287 \\
\hline $3 / 20 / 85$ & 2369 & 29 & 0.08 & 0.107 & 0.03 & 0.321 & 4.29 & 0.283 \\
\hline $3 / 22 / 85$ & 2382 & 1 & 0.08 & 0.004 & 0.03 & 0.011 & 4.32 & 0.236 \\
\hline $3 / 24 / 85$ & 2388 & 49 & 0.09 & 0.156 & 0.03 & 0.468 & 4.34 & 0.269 \\
\hline $3 / 26 / 85$ & 2401 & 82 & 0.11 & 0.216 & 0.04 & 0.648 & 4.38 & 0.307 \\
\hline $3 / 27 / 85$ & 2403 & 36 & 0.10 & 0.106 & 0.03 & 0.319 & 4.41 & 0.323 \\
\hline $3 / 28 / 85$ & 2408 & 10 & 0.07 & 0.039 & 0.02 & 0.118 & 4.44 & 0.310 \\
\hline $3 / 30 / 85$ & 2426 & 0 & 0.08 & 0.000 & 0.03 & 0.000 & 4.46 & 0.256 \\
\hline $3 / 31 / 25$ & 2441 & 11 & 0.12 & 0.027 & 0.04 & 0.082 & 4.50 & 0.257 \\
\hline $4 / 3 / 85$ & 2458 & 94 & 0.11 & 0.241 & 0.04 & 0.724 & 4.54 & 0.303 \\
\hline $4 / 6 / 85$ & 2466 & 84 & 0.11 & 0.223 & 0.04 & 0.670 & $4.5 B$ & 0.326 \\
\hline $4 / 7 / 65$ & 2476 & 32 & 0.11 & 0.081 & 0.04 & 0.242 & 4.61 & 0.349 \\
\hline $4 / 9 / 85$ & 2486 & 41 & 0.09 & 0.130 & 0.03 & 0.390 & 4.64 & 0.354 \\
\hline $4 / 12 / 85$ & 2500 & 0 & 0.10 & 0.000 & 0.03 & 0.000 & 4.68 & 0.347 \\
\hline $4 / 15 / 85$ & 2509 & 66 & 0.11 & 0.1 .74 & 0.04 & 0.522 & 4.71 & 0.355 \\
\hline $4 / 20 / 85$ & 2532 & 48 & 0.12 & 0.216 & 0.04 & 0.349 & 4.75 & 0.325 \\
\hline $4 / 22 / 85$ & 2540 & 26 & 0.11 & 0.071 & 0.04 & 0.214 & 4.79 & 0.316 \\
\hline $4 / 24 / 85$ & 2556 & 24 & 0.20 & 0.056 & 0.03 & 0.198 & 4.82 & 0.317 \\
\hline
\end{tabular}




\section{Table C-3. Waste Transfer Data and Calculations of Plutonium Concentration} for Condition 2.a and 2.b. (9 sheets)

\begin{tabular}{|c|c|c|c|c|c|c|c|c|}
\hline 1 & & & I CONDITION & 2.2 & | CONDITIOS & $\mathrm{N} 2 . \mathrm{B}$ & & | Average \\
\hline$\cdots$ & & 1 & -+ &..--- & $++\ldots-1$ & 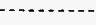 & $\cdots+\cdots$ & $++---n+\infty$ \\
\hline I (1) & (2) & (3) & 1 (4) & (5) & (6) & (7) & (8) & 1 (9) \\
\hline I DATE OF & DATA. & TOTAL & | sOLIDS & Pu & I sozids & Pu & ACCUM & | AVERAGE \\
\hline I TRANSFER & SOURCE & PLUTONIUM & I LAYER & CONC. & I LAYER & CONC. & SOLIDS & FOR THE \\
\hline i & & PBR & | HBIGHT & OVER & HEIGHT & $1 / 3$ AREA & UP To & I PREvious \\
\hline | & & TRANSFBR & I To & $1 / 3$ AREA & TO & D3 times & 8. B in & $1 \quad 10$ \\
\hline | & & $(g)$ & 126.4 in & (g Pu/L) & I B. a in & (g Pu/L) & $(i n)$ & |TRANSFERS | \\
\hline | & & & I (in) & & (in) & & & l $(g \mathrm{Pu} / \mathrm{L})$ \\
\hline$---1--4$ & 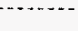 & $-0-$ & & $m=----$ & & 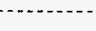 & 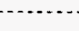 & 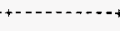 \\
\hline $4 / 28 / 85$ & 2564 & 3 & 0.12 & 0.007 & 0.04 & 0.022 & 4.86 & 0.310 \\
\hline $4 / 29 / 85$ & 2567 & 11 & 0.08 & 0.040 & 0.03 & 0.120 & 4.89 & 0.320 \\
\hline $4 / 30 / 85$ & 2571 & 23 & 0.11 & 0.061 & 0.04 & 0.184 & 4.93 & 0.267 \\
\hline $4 / 30 / 85$ & 2573 & 29 & 0.16 & 0.051 & 0.05 & 0.154 & 4.98 & 0.216 \\
\hline $5 / 1 / 85$ & 2574 & 21 & $0.1 \mathrm{~A}$ & 0.034 & 0.06 & 0.102 & 5.04 & 0.198 \\
\hline $5 / 1 / 85$ & 2574 & 1 & 0.13 & 0.002 & 0.04 & 0.006 & 5.08 & 0.165 \\
\hline $5 / 2 / 85$ & 2578 & 1 & 0.15 & 0.002 & 0.05 & 0.006 & 5.13 & 0.160 \\
\hline $5 / 16 / 85$ & 2596 & 5 & 0.11 & 0.013 & 0.04 & 0.040 & 5.17 & 0.121 \\
\hline $5 / 19 / 85$ & 2652 & 7 & 0.06 & 0.034 & 0.02 & 0.102 & 5.19 & 0.100 \\
\hline $5 / 20 / 85$ & 2659 & 24 & 0.06 & 0.126 & 0.02 & 0.377 & 5.21 & 0.102 \\
\hline $5 / 23 / 85$ & 2678 & 1 & 0.08 & 0.004 & 0.03 & 0.011 & 5.23 & $0.0 \mathrm{BB}$ \\
\hline $5 / 24 / 85$ & 2686 & 1 & 0.06 & 0.004 & 0.02 & 0.013 & 5.26 & 0.091 \\
\hline $5 / 26 / 85$ & 2704 & 1 & 0.07 & 0.004 & 0.02 & 0.012 & 5.28 & 0.084 \\
\hline $5 / 27 / 85$ & 2705 & 1 & 0.08 & 0.003 & 0.03 & 0.010 & 5.31 & 0.069 \\
\hline $5 / 29 / 85$ & 2718 & 73 & 0.11 & 0.197 & 0.04 & 0.590 & 5.34 & $0.10 \mathrm{a}$ \\
\hline $5 / 30 / 85$ & 2721 & 93 & 0.21 & 0.245 & 0.04 & 0.734 & 5.38 & 0.176 \\
\hline$E / 1 / 85$ & 2727 & 93 & 0.11 & 0.245 & 0.04 & 0.734 & 5.42 & 0.260 \\
\hline $6 / 23 / 85$ & 2777 & 46 & 0.10 & 0.133 & 0.03 & 0.400 & 5.45 & 0.314 \\
\hline $6 / 25 / 85$ & 2779 & 9 & 0.09 & 0.030 & 0.03 & 0.091 & 5.48 & 0.326 \\
\hline $6 / 26 / 85$ & 2784 & 12 & 0.07 & 0.051 & 0.02 & 0.153 & 5.50 & 0.327 \\
\hline $6 / 29 / 85$ & 2824 & 11 & 0.11 & 0.028 & 0.04 & 0.083 & 5.54 & 0.296 \\
\hline $7 / 2 / 85$ & 2807 & 1 & 0.10 & 0.003 & 0.03 & $0.00 \mathrm{~B}$ & 5.57 & 0.289 \\
\hline $7 / 4 / 65$ & 2823 & 151 & 0.10 & 0.446 & 0.03 & 1.338 & 5.61 & 0.403 \\
\hline $7 / 12 / 85$ & 2851 & 46 & 0.11 & 0.121 & 0.04 & 0.364 & 5.64 & 0.426 \\
\hline $07 / 16 / 85$ & 2874 & 53 & 0.10 & 0.159 & 0.03 & 0.478 & 5.68 & 0.463 \\
\hline $07 / 18 / 85$ & 2884 & 67 & 0.10 & 0.188 & 0.03 & 0.563 & 5.71 & 0.460 \\
\hline $07 / 21 / 85$ & 2897 & 74 & 0.10 & 0.207 & 0.03 & 0.620 & 5.74 & 0.447 \\
\hline $07 / 20 / 85$ & 2904 & 16 & 0.12 & 0.037 & 0.04 & 0.110 & 5.79 & 0.381 \\
\hline $07 / 25 / 85$ & 2915 & $5 B$ & 0.08 & 0.205 & 0.03 & 0.615 & 5.81 & 0.397 \\
\hline $07 / 28 / 85$ & 2921 & 51 & 0.13 & 0.115 & 0.04 & 0.344 & 5.85 & 0.414 \\
\hline $07 / 29 / 85$ & 2923 & 12 & 0.10 & 0.033 & 0.03 & $0.09 \mathrm{~g}$ & 5.89 & 0.401 \\
\hline $08 / 01 / 85$ & 2942 & 1 & 0.11 & 0.003 & 0.04 & 0.009 & 5.93 & 0.396 \\
\hline $08 / 01 / 85$ & 2949 & 7 & 0.10 & 0.021 & 0.03 & 0.062 & 5.96 & 0.402 \\
\hline
\end{tabular}


HNF-SD-W151-CSA-001, Rev. 1

Table C-3. Waste Transfer Data and Calculations of Plutonium Concentration for Condition 2.a and 2.b. (9 sheets)

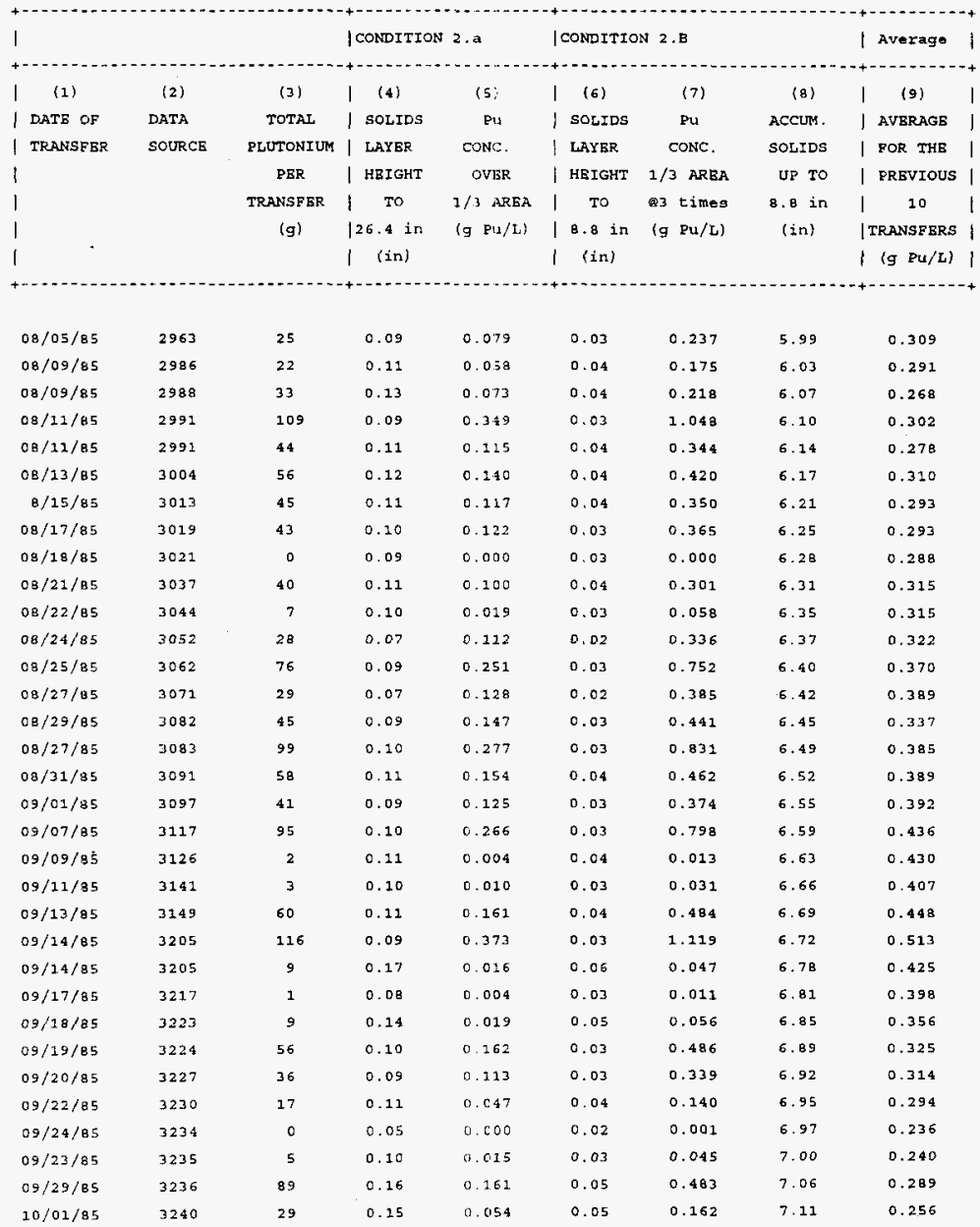


HNF-SD-W151-CSA-001, Rev. 1

Table C-3. Waste Transfer Data and Calculations of Plutonium Concentration for Condition 2.a and 2.b. (9 sheets)

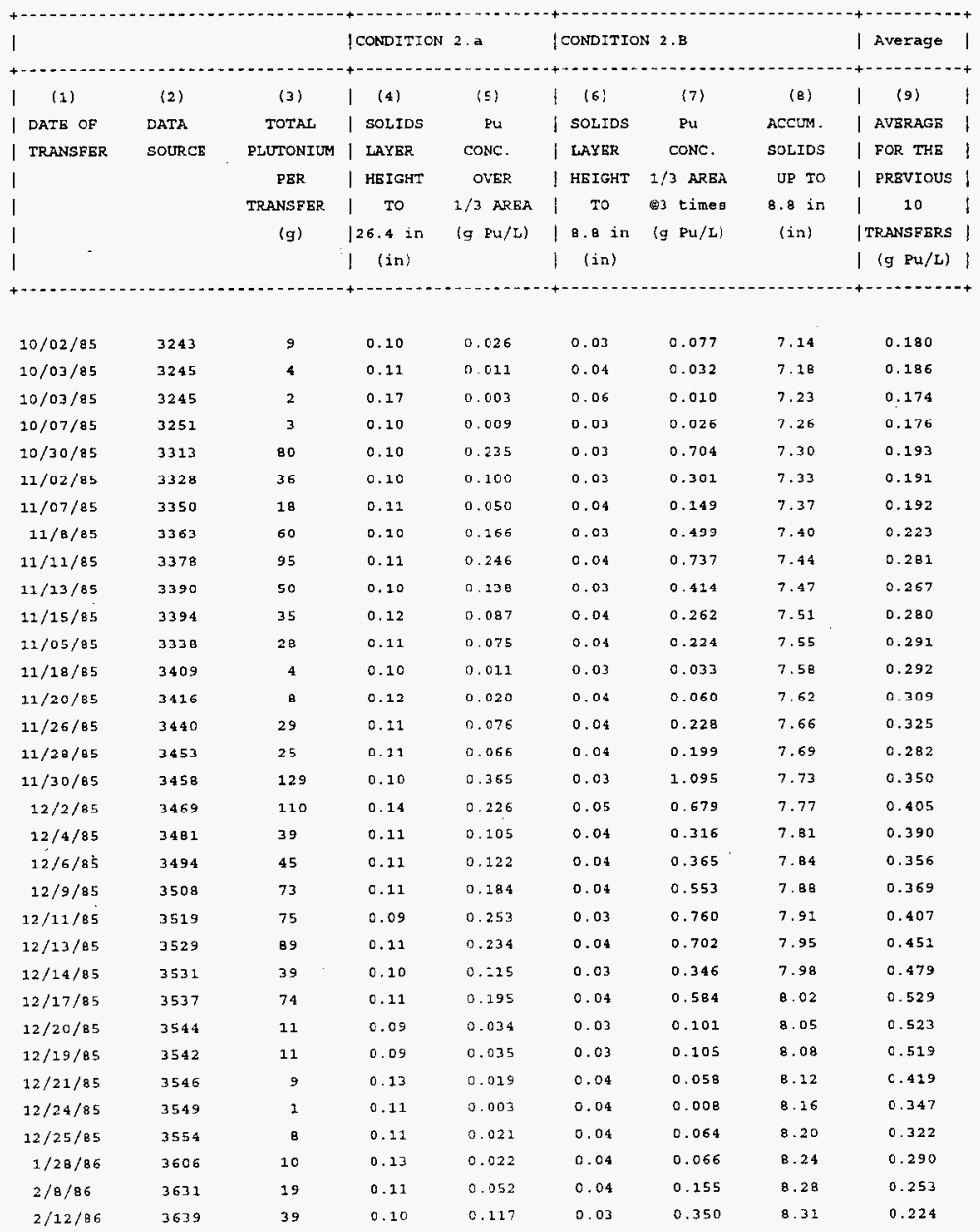


Table C-3. Waste Transfer Data and Calculations of Plutonium Concentration for Condition 2.a and 2.b. (9 sheets)

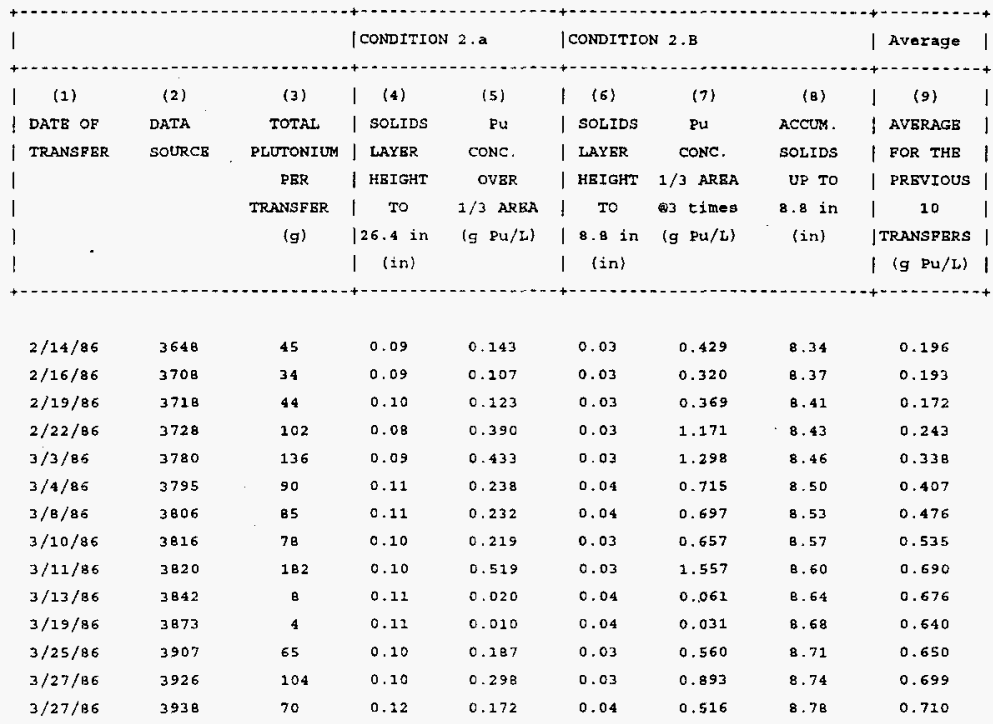


HNF-SD-W151-CSA-001, Rev. 1

\section{11 REFERENCES}

Carter, R.D., G. R. Kiel, K. R. Ridgway, 1968, Criticality Handbook, ARH-600, Atlantic Richfield Hanford Company, Richland, Washington.

Rogers, C.A., K. N. Schwinkendorf, H. Harris, 1996, Criticality Parameters for Tank Waste Evaluation, WHC-SD-SQA-CSA-507, Westinghouse Hanford Company, Richland, Washington.

Serne, R. J., G. A. Whyatt, S. V. Mattigod, Y. Onishi, P. G. Doctor, B. N. Bjornstad, M. R. Powell, L. M. Liljegren, J. H. Westsik, N. J. Aimo, K. P. Recknagle, G. R. Golcar, T. B. Miley, G. R. Holdren, D. W. Jeppson, R. K. Biyani, and G. S. Barney, 1996, Fluid Dynamic Particulate Segregation, Chemical Processes, and Natural Ore Analog Discussions that Relate to the Potential for Criticality in Hanford Tanks, WHC-SD-WM-TI-757, Westinghouse Hanford Company, Richland, Washington.

Whyatt, G. A., R. J. Serne, S. V. Mattigod, Y. Onishi, M. R. Powell, J. H. Westsik, L. M. Liljegren, G. R. Golcar, K. P. Recknagle, P. M. Doctor, V. G. Zhirnov, J. Dixon, D. W. Jeppson, and G. S. Barney, 1996, Potential for Criticality in Hanford Tanks Resulting from Retrieval of Tank Waste, PNL-11304, Pacific Northwest National Laboratory, Richland, Washington.

NMC records for the Campaigns, used in preparing Tables $\mathrm{C}-2$ and $\mathrm{C}-3$, are referenced below.

1. Durnil, J. R., Purex Perpetual Inventory Campaign \#1 Year 1983 Dissolution Process - MBA 201, RHO-PO-SR-83-00015 C) 1 BKL, Declassified, October 1983.

2. Durnil, J. R., Purex Perpetual Inventory Campaign \#2 Year 1984 Purex Plant 202-A Building, RH0-PO-SR-84-00020A0, Dec1assified, Rockwe11 Hanford Operations, 1984.

3. Light, A. R., Purex Perpetual Inventory Campaign \#3 Year 1985-86, Purex Plant 202-A, RHO-PO-SR-85-00020AO, Declassified, Rockwell Hanford Operations, 1985.

4. Light, A. R., Purex Perpetual Inventory Campaign \#4 Year 1986, Purex Plant 202-A Building, RHO-P0-SR-00020, Declassified, Rockwell Hanford Operations, 1986.

5. Light, A. R., Purex Perpetual Inventory Campaign 5 \& 6 1986-1990 Purex Plant 202-A Building-202 MBA, RHO-PO-SR-86-00020, Declassified, Rockwell Hanford Operations, 1990. 
HNF-SD-W151-CSA-001, Rev. 1

This page intentionally left blank. 
HNF-SD-W151-CSA-001, Rev. 1

APPENDIX D

PLUTONIUN MIXING SIMULATION

IN PUNP INTAKE AND hOUSING

D-1 
HNF-SD-W151-CSA-001, Rev. 1

This page intentionally left blank. 
HNF-SD-W151-CSA-001, Rev. 1

\section{PLUTONIUM MIXING SIMULATION \\ IN PUMP INTAKE AND HOUSING}

Prepared by

Y. Onishi

K. P. Recknagle

Pacific Northwest National Laboratory 
HNF-SD-W151-CSA-001, Rev. 1

This page intentionally left blank.

$$
\text { D-4 }
$$


HNF-SD-W151-ESA-001, Rev. 1

\section{APPENDIX D}

\section{PLUTONIUM MIXING SIMULATION IN PUMP INTAKE AND HOUSING}

\section{D.1 AZ-101 TANK WASTES AND RETRIEVAL}

Potential plutonium movements in the mixer pump housing during the jet mixer operation in the double-shell tank AZ-101 were evaluated using the three-dimensional computer code, TEMPEST (Trent and Eyler 1993; Onishi et al. 1995). The main objective of the simulation was to determine whether two pumps with four rotating $18.3-\mathrm{m}(60-\mathrm{ft})$ jets located $43 \mathrm{~cm}$ (17 in.) above the tank bottom can concentrate plutonium in their pump housings during mixer pump operation and cause a criticality. Following is the summary of the AZ-10I modeling study performed to address this question. The detailed study results are described in Onishi and Recknagle (1996b).

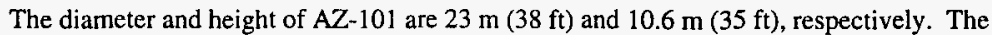
tank contains both sludge (a combination of solids and interstitial solution) and overlying supernatant liquid (Peterson et al. 1989). It contained 15 inches of sludge and 321 inches of supernatant liquid, totaling 336 inches of the tank waste; thus its volume ratio of sludge to supernatant liquid is 21.7 . Tank AZ-101 has a sludge layer with a bulk density of $1.56 \mathrm{~g} / \mathrm{mL}$, while the overlying supernatant liquid has a density of $1.22 \mathrm{~g} / \mathrm{mL}$ (Gray et al. 1993). The particle density of the average bulk sludge is $1.84 \mathrm{~g} / \mathrm{mL}$, and the weight fraction of the solids within the sludge is measured to be approximately $44 \%$ (Gray et al. 1993),

The solid particles vary in size from 0.5 to $13 \mu \mathrm{m}$, with the average size about $4 \mu \mathrm{m}$ based on the volume (Gray et al. 1993). These solids are divided into five size fractions (solids 3 through 7, as shown in Table D.1-1). The unhindered settling velocities were calculated by assigning fluid viscosity to be $2.0 \mathrm{cP}$ (Gray et al. 1.993). These particle size distributions actually represent heterogeneous agglomerates. As reported in Serne et al. (1996) and Whyat et al. (1996), solid plutonium is most likely aggregated with other precipitants. Serne et al. (1996) and Whyatt et al. (1996) also reported that if pure plutonium solids exist in the tank, they are most likely $\mathrm{PuO}_{2} \times \mathrm{H}_{2} \mathrm{O}$ and that they will be much smaller than $2 \mu \mathrm{m}$. The density of pure $\mathrm{PuO}_{2}$ is $11.4 \mathrm{~g} / \mathrm{L}$ (Whyatt et al. 1996). Thus to blanket the possible conditions, the following four types of plutonium solids were considered in this modeling: Solid 1, with the smallest particle diameter $(0.5 \mu \mathrm{m})$ and density of the aggregate $(1.84 \mathrm{~g} / \mathrm{L})$; Solid 2 , with the smallest size $(0.5 \mu \mathrm{m})$ and the largest density $(11.4 \mathrm{~g} / \mathrm{L})$; Solid 8 , with the largest particle size $(13 \mu \mathrm{m})$ and the density of an aggregate $(1.84 \mathrm{~g} / \mathrm{L})$; and Solid 9 , with the largest particle size $(13 \mu \mathrm{m})$ and the largest density $(11.4 \mathrm{~g} / \mathrm{L})$. The particle distribution and calculated unhindered settling (fall) velocity with $2 \mathrm{cP}$ viscosity are shown in Table D.1-1 for Solids 1 through 9.

Tank AZ-101 will use two mixer pumps, each with two jet nozzles. The four outlets have 6 -inch-diameter nozzles and are placed 17 inches above the tank bottom, while the pump suction line has a 18.5-inch diameter and is positioned 7 inches above the tank bottom. The volume of the pump housing was assigned to be approximately $122 \mathrm{~L}$ excluding the nozzle volume. The jet nozzles inject recirculating slurry in to the tank at a velocity of $60 \mathrm{ft} / \mathrm{s}$. These two mixer pumps are located 22 feet from the tank center on opposite ends of an imaginary diagonal line through the tank center. Each jet rotates over a half circle at the speed of $0.05 \mathrm{rpm}$. 
Table D.1-1. Particle Size Distributions of Tank AZ-101 Sludge.

\begin{tabular}{|c|c|c|c|c|}
\hline Size Fractions & $\begin{array}{l}\text { Particle Sizes } \\
(\mu \mathrm{m})\end{array}$ & $\begin{array}{l}\text { Particle Density } \\
\text { (g/L) }\end{array}$ & Weight Percent & $\begin{array}{c}\text { Fall Velocity* } \\
(\mathrm{mm} / \mathrm{s})\end{array}$ \\
\hline 1 & 0.5 & 1.84 & $<0.002$ & $4.2 \times 10^{-5}$ \\
\hline 2 & 0.5 & 11.4 & $<0.002$ & $6.9 \times 10^{-4}$ \\
\hline 3 & $0.5-2.0$ & 1.84 & 19.4 & $1.7 \times 10^{-4}$ \\
\hline 4 & $2.0-5.0$ & 1.84 & 40.9 & $1.7 \times 10^{-3}$ \\
\hline 5 & $5.0-8.0$ & 1.84 & 20.8 & $6.7 \times 10^{-3}$ \\
\hline 6 & $8.0-11.0$ & 1.84 & 14.7 & $1.5 \times 10^{-2}$ \\
\hline 7 & $11.0-13.0$ & 1.84 & 4.2 & $2.4 \times 10^{-2}$ \\
\hline 8 & 13.0 & 1.84 & $<0.002$ & $2.9 \times 10^{-2}$ \\
\hline 9 & 13.0 & 11.4 & $<0.002$ & $4.7 \times 10^{-1}$ \\
\hline Total & & & 100 & \\
\hline \multicolumn{5}{|c|}{$\begin{array}{l}\text { * An unhindered fall velocity is input to the model. TEMPEST internally calculates hindered fall } \\
\text { velocity for each particle size for the appropriate slurry conditions calculated at each } \\
\text { computational node and time step. }\end{array}$} \\
\hline
\end{tabular}

\section{D.2 TANK AZ-101 MODEL SETUP WITH THE TEMPEST CODE}

The general TEMPEST computer code can simulate flow and mass/heat transport and chemical reactions (equilibrium and kinetic reactions) coupled together (Onishi et al. 1996a). We used the T.2.10 version of TEMPEST for this study to solve three-dimensional, time-dependent equations of flow, momentum, heat, and mass transport, based on conservation of

- fluid mass (the equation of continuity)

- $\quad$ momentum (the Navier-Stokes equations)

- turbulent kinetic energy and its dissipation

- thermal energy

- mass of dissolved constituents

- $\quad$ mass of solid constituents

- mass of gaseous constituents.

Complete equations for conservation of mass, momentum, energy, and treatment of turbulence energy are documented in Trent and Eyler (1993). TEMPEST uses integral forms of the fundamental conservation laws applied in the finite volume formulation. It uses the $k-\varepsilon$ turbulence model (Rodi 1984) to solve the turbulence kinetic energy and its dissipation. TEMPEST can accommodate non-Newtonian power law fluids, as well as fluids whose rheology depends upon solid concentrations (Mahoney and Trent 1995; Onishi et al. 1995). Transport of multiple liquid, gas, and solid constituent species can be performed. 
A Tank AZ-101 conceptual model used in TEMPEST simulates the operation of two mixer pumps each with two rotating jet nozzles, as stated above. TEMPEST simulated the movements of supernatant liquid and nine different solid size fractions, as shown in Table D.1-1. The simulation was performed with nine solids instead of six (solids 3-7 and one of plutonium solids 1, 2, 8, or 9) to eliminate the need for four separate simulation runs because the plutonium-bearing solids make up a very small fraction (less than $0.002 \mathrm{wt} \%$ ) and their effects on flow and other solid movement are expected to be negligible. Tank AZ-101 TEMPEST runs were three-dimensional but covered one-half of the tank domain through symmetry of the pump jet operation.

Main parameters for the AZ-101 modeling are particle sizes and densities, solid volume fraction in the sludge, and those values needed to calculate solid settling velocities, viscosity, and yield stress. Particle size distributions are represented using the nine discrete particle sizes shown in Table D.1-1.

There are over 260 separate sludge layers containing plutonium solids, as discussed in Appendix C. Previous tank jet modeling for several Hanford double-shell tanks predicted that there is potential segregation of solids during solids settling and pump jet mixing. These TEMPEST modeling studies revealed increases of as much as about three times in concentrations of very coarse solids (100-175- $\mu \mathrm{m}$ diameters) within some parts of tanks due to jet-induced slurry flow movements and preferential settling of coarse particles over fine particles, but there is no segregation/preferential settling occurring for fine solids (less than $20-\mu \mathrm{m}$ diameter) (Whyatt et al. 1996; Onishi et al. 1996b). Nonetheless, the current modeling increases by three times the average plutonium concentration for every layer over 260 layers to make the assessment conservative.

To have the required computational time to achieve reasonable results, the number of plutonium-containing sludge layers was reduced to 35 by combining several layers to form each modeled layer. Most of the sludge layers used for modeling are between 0.2 and 0.3 inches thick. When the plutonium-containing layers were combined to form each modeled layer, the maximum plutonium concentration occurring within these several layers was assigned to the combined layer. As stated in Appendix C, there is six inches of the sludge layer in the tank bottom not containing plutonium solids. The layer containing the maximum plutonium concentration $(1.88 \mathrm{~g} / \mathrm{L})$ is located eight inches above the tank bottom. To make the sludge condition even more conservative, we reduced the thickness of this clean sludge layer to be from six inches to five inches, so that the sludge layer containing the maximum plutonium concentration will be sitting right at the pump inlet height of seven inches, instead of eight inches above the tank bottom. The initial distribution of the plutonium concentrations used in the modeling is shown in Figure D.2-1. Thus, the average plutonium concentrations over the entire sludge layers is $0.55 \mathrm{~g} / \mathrm{L}$ in the model and is higher than the actual plutonium concentration, as indicated in Appendix C. To get plutonium concentration below $0.55 \mathrm{~g} / \mathrm{L}$, the sludge must be mixed with overlaying supernatant liquid through the jet mixing.

All TEMPEST calculations assumed that the non-plutonium bearing solid particles have densities of $1.84 \mathrm{~g} / \mathrm{L}$, due to the lack of detailed information on the density of different size particles (Gray et al. 1993). Plutonium containing solids were assumed to have densities of either 1.84 or $11.4 \mathrm{~g} / \mathrm{L}$ (see Table D.1-1). The sludge layers in the AZ-101 model have a solid weight fraction of 0.54 , as measured by Gray et al. (1993). The corresponding volume fraction was estimated to be 0.44 . 
Figure D.2-1. Initial Plutonium Distribution Within AZ-1-1 Sludge Layers.

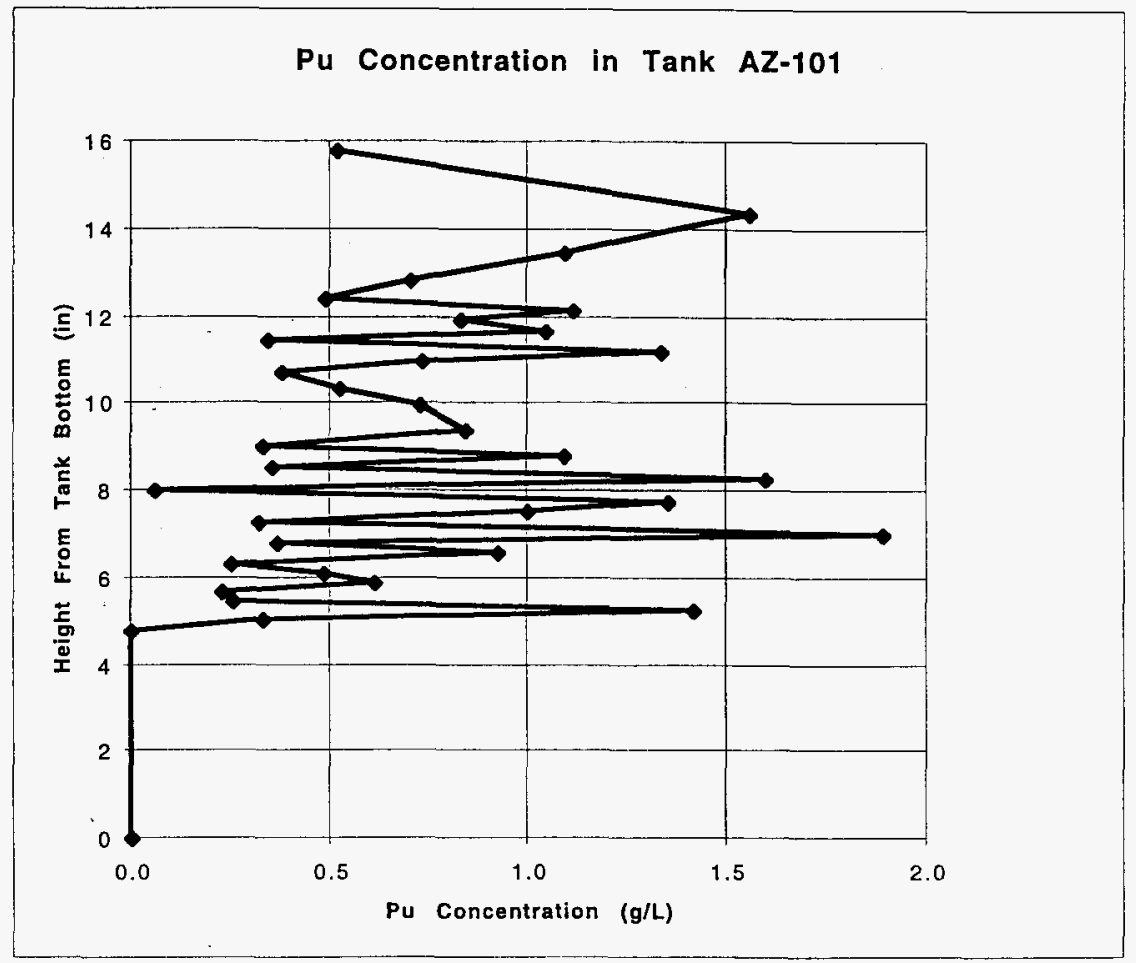

All particulates are assumed to be spherical, since there is no information available on the solid shapes. The unhindered settling velocities occurring under small solid concentrations for nine particle sizes were provided to TEMPEST by the Stokes Law (Vanoni 1973) with spherical particles. These input settling velocities do not include effects of particle interaction such as particle flocculation or agglomeration. The TEMPEST model does include the effect of hindered settling, which occurs under high solid concentrations. The unhindered settling velocity of each particle was internally adjusted by the model to account for effects of hindered settling by the following equation:

$$
V_{s}=V_{s o}(1-\beta)^{a}
$$


where

$$
\begin{array}{ll}
\mathrm{V}_{\mathrm{s}} & =\text { hindered settling velocity } \\
\mathrm{V}_{\mathrm{so}} & =\text { input settling velocity (unhindered settling velocity) } \\
\beta & =\mathrm{C}_{\mathrm{v}} / \mathrm{C}_{\mathrm{vmax}} \\
\mathrm{C}_{\mathrm{v}} & =\text { solid volume fraction in slurry } \\
\mathrm{C}_{\mathrm{v} \max } & =\text { maximum solid volume fraction }(=0.44 \text { in this study) } \\
\mathrm{a} & =4.7 \text { (based on the Stokes Law). }
\end{array}
$$

Turbulent Reynolds stresses are modeled through an effective viscosity. The PrandtlKolmogrov hypothesis is used to relate the effective viscosity to a velocity and a length scale. In this approach, transport equations for the turbulent kinetic energy (k) and the dissipation of turbulent kinetic energy ( $\varepsilon$ ) are solved by the $k-\varepsilon$ model to determine the effective turbulent (eddy) viscosity, $\mu_{\mathrm{T}}$ as

$$
\mu_{\mathrm{T}}=\mathrm{C}_{\mu} \rho \mathrm{k}^{2} / \varepsilon
$$

where

$$
\begin{array}{ll}
\mathrm{C}_{\mu} & =\text { constant equal to } 0.09 \\
\rho & =\text { fluid density } \\
\mathrm{k} & =\text { turbulent kinetic energy } \\
\varepsilon & =\text { dissipation of turbulent kinetic energy. }
\end{array}
$$

For the TEMPEST calculations of Tank AZ-101, a measured value for the supernatant liquid density $(1.22 \mathrm{~g} / \mathrm{mL})$ and the molecular viscosity of the supernatant liquid, $2 \mathrm{cP}$, were used for the supernatant liquid.

The slurry molecular viscosity is then calculated by multiplying the molecular viscosity of the base fluid by a factor of "b" raised to the power " $\beta$," as shown in Equation D.3.

$$
\mu=\mu_{T} b^{\beta}
$$

where

$$
\begin{array}{ll}
\mu_{\mathrm{T}} & =\text { base fluid viscosity }(=2.0 \mathrm{cP} \text { in this study }) \\
\mathrm{b} & =\text { ratio of the sludge viscosity to supernatant liquid viscosity } \\
\beta & =\mathrm{C}_{\mathrm{v}} / \mathrm{C}_{\mathrm{vmax}}
\end{array}
$$

This equation, which does not explicitly include the strain rate, was selected in a previous efforts to model the pump jet mixing in SY-102 (Onishi et al. 1996b), slumy injection into AY-102 (Whyatt et al. 1996; Seme et al. 1996), pumping out sluiced sludge from C-106 (Whyatt et al. 1996; Serne et al. 1996), and periodic rollover and gas release processes in tank SY-101 (Trent and Michener 1993). The value of " $b$ " was determined by dividing a high viscosity intended to represent a very high solids concentration $\left(C_{v}=C_{v \max }=0.44\right)$ by the viscosity of the supernatant $\left(C_{v}=0\right)$. Measured viscosities of diluted $A Z-101$ sludge were 10 to $40 \mathrm{cP}$ for $10 \mathrm{wt} \%$ slurry and 40 to $150 \mathrm{cP}$ for $30 \mathrm{wt} \%$ slurry (Gray et al. 1993). Thus we selected the viscosity of the sludge $\left(C_{v}=C_{v m a x}=0.44\right)$ to be 20 Pas-s. The variation of viscosity with the solid fraction used in the 
Figure D.2-2. Variation of Viscosity with Solid Concentrations for Sludge Viscosity of $20 \mathrm{~Pa}-\mathrm{s}$ and $\mathrm{C}_{\mathrm{vmax}}$ of 0.44 .

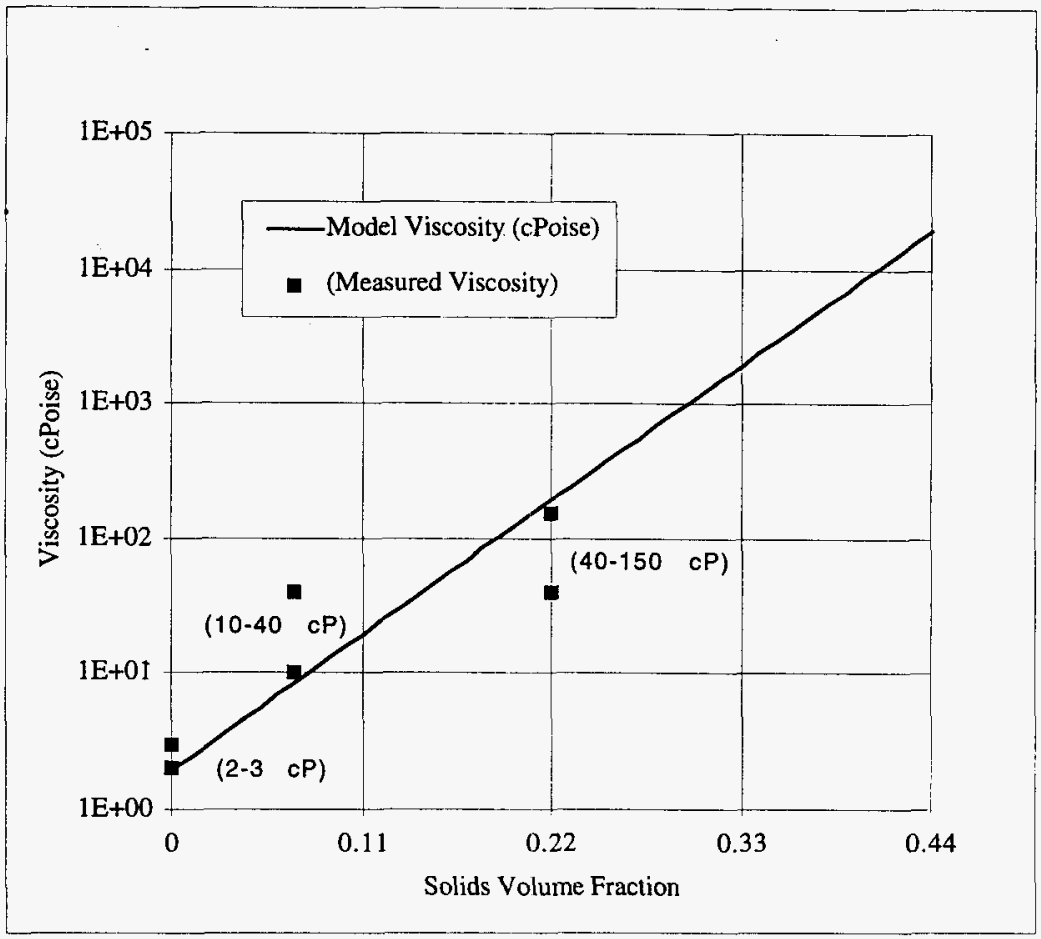

Figure D.2-2. Variation of Viscosity with Solid Concentrations for Sludge Viscosity of 20 Pa-s and $C_{\mathrm{rmax}}$ of 0.44 .

AZ-101 model is shown in Figure D.2-2 with these measured values. The molecular viscosity of the slurry is added to the turbulent viscosity, and the sum is used in fluid dynamic calculations.

Since the sludge in Tank AZ-101 is believed to have only small yield stress (Grey et al. 1993 unpublished report) and the current study is mostly concerned the sludge movements in and around the pump (high velocity areas), this study did not include the yield stress in the simulations. While TEMPEST has the capability to model diffusive effects on solutes and particles, the input was intentionally selected to eliminate diffusive effects to compensate potential numerical diffusion effects on the tank waste transport. 
HNF-SD-W151-CSA-001, Rev. 1

\section{D.3 MODEL APPLICATIONS AND RESULT EVALUATIONS}

We simulated movements, settling, and mixing of nine solids (see Table D.1-1) and supernatant liquid in Tank AZ-101 with TEMPEST to evaluate if two pumps having four rotating $18.3-\mathrm{m}(60-\mathrm{ft})$ jets can sufficiently concentrate plutonium within the pump housing to cause a criticality problem. Rotating jets with $0.5 \mathrm{rpm}$ were assigned at $22 \mathrm{ft}$ off the tank center.

Previous jet mixing simulations for AZ-101 and similar SY-101 tanks indicated that 6-inch diameter, $60-\mathrm{ft} / \mathrm{s}$ jets are very effective to mix the sludge and supernatant liquid to form a mostly homogeneous mixture. These studies also indicated that it will take 10 minutes to two hours to mix most of the wastes in these tanks, depending on the jet and sludge conditions (Onishi et al. 1996b; Antoniak and Recknagle 1996).

Since the maximum plutonium concentration in the pump housing is expected to occur at the very early stage of the jet mixing operation before much of the sludge and supernatant liquid are being mixed within the tank, we set up two cases with identical conditions, except that the starting directions of the jets covered both ends of the early jet mixing conditions. For Case 1, the jets initially point approximately in the 11 o'clock position (the direction of the longest distance to the tank wall) and the $50^{\prime}$ clock position ( $180^{\circ}$ from the $110^{\prime}$ clock position). In Case 2 , the jet is initially directing at the 3 o'clock position (the shortest distance to the tank wall) and 9 o'clock (toward the tank center). As stated above, all these jets are rotating at $0.5 \mathrm{rpm}$ (or for minutes to sweep $180^{\circ}$ ). The pump was assumed to have an initial ramp-up time of 20 seconds to reach full $60 \mathrm{ft} / \mathrm{s}$.

The previous modeling studies for tanks, including AZ-101 (Whyatt et al. 1996; Antoniak and Recknagle 1996), reveal that when they are not operated, air lift circulators do not change flow patterns near the tank bottom, since the bottoms of the air lift circulators are 30 inches above the tank bottom. Since the sludge thickness is about 15 inches, the air lift circulators have very little effect on the sludge movement (Antoniak and Recknagle 1996). Jet-induced flows move around the circulators and show minor wakes behind the circulators, but these effects on the overall flow patterns are minimal. When the circulators are operated, the induced slurry flows can lift sludge around the circulators (Eyler 1983), probably less than $1 \mathrm{~m}$ from the edge of the circulators (Whyatt et al. 1996). Since the mixing of the sludge by circulators will homogenize the sludge, this study did not include the air lift circulator effects in the modeling.

The predicted results presented here is excerpted from a more detailed Pacific Northwest National Laboratory report on this subject (Onishi and Recknagle 1996). Predicted jet induced velocity at 1.5 minutes for Case 1 are shown in Figures D.3-1 for the area from the pump to the tank wall and from the tank bottom to the surface of the supernatant liquid. Figure D.3-2 shows the part of Figure D.3-1 that is in the proximity of the pump. Figure D.3-3 shows the predicted velocity in the area from the pump to the tank wall but just within $0.9 \mathrm{~m}$ of the tank bottom for Case 2. As stated previously, the center of the 6-inch-jet nozzle is 17 inches above the tank bottom, and the surface of the sludge in the model is more than one inch below the nozzle centerline. At this time ( 1.5 simulator minutes), the jets are already rotated $27^{\circ}$ away from the original jet directions. Figures D.3-1 and D.3-3 indicate that the jets are reaching the tank wall with a small reverse flow there moving back toward the pump just above the tank bottom. The significant difference in the distance from the pump to the tank wall between these two jet directions initially makes the velocity distributions somewhat different around the tank wall between the two cases, but as the jets rotating away from the initial directions, these flow differences become smaller. The flow around the pump are relatively similar between these two cases even in the early times. 
HNF-SD-W15]-CSA-001, Rev. 1

Figure D.3-1. Predicted Velocity Distribution at 1.5 Simulation Minutes for Case 1.

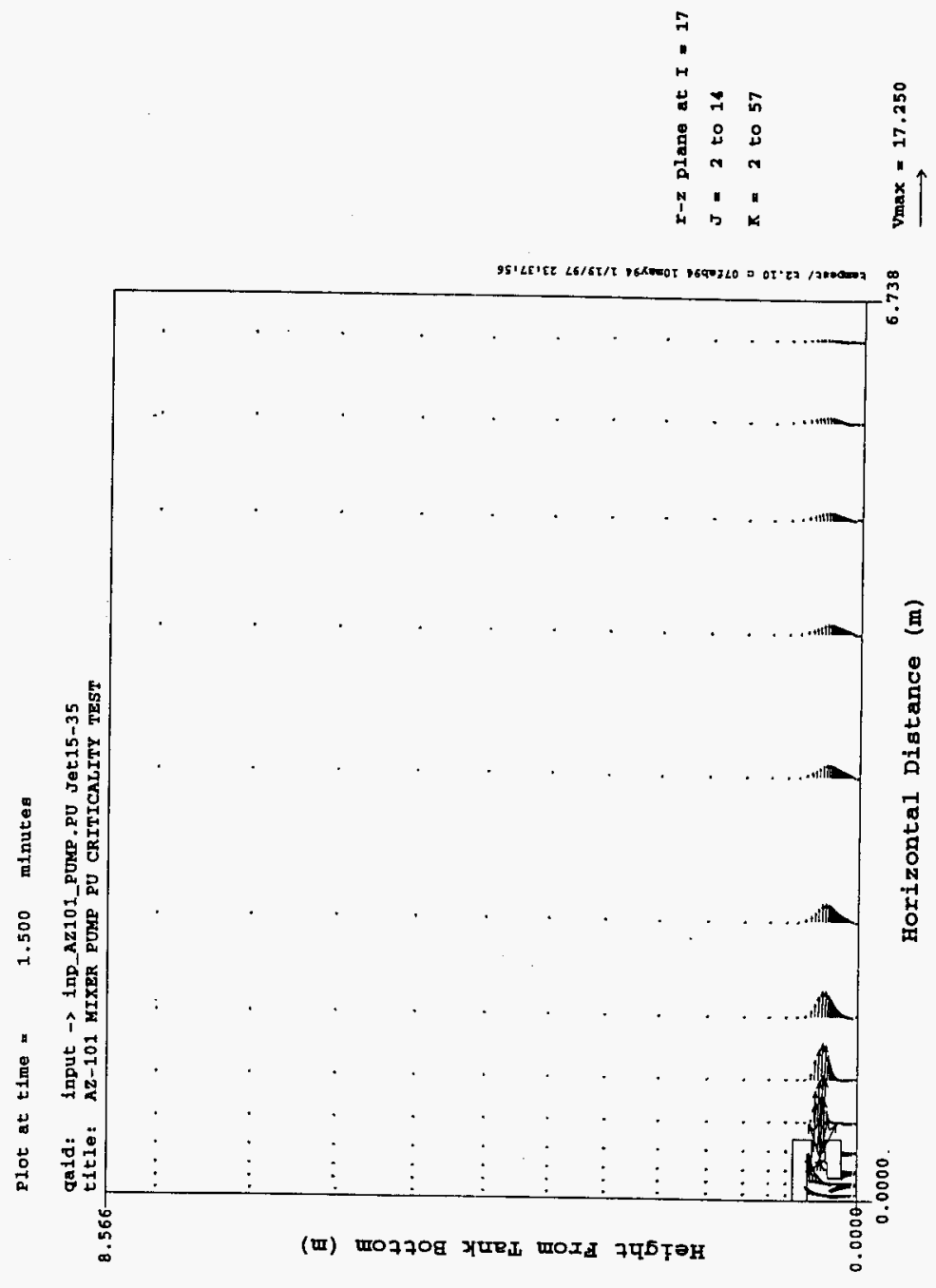


HNF-SD-W151-CSA-001, Rev. 1

Figure D.3-2. Predicted Velocity Distribution in and around the Pump at 1.5 Simulation Minutes for Case 1.

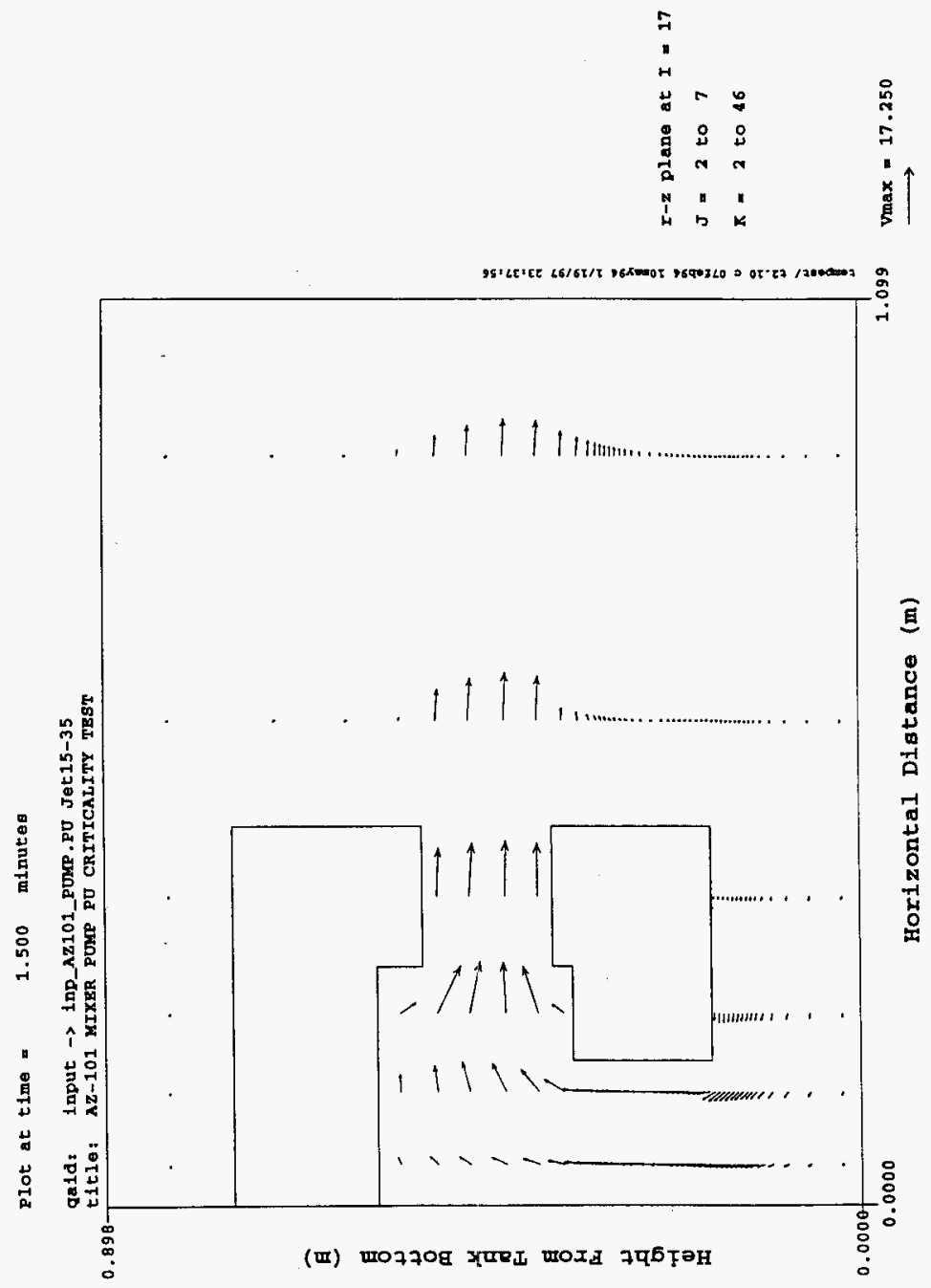


HNF-SD-W151-CSA-001, Rev. 1

Figure D.3-3. Predicted Velocity Distribution near the Tank Bottom at 1.6 Simulation Minutes for Case 2 .
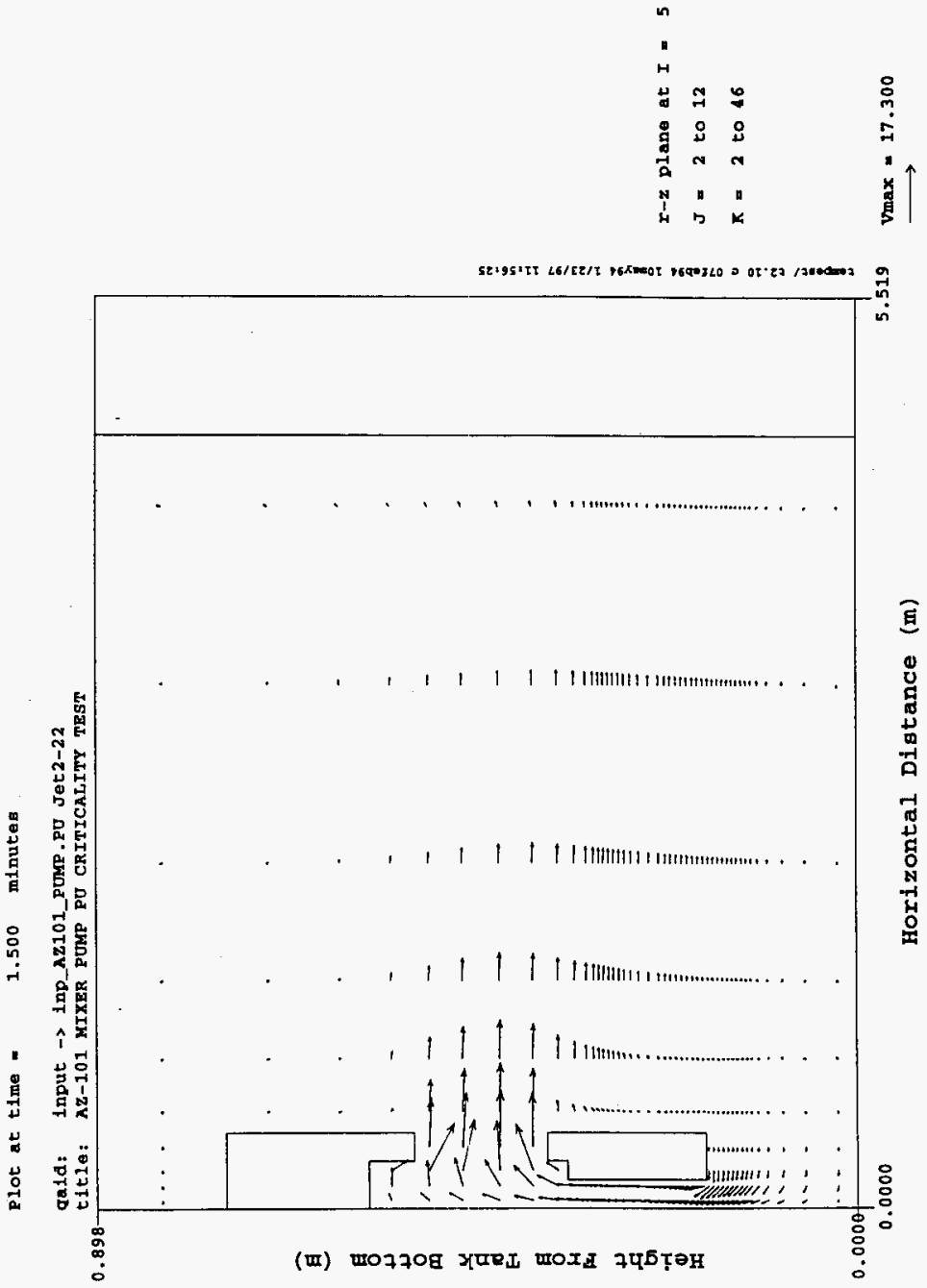
Predicted plutonium concentrations in the pump housing show the overall reduction of concentrations over the first 1.5 minutes with several peaks along the way, as shown in Figures D.3-4 for Solid 1 (lightest and smallest plutonium-bearing solid) and D.3-5 for Solid 9 (the heaviest and largest plutonium-bearing solid) of Case 1, and Figures D.3-6 for Solid 1 and D.3-7 for Solid 9 of Case 2 . Numbers 1 and 2 in these figures indicate predicted plutonium concentrations at each of the two hemispheres just inside of the pump inlet (the bottom of the pump housing). Numbers 27 and 28 are at two hemispheres at the top of the pump housing. Plutonium concentrations of different solids (Solids 1, 2, 8, and 9) are very similar within the pump housing, as shown for Solids 1 and 9 in these four figures. Because of the large flow velocity inside and around the pump, the different densities and sizes of these solids do not make a significant difference in their movements. As indicated in previous tank jet mixing (Onishi et al. 1996b), these differences become more apparent in the areas away from the pump, such as near the tank wall, due to preferential settling of some heavier, larger particles.

There are several plutonium concentration peaks over 1.5 -minute simulations, as seen in these four figures. The first plutonium concentration peak of $0.9 \mathrm{~g} / \mathrm{L}$ occurs at the bottom of the pump at approximately 0.3 second; the second peak of approximately $0.6 \mathrm{~g} / \mathrm{L}$ appears at around 10 seconds. The third peak of approximately 0.25 to $0.4 \mathrm{~g} / \mathrm{L}$ occurs at around $40-50$ seconds, showing some difference between the two cases, reflecting their difference on reverse flows around the tank wall around this time. Each succeeding peak is of reduced maximum value with time for both cases. After one minute, the plutonium very gradually decreases in concentration within the pump housing over time, and at 1.5 minutes, all plutonium concentrations within the pump are approximately $0.2 \mathrm{~g} / \mathrm{L}$.

Figure D.3-8 shows predicted concentrations of Solid 9 (heaviest and largest plutonium solid) at four locations within the pump housing over the first 10 seconds for Case 1 . Numbers 2 , 16,26 , and 28 in this figure represent plutonium concentrations at the bottom, 1/3 up, $2 / 3$ up, and at the top of the pump housing. As clearly shown here, the highest plutonium concentration, $0.9 \mathrm{~g} / \mathrm{L}$, occurs only at the pump bottom at 0.3 second, as plutonium from the sludge layer (with the highest concentration of $1.88 \mathrm{~g} / \mathrm{L}$ ) just below the pump intake is initially drawn into the pump without much dilution. But as this initial pulse of the high plutonium concentration moves up within the pump housing, the plutonium concentration is reduced significantly, such that at the top of the pump housing (See plutonium concentration with Number 28), there is no predicted increase in the plutonium concentration. This is also clearly indicted by Figure D.3-9, showing the distribution of Solid 9 plutonium concentrations at 0.3 seconds for Case 1 . This figure depicts that there is an original high plutonium sludge layer at the pump intake level, but immediately below the pump intake opening, plutonium concentrations are already diluted from the original $1.88 \mathrm{~g} / \mathrm{L}$ by the pump, which is also withdrawing the sludge from layers of less or no plutonium concentraions. Within the pump near the pump inlet, this high plutonium concentration of approximately $0.9 \mathrm{~g} / \mathrm{L}$ is rapidly reducing its concentration, as clearly seen in Figure D.3-9.

As indicated in Figures D.3-4 through D.3-7, plutonium also peaks within the pump housing around 10 seconds. At that time, predicted plutonium concentrations within the pump housing are fairly uniform for all plutonium solids (Solids 1, 2, 8, and 9). Figures D.3-10 and D.3-11 show predicted Solid 1 (the light and smallest) and 9 (the heaviest and largest) plutonium concentrations in and around pump in the vertical plane along 11 clock position for Case 1 . The predicted Solid 9 plutonium distribution along the 3 o'clock position for Cases 1 and 2 is also shown in Figures D.3-12 and D.3-13. The jets are injecting the sludge at the 11 o'clock position for Case 1 and $30^{\prime}$ clock position for Case 2 (Figures D.3-10 and D.3-13), showing jets penetrating into and mixing with the sludge layers. These figures also show that the pump is withdrawing the sludge not only from the layer with the highest plutonium concentration 
(originally $1.88 \mathrm{~g} / \mathrm{L}$ ), but also suctioning the sludge from other layers that contain little or no plutonium. As a result of this suction flow pattern, the high plutonium-containing layers and low and non-plutonium-containing layers are mixing together to lower the highest plutonium concentration in the sludge layer. This mixing also makes plutonium penetrate into the layers near the tank bottom, where there was none originally. These figures also show relatively uniform plutonium concentrations of 0.42 to $0.64 \mathrm{~g} / \mathrm{L}$ throughout the pump in both cases.

Predicted distributions of the solids at 40 seconds show the similar distribution patterns at 10 seconds, except there are more mixing and dilution occurring at 40 seconds, as an example shown in Figures D.3-14 for Solid 9 plutonium.

At 1.5 simulation minutes, the mixing and dilution are progressing, as evidenced by the predicted distributions of Solid 4 concentrations in the vicinity of the pump (see Figure D.3-15). Solid 4 has the particle diameter of 2 to $5 \mu \mathrm{m}$ and consists of $40.9 \mathrm{vol} \%$ of the total solids in the AZ-101 sludge (See Table D.1-1). The concentration of Solid 4 within the pump at 1.5 minutes is between approximately 110 to $160 \mathrm{~g} / \mathrm{L}$. Since this solid was originally distributed uniformly within the sludge layers with its concentration of $331 \mathrm{~g} / \mathrm{L}$, Solid 4 concentration in the pump housing suggests that the sludge was diluted approximately two to three times by the supernatant liquid by this time. Predicted Solids 1 and 9 plutonium concentrations are very similar to each other in and around the pump,and are approximately $0.2 \mathrm{~g} / \mathrm{L}$ within the pump, as shown in Figures D.3-16 and D.3-17, respectively.

Figures D.3-18 and D.3-19 summarize the model results, showing plutonium total amount and its average concentration in the entire pump housing for both Case 1 (initially 11 and 5 o'clock jet directions) and Case 2 (initially 3 and 9 o'clock jet directions). These two figures reveal that the plutonium trends are similar to those shown in Figures D.3-4 though D.3-7. The total amount of plutonium within the pump housing peaks at $75 \mathrm{~g}$ at 10 simulation seconds and decreases with time to less than $25 \mathrm{~g}$ at 100 seconds. The difference between Cases 1 and 2 at $40-50$ seconds is attributed to Case 2's more vigorous early mixing of sludge near the tank wall. This is because its jet is initially directed in the shortest distance to the tank wall, while the Case 1 jet is initially directed toward the farthest distance to the wall. But these differences disappear as the time goes to 80 seconds. Similarly, the average plutonium concentration in the entire pump housing peaks at $0.6 \mathrm{~g} / \mathrm{L}$ at 10 simulation seconds, and is reduced to below $0.2 \mathrm{~g} / \mathrm{L}$ as time goes beyond 100 seconds.

These predicted maximum total amounts $(75 \mathrm{~g})$ and concentrations $(0.6 \mathrm{~g} / \mathrm{L})$ in the entire pump housing are much lower than the plutonium conditions needed to reach a criticality level.

\section{D.4 SUMMARY AND CONCLUSIONS}

Three-dimensional simulation was performed with the TEMPEST code to determine whether the pump jet mixing operation of Tank AZ-101 will concentrate plutonium in the pump housing and cause a criticality. With conservative initial distributions of plutonium, the simulation predicted that the maximum plutonium amounts and concentrations in the pump housing are $75 \mathrm{~g}$ and $0.6 \mathrm{~g} / \mathrm{L}$, respectively, at 10 seconds, and that these values decrease with time to be less than $25 \mathrm{~g}$ and $0.2 \mathrm{~g} / \mathrm{L}$, respectively, at 100 seconds. These values are much lower than are needed to reach a criticality level. Thus, the pump jet mixing operation of AZ-101 will not produce sufficient plutonium distributions within the pump housing to cause a criticality. 
Figure D.3-4. Predicted Time-Varying Solid 1 Pu Concentrations within Pump Housing over Two Simulation Minutes for Case 1.

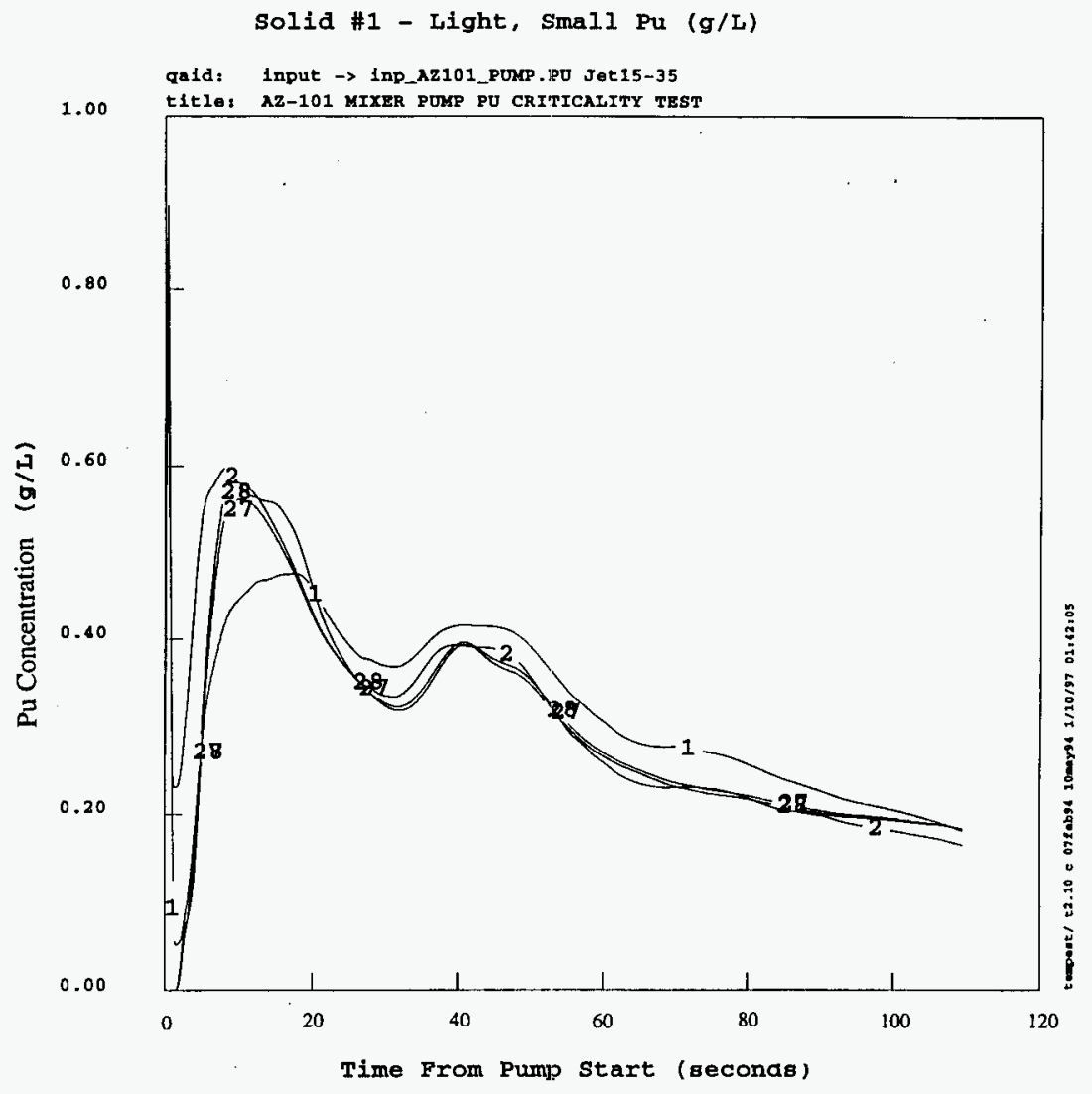


Figure D.3-5. Predicted Time-Varying Solid 9 Pu Concentrations within Pump Housing over Two Simulation Minutes for Case 1.

Solid \#9 - Heavy, Large Pu (g/L)

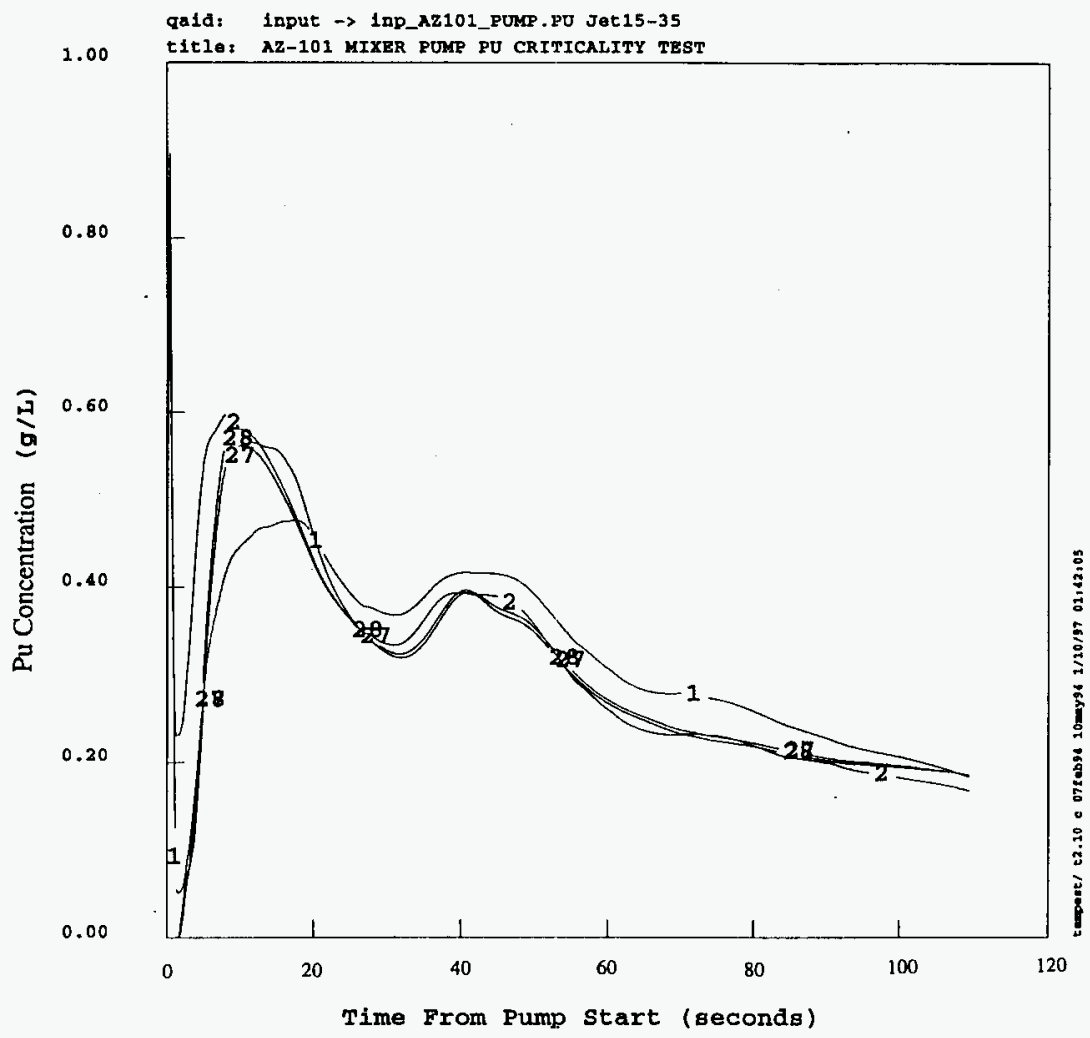

Figure D.3-5 Predicted Time-Varying Solid 9 Pu Concentrations within Pump Housing over Two Simulation Minutes for Case 1 
Figure D.3-6. Predicted Time-Varying Solid 1 Pu Concentrations within Pump Housing over Two Simulation Minutes for Case 2.

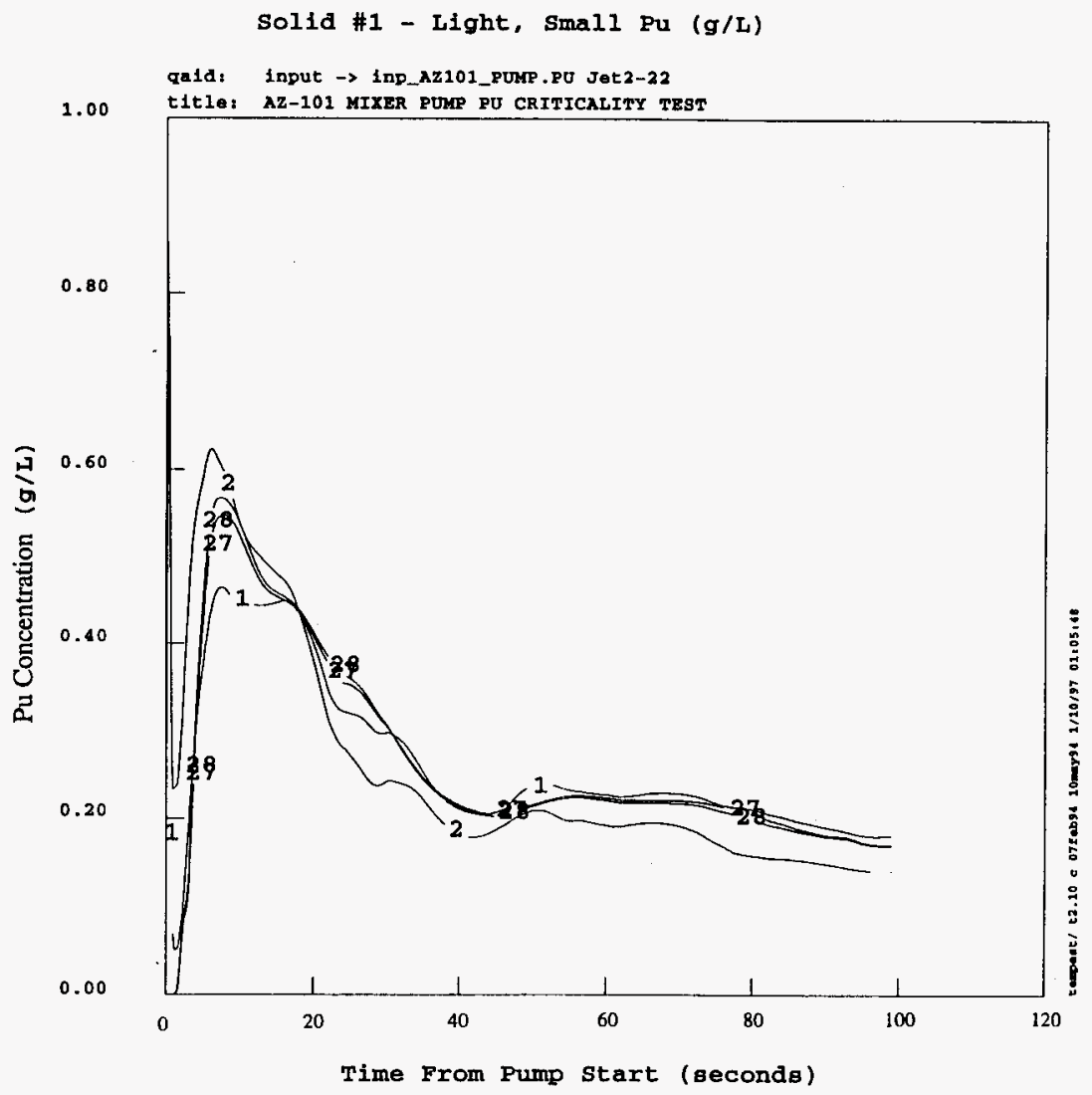

Figure D.3-6 Predicted Time-Varying Solid 1 Pu Concentrations within Pump Housing over Two Simulation Minutes for Case 2 
HNF-SD-W151-CSA-001, Rev. 1

Figure D.3-7. Predicted Time-Varying Solid 9 Pu Concentrations within Pump Housing over Two Simulation Minutes for Case 2.

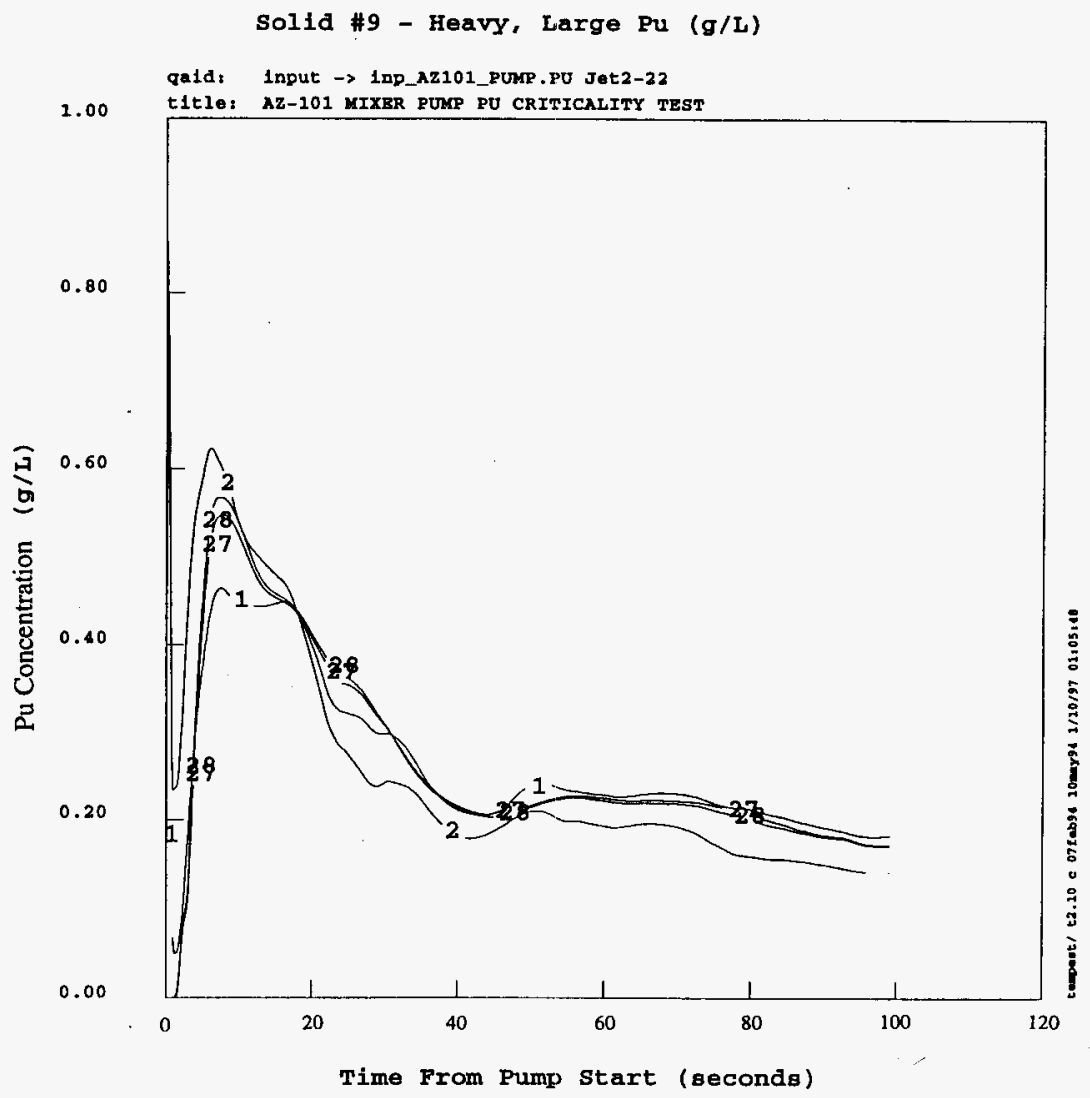

Figure D.3-7 Predicted Time-Varying Solid 9 Pu Concentrations within Pump Housing over Two Simulation Minutes for Case 2 
HNF-SD-W151-CSA-001, Rev. 1

Figure D.3-8. Predicted Time-Varying Solid 9 Pu Concentrations within Pump Housing over 10 Simulation Minutes for Case 1.

Solid \#9 - Heavy, Large Pu

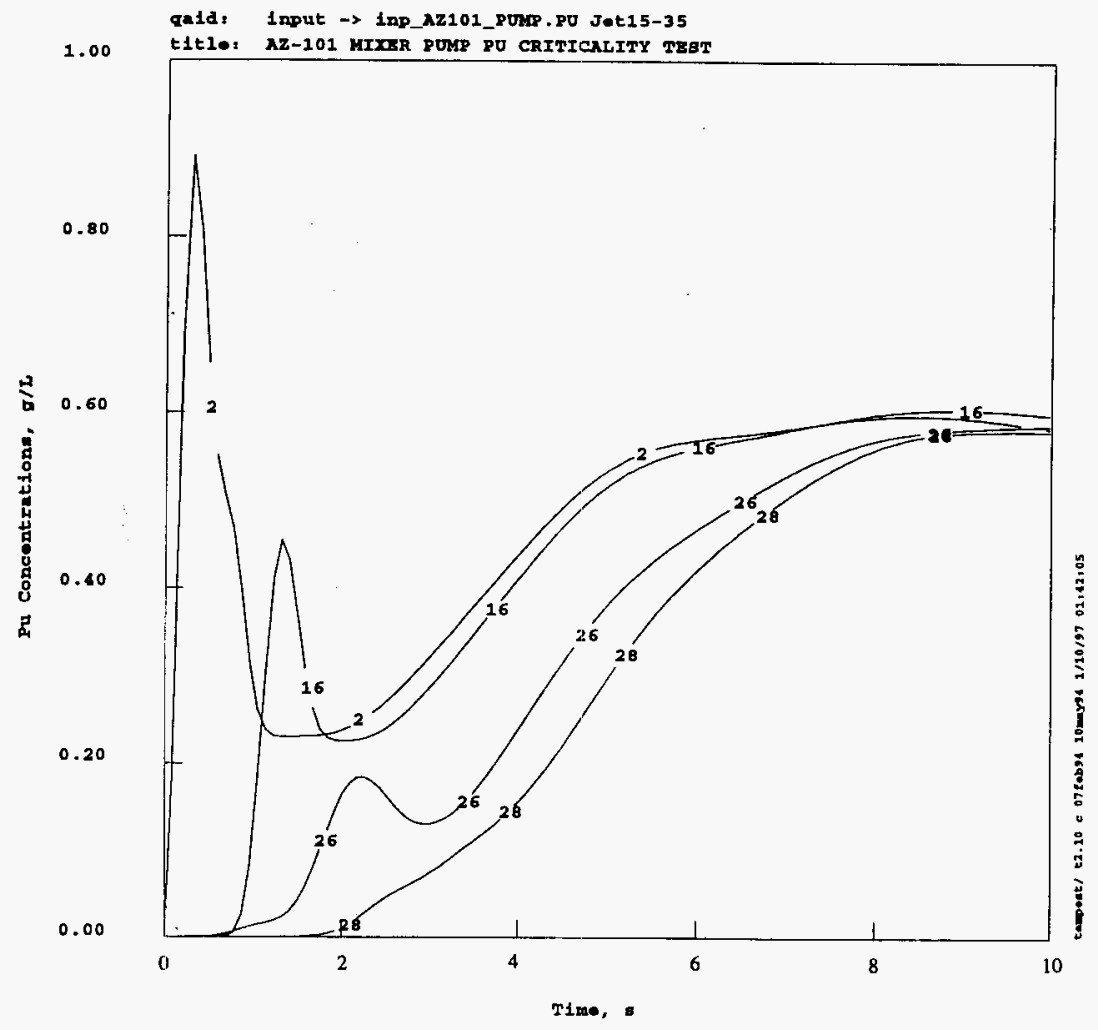


Figure D.3-9. Predicted Distribution of Solid $9 \mathrm{Pu}$ Concentrations on 11 Clock Position at 0.3 Simulation Seconds for Case 1.
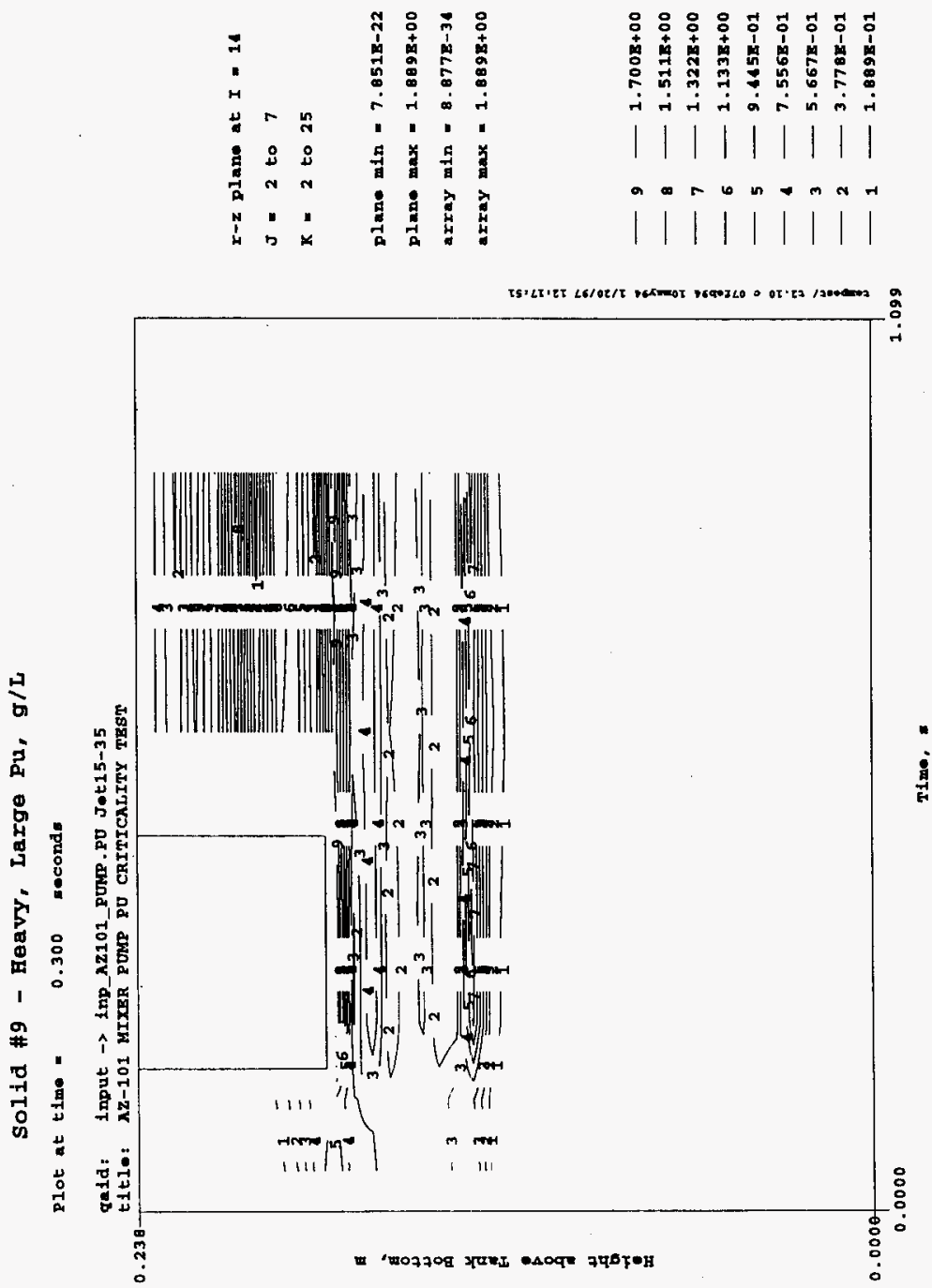
Solid \#1 - Light, Small Pu (g/L)

plot at time $=\quad 10.000$ reconds

ge1d: Input $\rightarrow$ 1np_Az101_PUMP.PU Jet15-35

title: AZ-101 MIXER PUMP PU CRITICALITY TEST

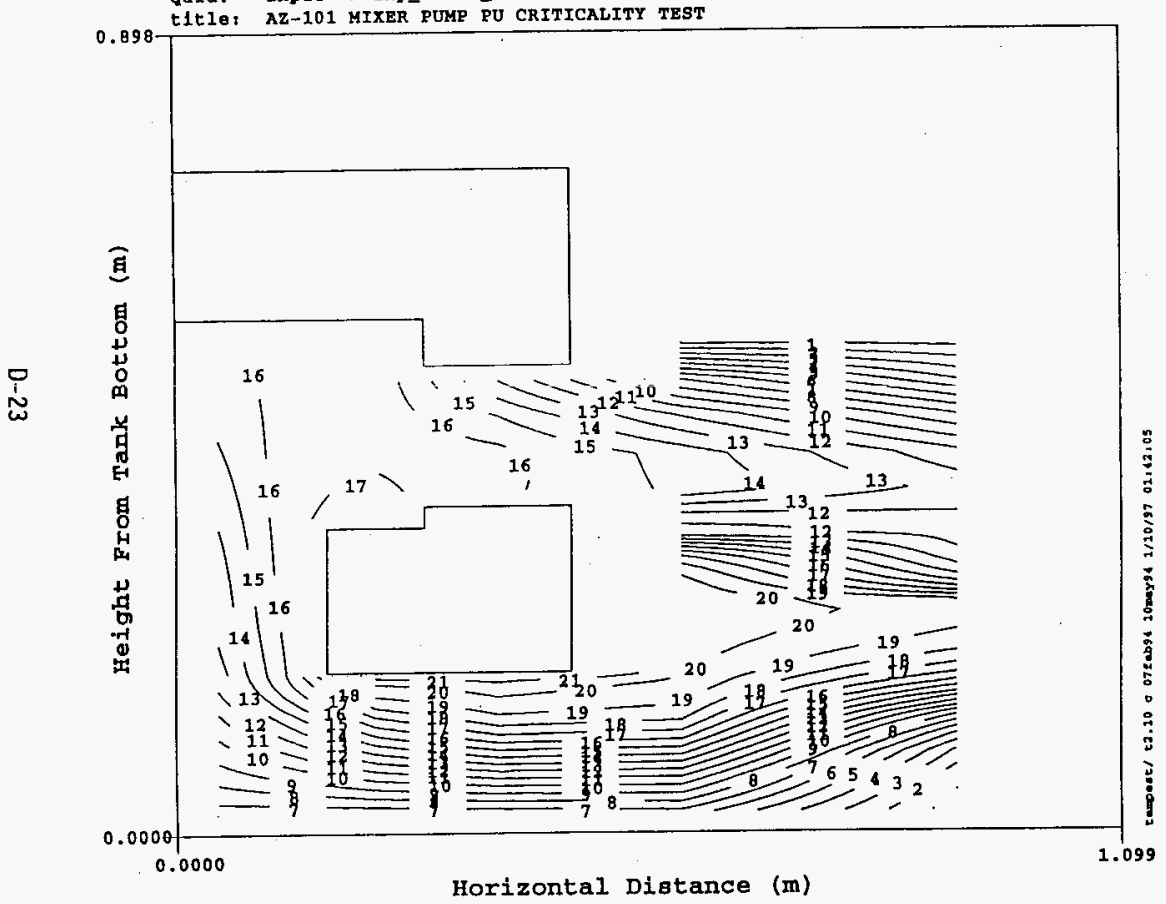

$x-z$ plane at $I=14$

$J=2$ to 7

$\pi=2$ to 46

Dlane min $=1.000 \mathrm{E}-05$ plane $\max =8.596 \mathrm{E}-01$

array min $=4.403 \mathrm{E}-26$

array $\max =1.882 \mathrm{E}+00$

$\longrightarrow 21-7.500 \mathrm{E}-01$

- $20-7.1378-01$

- $19-6.775 \mathrm{E}-01$

- $18-6.412 \mathrm{E}-01$

$-17-6.050 \mathrm{E}-01$

$-16-5.687 \mathrm{~B}-01$

- $15-5.325 \mathrm{E}-01$

$-14-4.963 \mathrm{~B}-01$

$-13-6.600 \mathrm{E}-01$

$-12-4.238 \mathrm{E}-01$

$-11-3.875 \mathrm{E}-01$

- $10-3.513 \mathrm{E}-01$

- $9-3.150 \mathrm{E}-01$

- $8-2.787 \mathrm{E}-01$

- $2.425 \mathrm{E}-01$

- $-2.062 \mathrm{E}-01$

- $5-1.700$ B-01

$-1.338 \mathrm{E}-01$

- $3-9.750 \mathrm{E}-02$

- $2-6.125 \mathrm{E}-02$

- $1-2.500 \mathrm{E}-02$ 
Solid \#9 - Heavy, Large Pu (g/L)

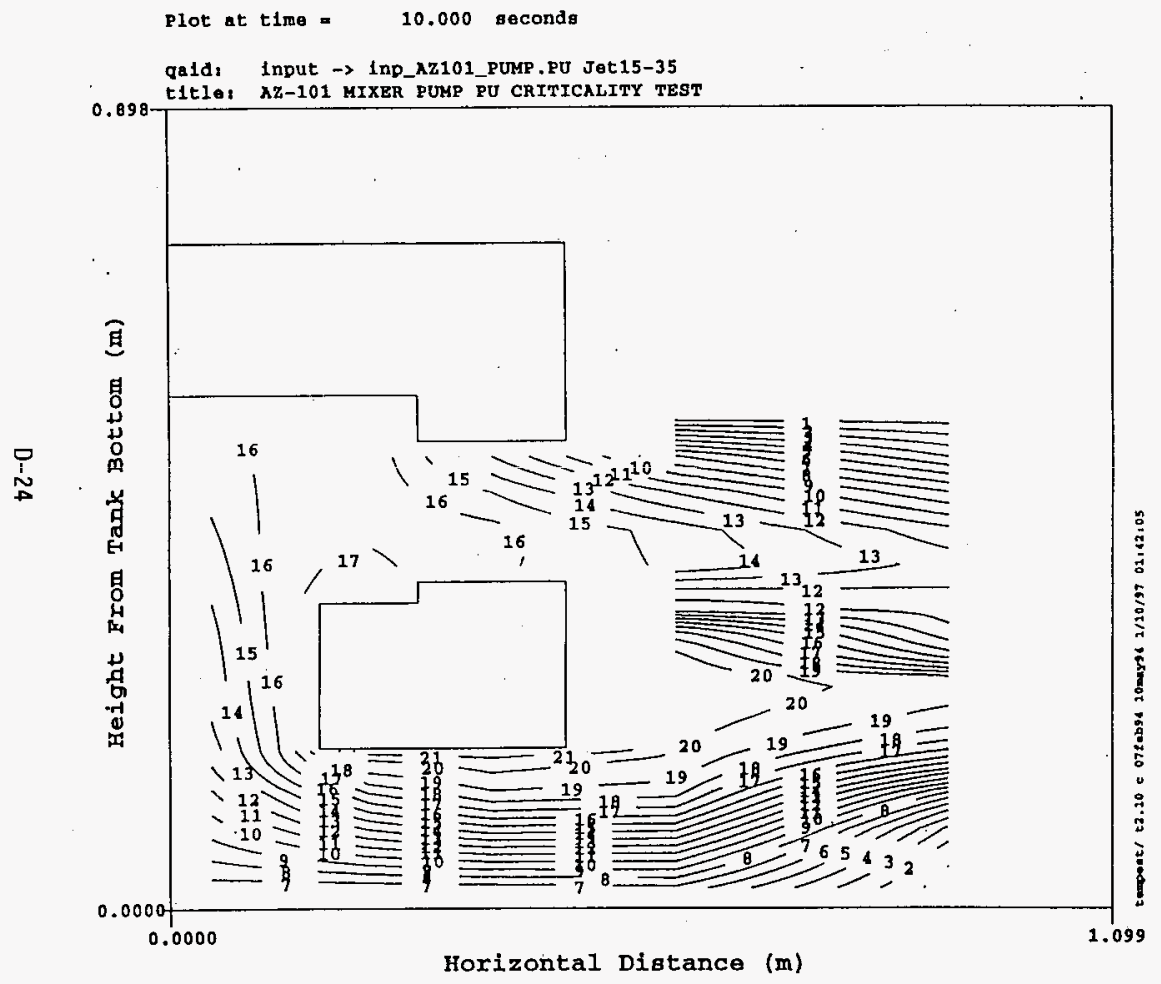

$r-z$ plane at $I=14$

$J=2$ to 7

$K=2$ to 46

plane min = $1.011 \mathrm{E}-05$

plane $\max =8.596 \mathrm{E}-01$

array $\mathrm{min}=4.4038-26$

array $\max =1,882 \mathrm{~B}+00$

- $21-7.500 \mathrm{E}-01$

$-20-7.137 \mathrm{E}-01$

$-19-6.775 \mathrm{E}-01$

- $18-6.412 \mathrm{E}-01$

$-17-6.050 \mathrm{E}-01$

$-16-5.6878-01$

- $15-5.325 \mathrm{E}-01$

$-14-4.963 \mathrm{E}-01$

- $13-4.600 \mathrm{~g}-01$

- $12-4.238 \mathrm{E}-01$

$-11-3.675 \mathrm{E}-01$

$-10-3.513 \mathrm{E}-01$

$-9-3.150 \mathrm{E}-01$

- $8-2.787 \mathrm{E}-01$

- $7-2.425 \mathrm{z}-01$

$-6-2.062 \mathrm{E}-01$

$-5-1.700 \mathrm{E}-01$

$-1-1.33 \mathrm{BB}-01$

- $3-9.750 \mathrm{E}-02$

- $2-6.125 \mathrm{~g}-02$

$-1-2.500 \mathrm{E}-02$ 
HNF-SD-W151-CSA-001, Rev. 1

Figure D.3-12. Predicted Distribution of Solid 9 Pu Concentrations on 3 Clock Position at 10 Simulation Seconds for Case 1.
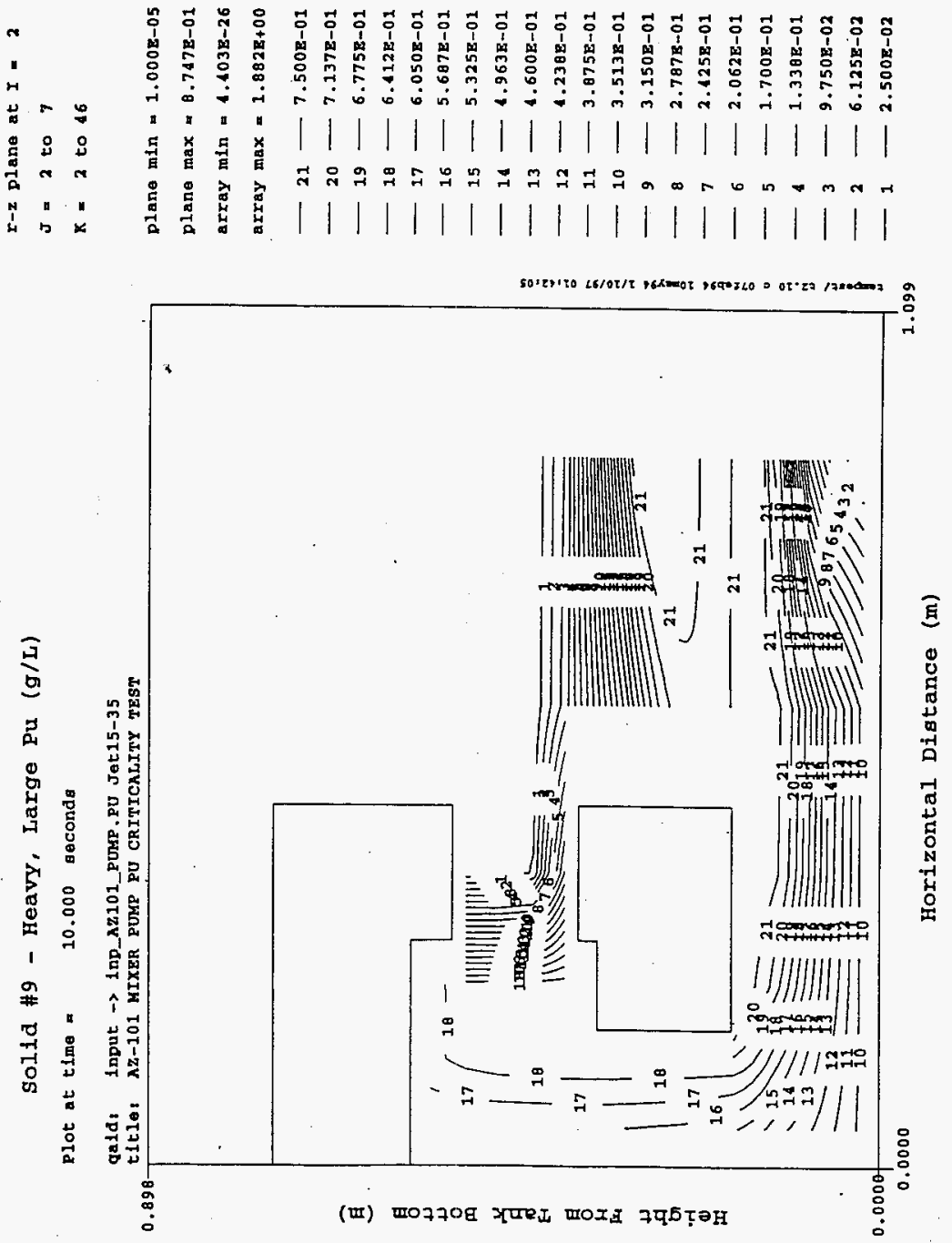
Figure D.3-13. Predicted Distribution of Solid 9 Pu Concentrations on 3 Clock Position at 10 Simulation Seconds for Case 2.
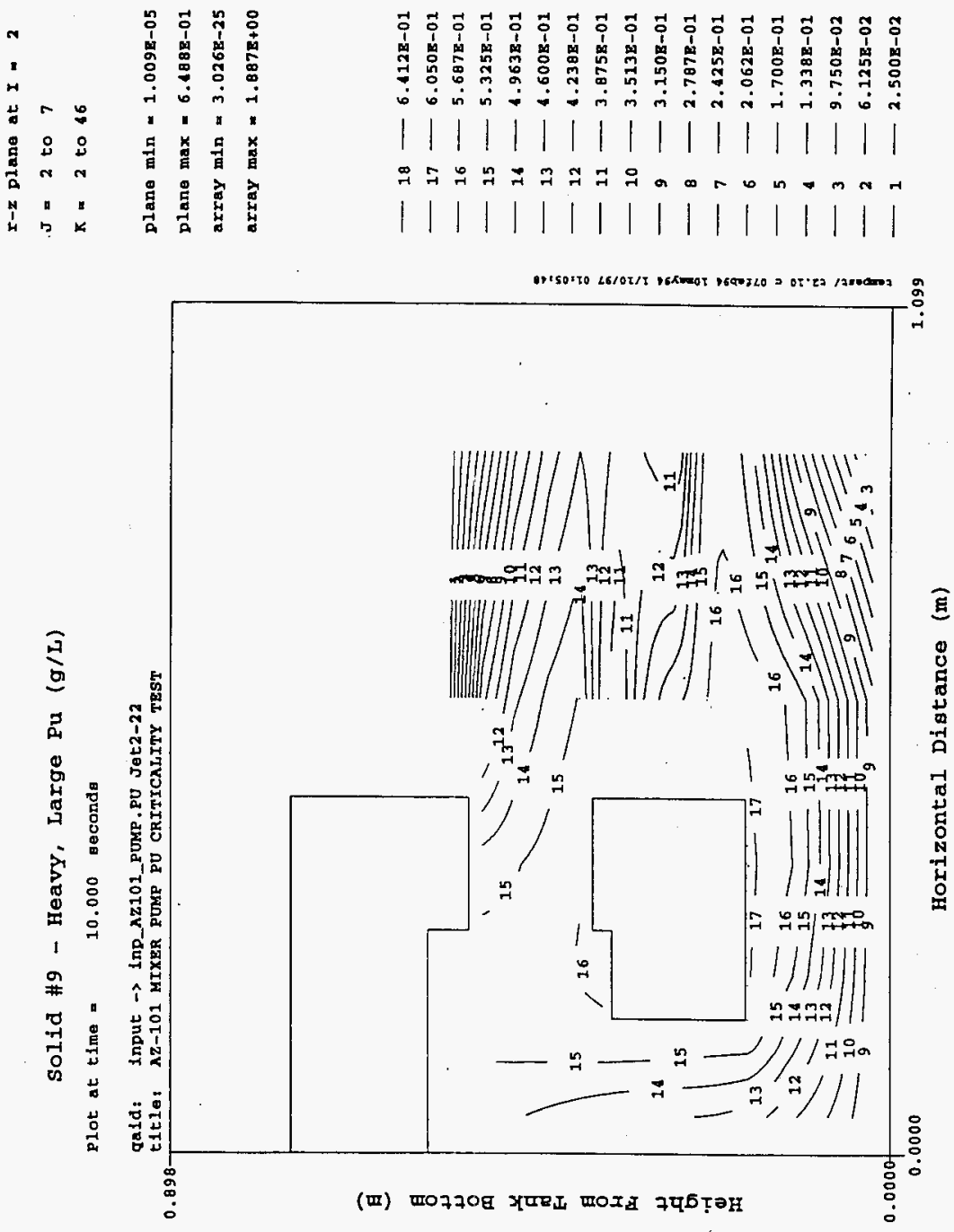
Figure D.3-14. Predicted Distribution of Solid 9 Pu Concentrations on 10:50 Clock Position at 40 Simulation Seconds for Case 1.
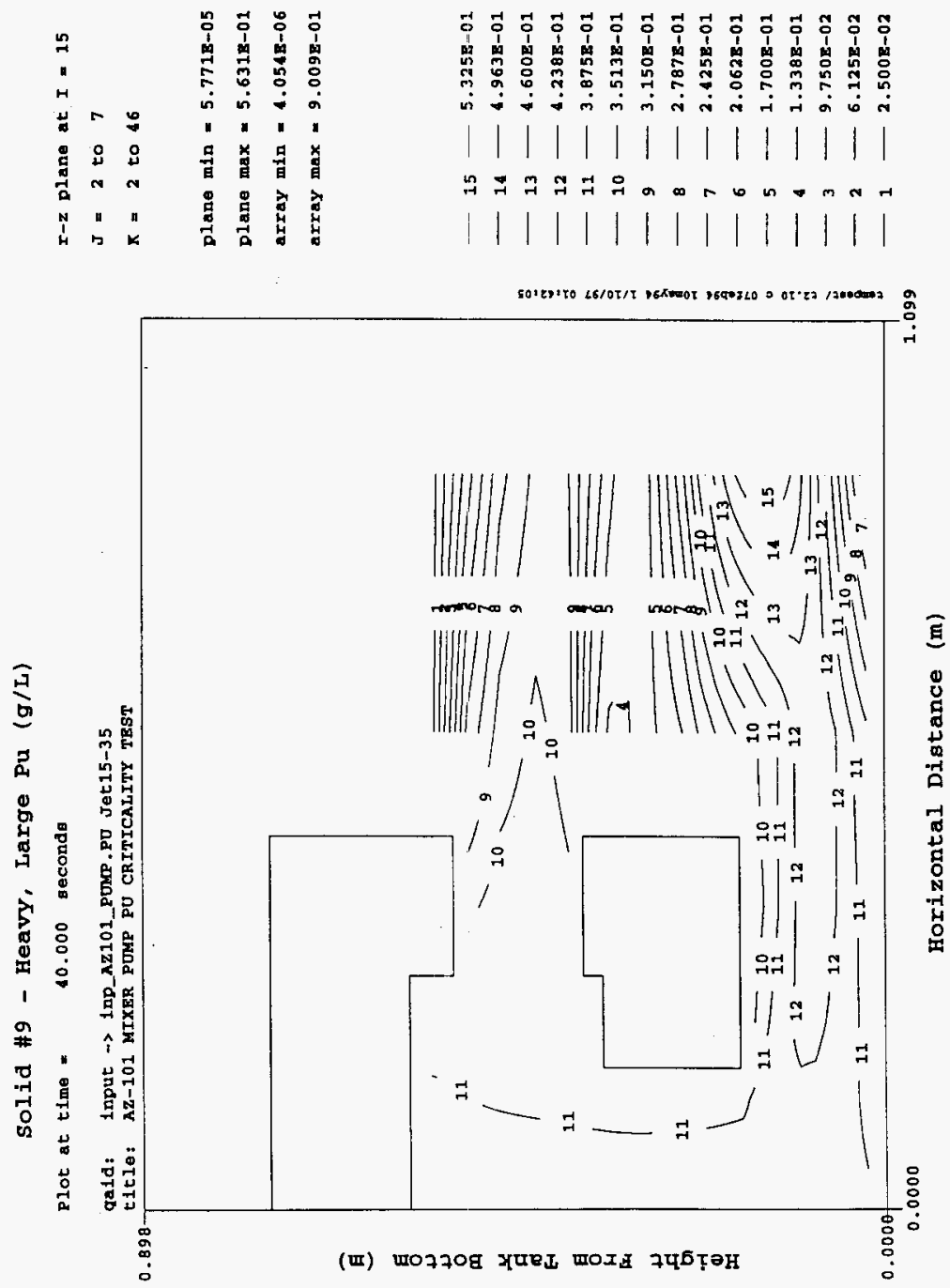

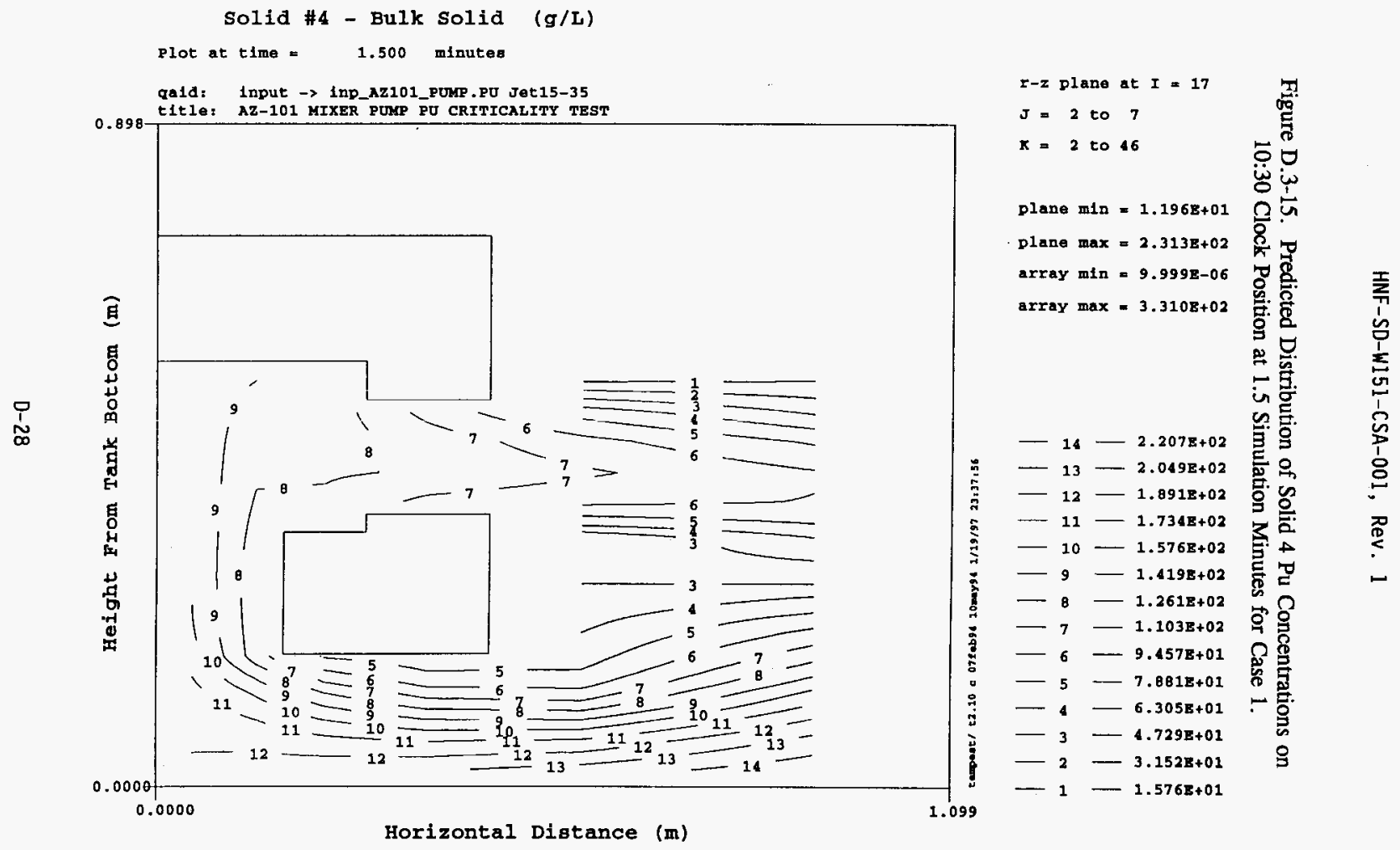
HNF-SD-W151-CSA-001, Rev. 1

Figure D.3-16. Predicted Distribution of Solid 1 Pu Concentrations on 10:30 Clock Position at 1.5 Simulation Minutes for Case 1.
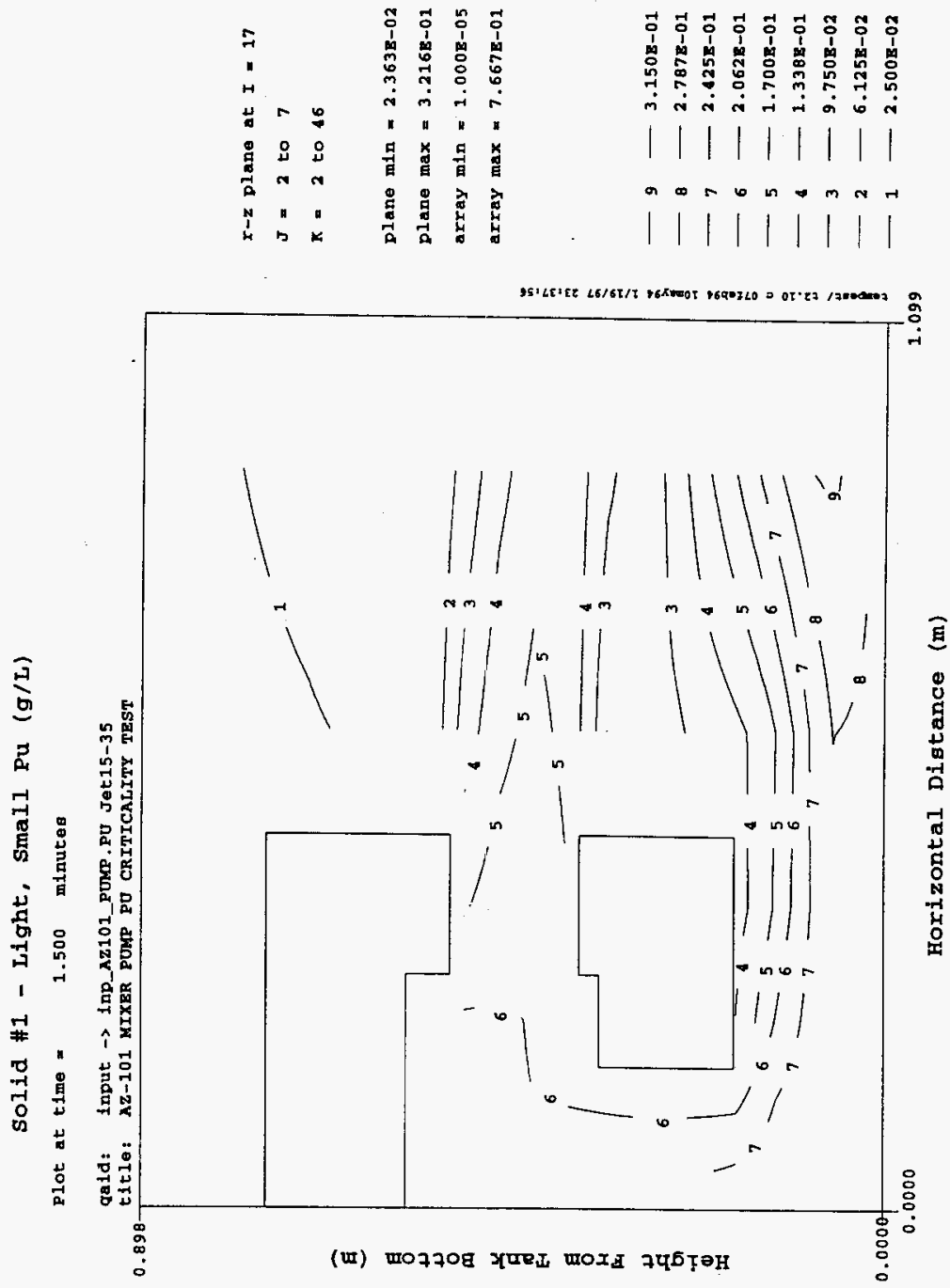
Solid \#9 - Heavy, Large $\mathrm{Pu}$ ( $g / \mathrm{L}$ )

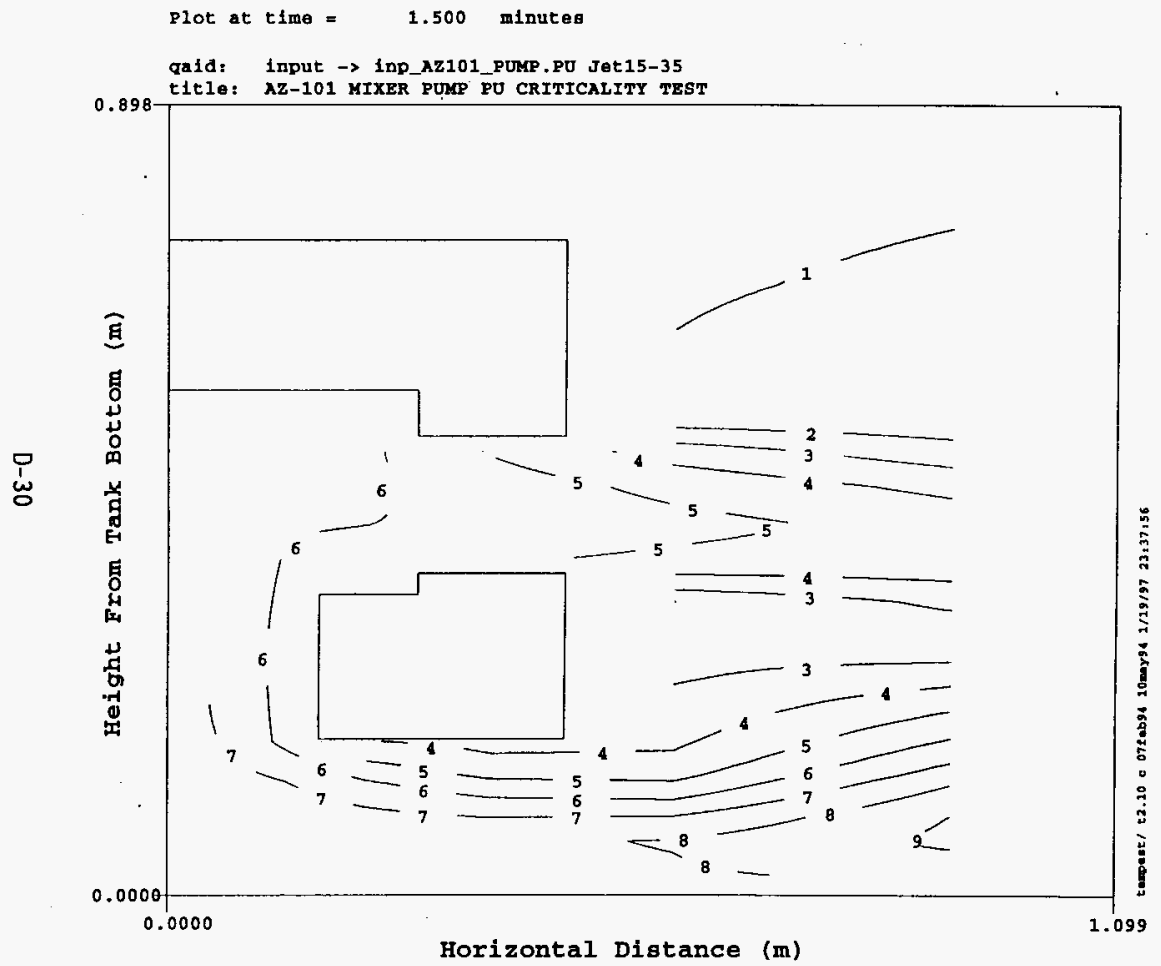

$r-z$ plane at $I=17$

$J=2$ to 7

$K=2$ to 46

plane $\min =2.338 \mathrm{~B}-02$

Dlane $\max =3.233 \mathrm{E}-01$

array $\mathrm{min}=9.629 \mathrm{E}-06$

array $\max =7.667 \mathrm{E}-01$

- $9-3.150 \mathrm{E}-01$

- 2.787 E-01

- $7-2.425 \mathrm{E}-01$

- $6-2.0625-01$

- $5-1.700 \mathrm{E}-01$

- $1.338 \mathrm{E}-01$

- $3-9.750 \mathrm{~B}-02$

$-2-6.125 \mathrm{E}-02$

$-1-2.500 \mathrm{E}-02$

Horizontal Distance (m) 
HNF-SD-W151-CSA-001, Rev. 1

Figure D.3-18. Predicted Total Plutonium Amount (kg) Within the Pump.

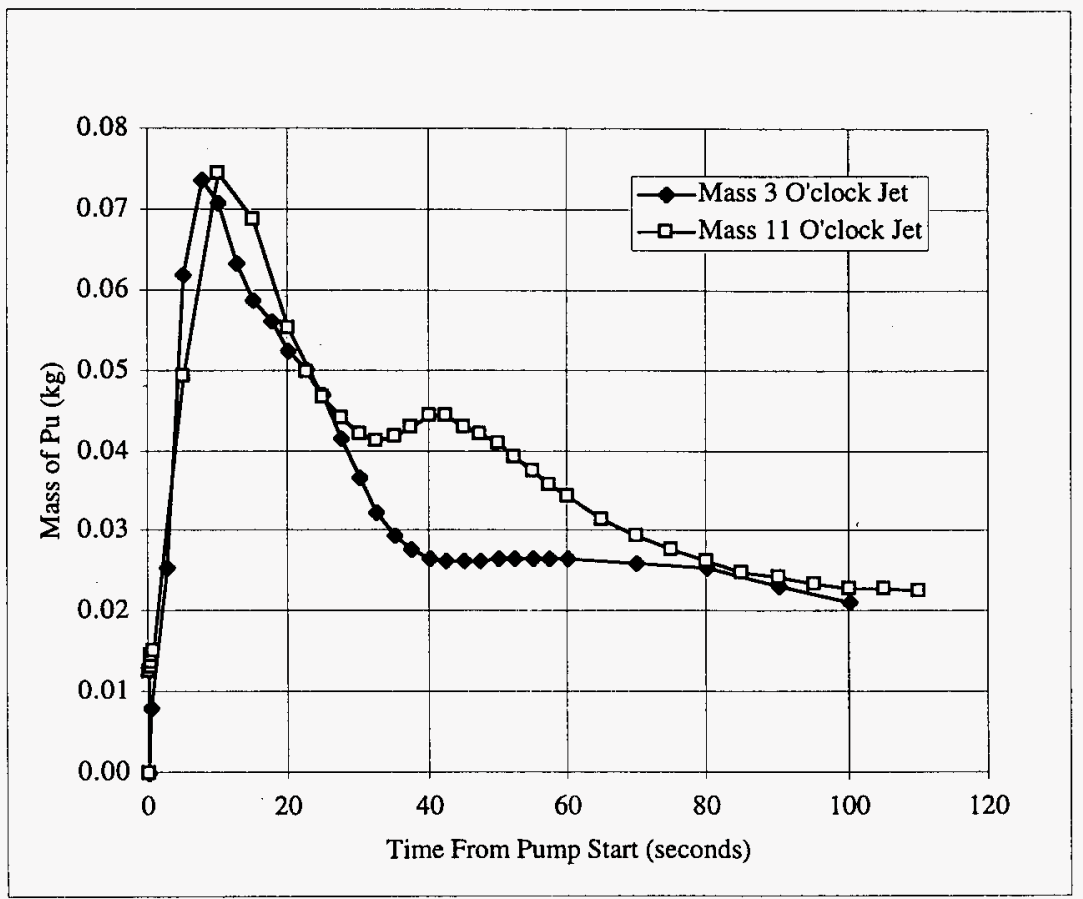


HNF-SD-W151-CSA-001, Rev. 1

Figure D.3-19. Predicted Average Plutonium Concentration (g/L) Within the Pump.

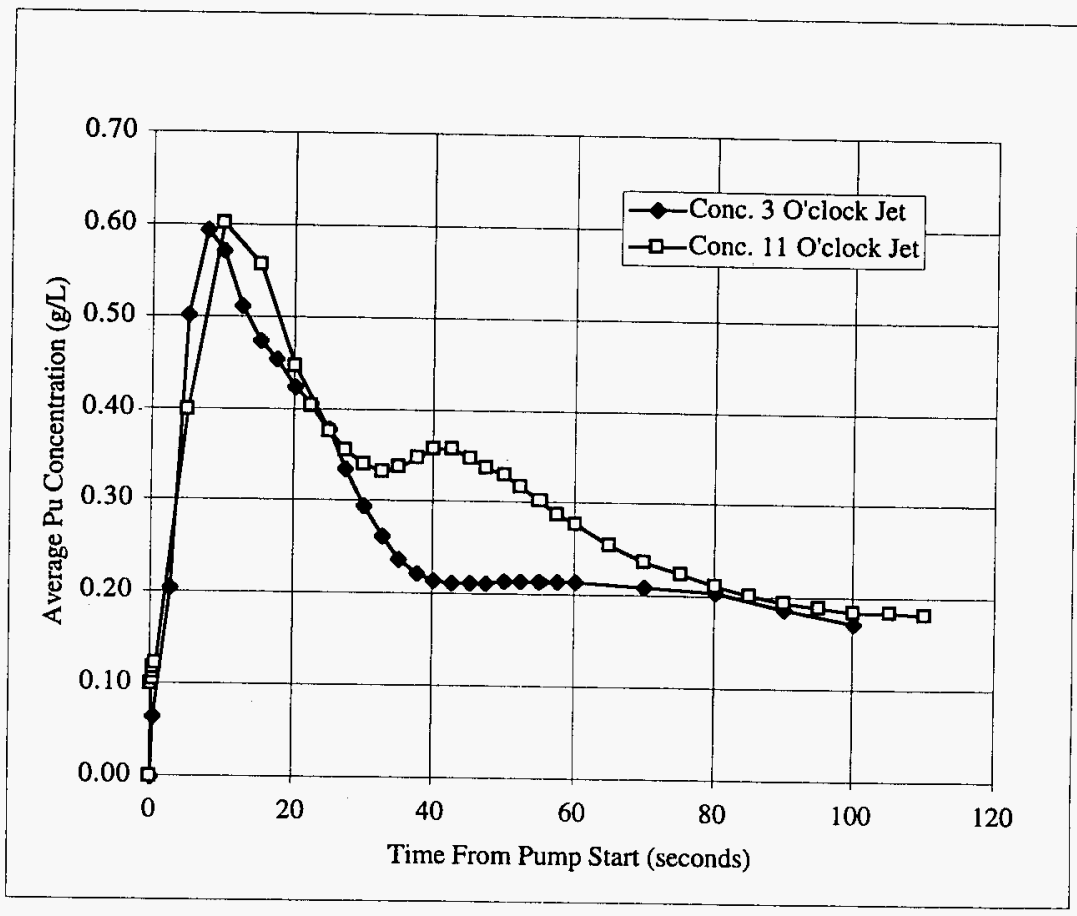


HNF-SD-W151-CSA-001, Rev. 1

\section{D.5 REFERENCES}

Antoniak, Z. I. and K. P Recknagle. 1996. Simulation of Tank 101-AZ Mobilization Tests and TEMPEST Code Performance Evaluation. Letter Report, Pacific Northwest National Laboratory, Richland, Washington.

Gray, W. J., M. E. Peterson, R. D. Scheele, and J. M. Tingey. 1993. Characterization of the Second Core Sample of Neutralized Current Acid Waste from Double Shell Tank 10I-AZ (draft). Pacific Northwest Laboratory, Richland, Washington.

Eyler, L. L. 1983. Sediment Settling and Resuspension in Waste Storage Tanks with Air Injection Circulators. Letter Report FATE-83-109, Pacific Northwest Laboratory, Richland, Washington.

Mahoney, L. A. and D. S. Trent. 1995. Correlation Models for Waste Tank Sludges and Slurries. PNL-10695, Pacific Northwest National Laboratory, Richland, Washington.

Onishi, Y., H.C. Reid, and D.S. Trent. 1995. Dilution Physics Modeling:

Dissolution/Precipitation Chemistry. PNL-10815, Pacific Northwest National Laboratory, Richland, Washington.

Onishi, Y. and K. P. Recknagle. 1996. Tank AZ-101 Criticality Assessment Resulting from Pump Jet Mixing: Sludge Mixing Simulations. PNNL-11486, Pacific Northwest National Laboratory, Richland, Washington.

Onishi, Y., H.C. Reid, D.S. Trent, and J. D. Hudson. 1996a. "Tank Waste Modeling with Coupled Chemical and Hydrothermal Dynamics." The American Nuclear Society's Proceedings of 1996 National Heat Transfer Conference, Houston Texas, August 3-6, 1996, pp. 262-269.

Onishi, Y., R. Shekarriz, K. P. Recknagle, P. A. Smith, J. Liu, Y. L. Chen, D. R. Rector, and J. D. Hudson. 1996b. Tank SY-102 Waste Retrieval Assessment: Rheological Measurements and Pump Jet Mixing Simulations. PNNL-11352, Pacific Northwest National Laboratory, Richland, Washington.

Peterson, M. E., R. D. Scheele, and J. M. Tingey. 1989. Characterization of the First Core Sample of Neutralized Current Acid Waste from Double Shell Tank 101-AZ. PNL-7758, Pacific Northwest Laboratory, Richland, Washington.

Serne, R.J., G. A. Whyatt, S. V. Mattigod, Y. Onishi, P. M. Doctor, B. N. Bjornstad, M. R. Powell, L. M. Liljegren, J. H. Westsik, Jr., N. J. Aimo, K. P. Recknagle, G. R. Golcar, G. R. Holder, D. W. Jeppson, and G. S. Berney. 1996. Fluid Dynamics, Particulate Segregation, Chemical Processes, Natural Ore Analog and Tank Inventory Discussions that Relate to the Potential for Criticality in Hanford Tanks. WHC-SD-WM-TI-757 Rev. 0, Westinghouse Hanford Company, Richland, Washington.

Rodi, W. 1984. Turbulence Models and Their Application in Hydraulics - a State-of-the-Art Review. Institut fur Hydromechanik, University of Karlsruhe, Germany.

Trent, D.S. and L.L. Eyler. 1993. TEMPEST: A Computer Program for Three- Dimensional Time Dependent Computational Fluid Dynamics. PNL-8857 Vol. 1, Version T, Mod 2, Pacific Northwest National Laboratory, Richland, Washington. 
Trent, D.S. and T.E. Michener. 1993. Numerical Simulation of Jhet Mixing Concepts in Tank 241-SY-101. PNL-8859, Pacific Northwest Laboratory, Richland, Washington.

Vanoni, V. A., ed. 1975. Sedimentation Engineering. ASCE Manuals and Reports on Engineering Practice, ASCE, New York.

Whyatt, G. A., R. J. Serne, S. V. Mattigod, Y. Onishi, M. R. Powell, J. H. Westsik, Jr., L. M. Liljegren, G. R. Golcar, K. P. Recknagle, P. M. Doctor, V. G. Zhirnov, J. Dixon, D. W. Jeppson, and G. S. Berney. 1996. The Potential for Criticality in Hanford Tanks Resulting from Retrieval of Tank Waste. PNNL-1 1304, Pacific Northwest Laboratory, Richland, Washington. 
DISTRIBUTION SHEET

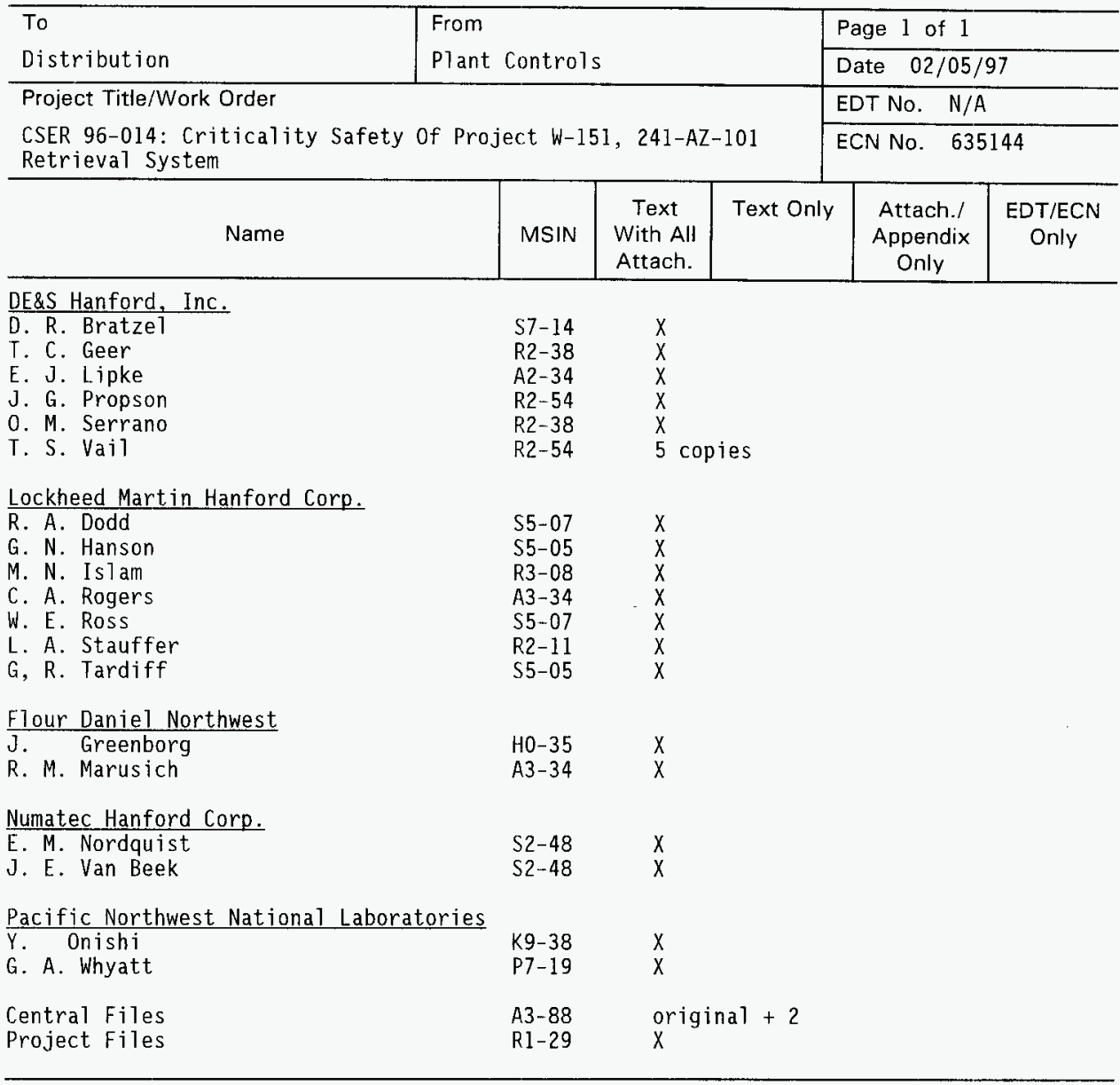

